\title{
Una nueva rana nodriza (Anura: Dendrobatidae) de los bosques de niebla asociados a la cuenca del Orinoco de Colombia
}

\author{
A new nurse frog (Anura: Dendrobatidae) from the cloud forests of the Orinoco \\ basin of Colombia
}

\author{
Andrés R. Acosta-Galvis y Adrián Pinzón
}

\begin{abstract}
Resumen
Se describe una nueva especie de rana nodriza proveniente de las estribaciones andinas en el departamento de Boyacá y asociada a la cuenca del río Orinoco en Colombia. Esta especie posee una similitud morfológica con Hyloxalus picachos que habita en las estribaciones andinas en el departamento de Caquetá, pero difiere de esta porque la banda lateral oblicua se extiende hasta el rostro y por su patrón cromático del iris en vida. Se describe el cambio ontogénico de sus estados larvales junto con sus vocalizaciones que están compuestas por notas simples, con una tasa de vocalización de 124 notas por minuto y con estructura espectral que consiste en 5 armónicos con una frecuencia dominante entre 4213,3--5828,2 Hz. Con la descripción de esta nueva especie se reconocen 23 especies para este género en Colombia.
\end{abstract}

Palabras clave. Bioacustica. Hyloxalus. Piedemonte. Renacuajos. Taxonomía.

\begin{abstract}
A new species of nurse frog is described from the Andean foothills in the department of Boyacá and associated Orinoco River basin in Colombia. This species has a morphological similarity to Hyloxalus picachos, which inhabits the Andean foothills in the department of Caquetá but differs due to the presence of an oblique lateral band that extends to the snout, in addition to its chromatic pattern of the iris in life. We describe the ontogenetic change of its larval stages along with its vocalizations, which are composed of simple notes, with a vocalization rate of 124 notes per minute and spectral structure consisting of 5 harmonics with a dominant frequency between 4213.3 and $5828.2 \mathrm{~Hz}$. With the description of this new species, 23 species are recognized for this genus in Colombia.
\end{abstract}

Keywords. Bioacustics. Foothills. Hyloxalus. Tadpoles. Taxonomy.

\section{Introducción}

Durante los últimos 20 años, significativos avances en el desarrollo de hipótesis filogenéticas alrededor de las ranas dendrobátidas han permitido en parte evaluar, delimitar, direccionar y entender las relaciones evolutivas de este complejo grupo bioló-

gico (Coloma, 1995; Vences et al., 2000; Grant y Rodríguez, 2001; Vences et al., 2003; Santos et al., 2003; Grant et al., 2006; Páez-Vacas et al., 2010; Pyron y Wiens, 2011; Santos et al., 2014; Grant et al., 2017). 
Sin embargo, aún hoy en día existe una gran dificultad para cualquier taxónomo de establecer un diagnóstico contundente en base a rasgos morfológicos del grupo para diferenciar los géneros Hyloxalus y Allobates, así se empleen combinaciones de estado de caracteres (Anganoy, 2013). Tal dificultad se debe a la ambigüedad existente en aquellos rasgos que han sido propuestos como una novedad evolutiva que permite diferenciar a un taxón de otro, lo que resulta en que pocos caracteres (sinapomorfías únicas) sirven de diagnóstico (Tabla 1). Así es como se evidencia que parte de las propuestas vigentes en la asignación genérica con base en rasgos morfológicos son imprecisas y están soportadas únicamente desde una perspectiva molecular donde a medida que se agregan más taxones terminales a la matriz o más genes secuenciados e incluidos, la clasificación resultante puede cambiar (Zardoya y Meyer, 1996; San Mauro et al., 2004; Grant et al., 2017).

Durante trabajos de campo en los bosques subandinos de las montañas del municipio de Santa María en el departamento de Boyacá desarrollados en abril de 2017, se obtuvo una serie de ejemplares en diferentes estados de desarrollo biológico (larvas libres, ejemplares nodriza y formas maduras de ambos sexos), pertenecientes a una forma indescrita que según evidencia morfológica (sensu Grant et al., 2006) pertenece al género Allobates (carácter 8 en Tabla 1), siendo similar en su morfología con Allobates picachos.

Recientes análisis filogenéticos (Grant et al., 2017) transfieren a $A$. picachos, junto con $A$. cepedai, al género Hyloxalus. Esto evidencia la problemática de la ambigüedad frente a los caracteres morfológicos, debido a que estas dos especies presentan el tercer dedo manual ensanchado (condición considerada ausente en la diagnosis para Hyloxalus, sensu Grant et al., 2006 [= cuarto dedo manual sensu Grant et al., 2017]), y en el caso de Hyloxalus cepedai presenta una banda pálida ventrolateral (considerada una sinapomorfia sin ambigüedades optimizadas para el género Allobates Grant et al., 2017).
El género Hyloxalus en Colombia está representado por 22 especies nominales (AcostaGalvis, 2017, http://www.batrachia.com) con mayor riqueza en los Andes. Se distribuyen desde las tierras bajas hasta los páramos, concentrando el mayor número de especies en los bosques de niebla (Boulenger, 1912; Cochran y Goin, 1970; Silverstone, 1971; Edwards, 1974; Silverstone, 1975; Lynch, 1982; Rivero y Serna, 1986; Rivero y Granados, 1990 "1989”; Myers, 1991; Rivero y Serna, 1991; Rivero, 1991; Rivero y Serna, 1995; Grant y Castro, 1998; Ardila-Robayo et al., 1999; Ardila-Robayo y Acosta-Galvis, 2000; Grant y Ardila-Robayo, 2002; Morales, 2002, “2000”; Grant et al., 2006; Bernal y Lynch, 2008; Sánchez, 2013; Anganoy, 2013).

De las especies reportadas para el país, ocho se distribuyen en la cordillera Oriental (Figura 1), de las cuales tres habitan en las estribaciones cisandinas. Una de ellas es endémica de las estribaciones orinoscences (Hyloxalus cepedai Morales, 2002, “2000") con reportes en los departamentos de Boyacá, Casanare, Cundinamarca y Meta entre los $500-1123$ m s.n.m.) (Morales, 2002, “2000”; Lynch, 2006; Angarita-Sierra et al., 2013; Pedroza-Banda et al., 2014; Acosta-Galvis, 2017) y dos especies de las estribaciones amazónicas al suroriente de la cordillera Oriental (Hyloxalus saltuarius (Grant y Ardila-Robayo, 2002) e Hyloxalus picachos (ArdilaRobayo et al., 1999), de los bosques subandinos (1200-1600 m s.n.m.) en el departamento de Caquetá, endémicas del Parque Nacional Natural Los Picachos) (Ardila-Robayo et al., 1999; Grant y Ardila-Robayo, 2002; Bernal y Lynch, 2008).

En concordancia con las hipótesis filogenéticas propuestas por Grant et al. (2017), sumado a la similitud morfológica identificada con Hyloxalus picachos (y en ausencia de análisis de este taxón terminal en un contexto filogenético), describimos y asignamos esta nueva especie tentativamente al género Hyloxalus (Anexo 1). 


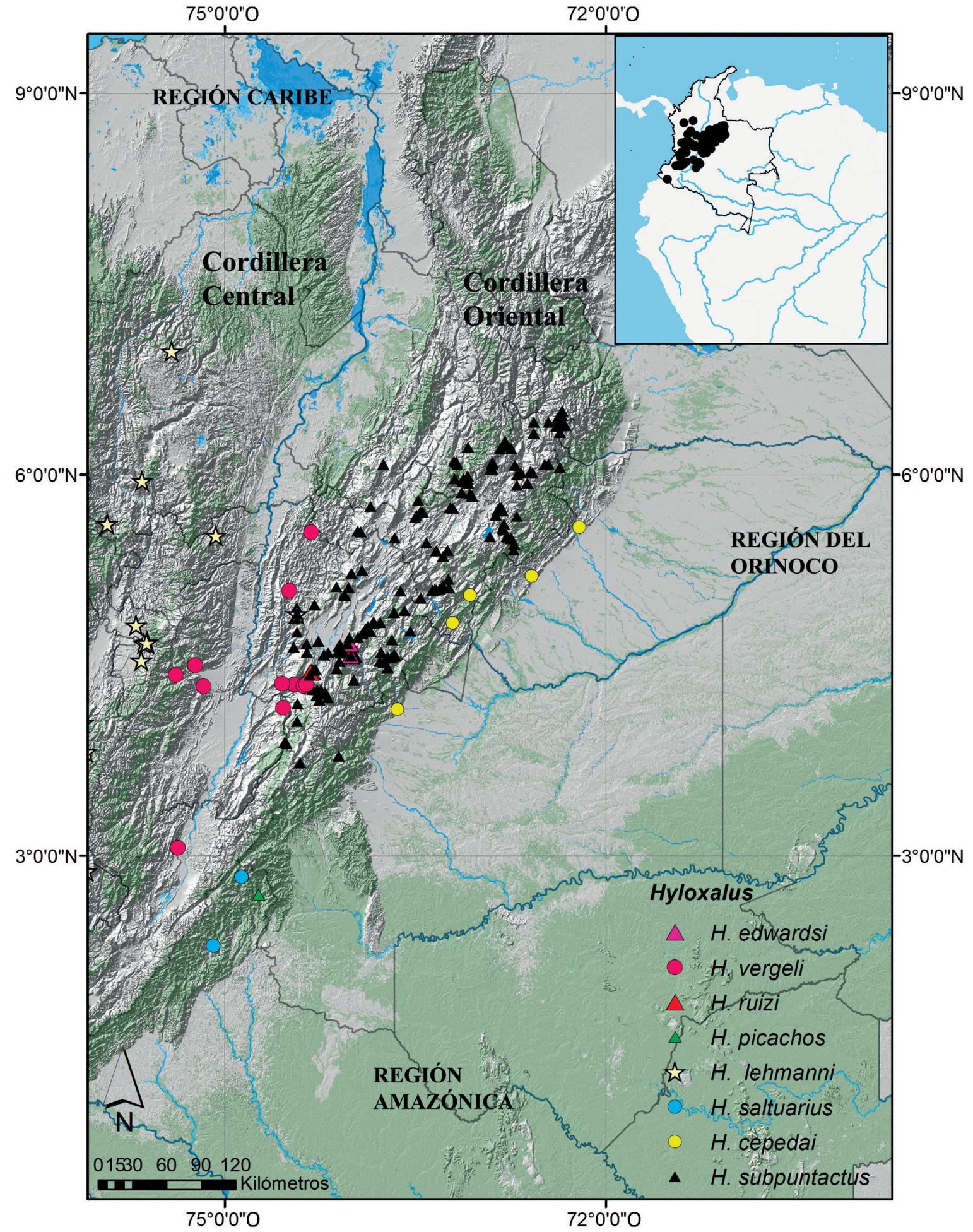

Figura 1. Mapa de distribución de las especies del género Hyloxalus en la cordillera Oriental de Colombia basados en literatura científica (Silverstone, 1971; Lynch, 1982; Ardila-Robayo et al., 1999; Ardila-Robayo y Acosta-Galvis, 2000; Grant y Ardila-Robayo, 2002; Morales 2002, “2000”; Bernal y Lynch, 2008; Sánchez, 2013; Anganoy, 2013). 
Tabla 1. Resumen de los rasgos morfológicos empleados en las diagnosis vigentes de los géneros Allobates e Hyloxalus (Grant et al., 2006, 2017). Acorde con Grant et al. (2017) el género Hyloxalus carece de sinapomorfias fenómicas optimizadas.

\begin{tabular}{|c|c|c|c|}
\hline Caracter & $\begin{array}{c}\text { Hyloxalus } \\
\text { (sensu Grant et al. 2006) }\end{array}$ & $\begin{array}{c}\text { Allobates } \\
\text { (sensu Grant et al. 2006) }\end{array}$ & $\begin{array}{c}\text { Allobates } \\
\text { (sensu Grant et al. 2017) }\end{array}$ \\
\hline 1) Coloración dorsal & $\begin{array}{l}\text { Usualmente críptica } \\
\text { (gris, café a negro) }\end{array}$ & $\begin{array}{l}\text { Críptica en muchas } \\
\text { especies }\end{array}$ & - \\
\hline 2) Banda lateral oblicua & Presente & Presente/ausente & Presente difusa \\
\hline 3) Banda dorsolateral pálida & $\begin{array}{l}\text { Ausente (mayoría)/ } \\
\text { presente }\end{array}$ & Ausente/presente & - \\
\hline 4) Banda ventrolateral pálida & Ausente usualmente & Ausente/presente & Presente \\
\hline 5) Textura dorsal de la piel & Posteriormente granular & $\begin{array}{l}\text { Posteriormente } \\
\text { granular/muy granular } \\
\text { en el grupo femoralis }\end{array}$ & - \\
\hline 6) Membrana interdigital pedial & $\begin{array}{l}\text { Ausente (mayoría), basal } \\
\text { o extensiva }\end{array}$ & Ausente, basal (mayoría) & - \\
\hline $\begin{array}{l}\text { 7) Tercer dedo manual en los } \\
\text { machos }\left({ }^{*}=\text { cuarto dedo sensu }\right. \\
\text { Grant et al. } 2017)\end{array}$ & No expandido & $\begin{array}{l}\text { Expandido/No } \\
\text { expandido }\end{array}$ & Expandido \\
\hline $\begin{array}{l}\text { 8) Relación entre los dedos I-II } \\
\text { manual (II-III manual sensu Grant } \\
\text { et al. 2017) }\end{array}$ & I más corto que el dedo II & $\begin{array}{l}\text { I más largo que el dedo } \\
\text { II en la mayoría de las } \\
\text { especies (igual o más } \\
\text { corto en algunas). }\end{array}$ & - \\
\hline 9) Discos de los dedos manuales & $\begin{array}{l}\text { Estrechos a } \\
\text { moderadamente } \\
\text { expandidos }\end{array}$ & Débilmente expandidos & - \\
\hline 10) Proceso lingual medial & Ausente & Ausente & - \\
\hline 11) Posición del tubo cloacal larval & Dextral & Dextral & - \\
\hline $\begin{array}{l}\text { 12) Forma del disco oral de las } \\
\text { larvas }\end{array}$ & $\begin{array}{l}\text { Normal (no } \\
\text { umbeliforme) }\end{array}$ & $\begin{array}{l}\text { Normal (no } \\
\text { umbeliforme) }\end{array}$ & - \\
\hline 13) Disco oral & Emarginado & Emarginado & - \\
\hline 14) Alcaloides lipofílicos & Ausentes & Ausentes & \\
\hline 15) Número de cromosomas & $\begin{array}{l}2 \mathrm{n}=22 \text { (conocidos en } 3 \\
\text { especies) }\end{array}$ & $\begin{array}{l}2 \mathrm{n}=22 \text { (conocidos en } 3 \\
\text { especies) }\end{array}$ & - \\
\hline 16) Coloración de los testículos & $\begin{array}{l}\text { Despigmentados en } \\
\text { muchas especies }\end{array}$ & Despigmentados & - \\
\hline 17) Collar en la garganta & Ausente & Ausente & - \\
\hline $\begin{array}{l}\text { 18) Relación del dedo manual IV } \\
\text { con el tubérculo subarticular distal } \\
\text { del dedo III (*=V con el tubérculo } \\
\text { subarticular distal del IV, sensu } \\
\text { Grant et al. 2017; }\end{array}$ & - & $\begin{array}{l}\text { Alcanza la mitad } \\
\text { distal (ver definición } \\
\text { Allobatinae sensu Grant } \\
\text { et al. 2006) }\end{array}$ & No alcanza \\
\hline
\end{tabular}




\section{Materiales y métodos}

Trabajo de campo y colección de referencia. La nueva especie fue registrada en la expedición de campo conducida en la Reserva Natural Privada Bosque La Almenara, municipio de Santamaría $\left(4^{\circ} 53^{\prime} 10.3^{\prime \prime} \mathrm{N}\right.$; $73^{\circ} 15^{\prime} 34^{\prime \prime} \mathrm{O}, 1289 \mathrm{~m}$ s.n.m.), departamento de Boyacá y localizada en los bosques de niebla de la vertiente Oriental de la cordillera Oriental de los Andes. La localidad está constituida por bosques protegidos con más de 20 años de regeneración y localizada en la ecorregión de Apure-Villavicencio (Dinerstein et al., 1995; Olson y Dinerstein 2002). Las coordenadas geográficas y las elevaciones fueron registradas con un GPS Garmin GPSMAP 60CSx (datum WGS 84). Los especímenes fueron sacrificados empleando una solución de Benzocaína (Chen y Combs, 1999), fijados en una solución de formol al $10 \%$, preservados en etanol al $70 \%$ y depositados en la colección de anfibios del Instituto de Investigación de Recursos Biológicos Alexander von Humboldt Colombia, Villa de Leyva, Boyacá, Colombia Suramérica. (IAvH-Am).

Morfología de los adultos. Los criterios empleados para la descripción morfológica y los caracteres diagnósticos siguen previas propuestas taxonómicas en este grupo de organismos (Myers et al., 1991; Coloma, 1995; Grant et al., 1997; Kaplan, 1997; Grant y Castro, 1998; ArdilaRobayo et al., 1999; Grant, 2004; Grant et al., 2006, Cisneros-Heredia y Mcdiarmid, 2007; Duellman y Lehr, 2009). Las observaciones morfológicas fueron realizadas mediante un estereoscopio Nikon optical devices SMZ-1B con luz de alta intensidad NI-150 Nikon y App Scope 3xSRA41. Las medidas y proporciones fueron registradas mediante un calibrador digital marca Mitutoyo (precisión $\pm 0,1 \mathrm{~mm}$ ) y se siguieron los siguientes parámetros morfométricos: LRC (longitud rostro cloacal), AC (anchura cefálica), LC (longitud cefálica medida desde el borde del proótico hasta el extremo del rostro), DIN (distancia internarinas), DIO (distancia interorbital), DO (diámetro del ojo), DON (distancia ojo-narina), DT (diámetro timpánico), AP (anchura del párpado), LR (distancia entre el margen anterior del ojo hasta el extremo del rostro), AR (anchura rostral),
LT (longitud tibial), LF (longitud femoral), LPd (longitud del pie), LM (longitud manual), LAb (longitud del antebrazo), IIIDM (diámetro del disco del tercer dedo manual) y IVDP (diámetro del disco del cuarto dedo pedial). Los promedios de estas medidas morfométricas son reportados junto con la desviación estándar. La madurez sexual fue determinada por la evaluación de rasgos sexuales secundarios. Machos con saco y hendidura vocal fueron identificados como adultos y las hembras fueran identificadas por su coloración del vientre y la ausencia de sacos vocales. Los especímenes in vivo fueron fotografiados con una cámara Canon EOS 70D y los ejemplares preservados con una cámara digital Canon EOS 5D Mark II y una caja de luz Safe-box and LED light que emplea luces de 5500 Kelvin.

Morfología de las larvas. Los especímenes fueron fijados y preservados en formol al $10 \%$. Una serie de tres lotes de renacuajos en diferentes estadios de desarrollo fueron obtenidos e incluyen renacuajos libres (lote IAvH-Am-14680), larvas de machos nodriza (IAvH-Am-14675, IAvHAm-14658) y una pequeña serie de especímenes desarrollados in situ para un total de 69 ejemplares estudiados entre los estadios 26-41 (sensu Gosner, 1960) (Anexo 2). Los estados de desarrollo, la morfología del disco oral, la formula dentaria y las variables morfométricas empleadas son basadas en previas contribuciones (Gosner, 1960; Altig y McDiarmid, 1999; McDiarmid y Altig, 1999; Lima et al., 2009, 2010; Anganoy-Criollo, 2013). El color in vivo fue descrito a partir de las Fotos y notas de campo. Las medidas estándar registradas para los renacuajos son las siguientes: LT (longitud total desde el extremo del rostro hasta el extremo apical de la región caudal), LC (longitud del cuerpo desde el extremo del rostro hasta la base de la musculatura caudal), LCD ( longitud caudal desde la base de la musculatura caudal hasta el extremo apical de la cola), ACo (mayor altura del cuerpo), AnCo (mayor anchura del cuerpo), ACf (anchura cefálica a la altura de los ojos), Mcd (altura de la musculatura caudal en la base de la cola), Amcd (anchura muscular en la base de la cola) MxAcd (máxima altura de la cola), 
DR-N (distancia desde el extremo del rostro hasta la porción anterior de la narina), DIN (distancia Internarinas), DIO (distancia interorbital), DO (diámetro del ojo), O-N (distancia ojo-narina), DNR (distancia narina rostro), Ltc (longitud del tubo cloacal), Atc (anchura del tubo cloacal), Ado (anchura disco oral), Hdo (altura del disco oral) y Dae (distancia del rostro a la abertura espiracular). Las medidas morfométricas fueron registradas empleando los mismos equipos presentados en la morfología de los adultos y la morfología del disco oral fue evaluada y fotografiada empleando un estereoscopio digital Leica MC 190-HD.

Vocalizaciones. La vocalización de un ejemplar fue grabado a $1 \mathrm{~m}$ de distancia el 30 de abril de 2017 a un ejemplar localizado sobre la hojarasca asociada a bosque natural a las 13:19 horas. Fue registrada mediante una grabadora digital Marantz PMD 671 con un micrófono unidireccional Sennheiser MKH 60 P48. El análisis de la vocalización fue realizado mediante el software Raven 1.4 para Windows (Charif et al., 2010), que incluye vocalizaciones a $44.1 \mathrm{KHz}$ y 16-bits de resolución y para el análisis se empleó un FFT (Fast Fourier Transformation) $=256$ y una superposición $($ Overlap $)=50$. Los siguientes parámetros, que incluyen variables espectrales y temporales, siguen diferentes propuestas (Duellman y Pyles, 1983; Cocroft y Ryan, 1995; Coloma, 1995; Lima et al., 2009; Kok, 2010; Lima et al., 2010; Koch et al., 2011; Kok et al., 2013; Köhler et al., 2017) que incluyen: 1. Llamado (definido por la unidad acústica principal en una vocalización; un llamado está separado de otro por silencio), 2. Duración de la llamada (la duración de una sola llamada, independientemente de si está compuesta por una o varias notas), 3. Nota (subunidades más pequeñas, casi siempre separadas por intervalos de silencio, el llamado se suele dividir en notas), 4 . Número de notas por llamada (número de señales acústicas reconocibles en una llamada), 5. Duración de una nota (duración de una nota dentro de una llamada; medida desde el principio hasta el final de la nota), 6. Duración de los intervalos entre notas, pulso (ráfagas de sonido dentro de una nota), 7. Número de pulsos por nota, frecuencia dominante (la frecuencia de mayor energía) y número de armónicos (número de armónicos presente en las llamadas). Las grabaciones fueron depositadas en el Banco de Sonidos Ambientales (BSA), del Instituto Humboldt con el número BSA-15986 y las URL con las vocalizaciones están disponibles en http://colecciones.humboldt.org. co/rec/sonidos/BSA-15986/

\section{Resultados}

\section{Hyloxalus sanctamariensis sp. nov.} urn:lsid:zoobank.org:act:C06E11C1-FDE243FA-8260-717CF7E193FE

Holotipo (Figura 2): macho adulto, IAvHAm-14658 (número de Campo ARA 7630), colectado por Andrés Acosta, Adrián Pinzón, Nicolás Muñoz y Mariana Pineda el 30 de abril de 2017, y depositado en la colección de anfibios del Instituto de Investigación de Recursos Biológicos Alexander von Humboldt Colombia, Villa de Leyva, Boyacá, Colombia.

Localidad típica. Reserva Natural Privada Bosque La Almenara ( $04^{\circ} 53^{\prime} 10,3^{\prime \prime}$ N y $73^{\circ} 15^{\prime \prime} 3,4^{\prime \prime}$ O, 1289 m s.n.m), municipio de Santa María, departamento de Boyacá, (Figura 3, Figura 15).

Paratipos. (Figura 4): machos adultos IAvHAm-14673-5 y hembras adultas IAvH-Am-14654-5, IAvH-Am-14659, IAvH-Am-14672 colectados con el holotipo el 30 de Abril de 2017, colectados por Andrés Acosta, Adrián Pinzón, Nicolás Muñoz y Mariana Pineda.

Ejemplares referidos. Ejemplar juvenil IAvHAm-14647, Quebrada La Cristalina (4 50’ 53,6" N y $73^{\circ} 16^{\prime \prime} 21^{\prime \prime}$ O, 869 m s.n.m.), municipio de Santa María, departamento de Boyacá.

Etimología. El epíteto específico hace alusión al municipio de Santa María situado en el sureste de la Provincia de Neira, en el departamento de Boyacá; área geográfica donde fue encontrada la especie. 


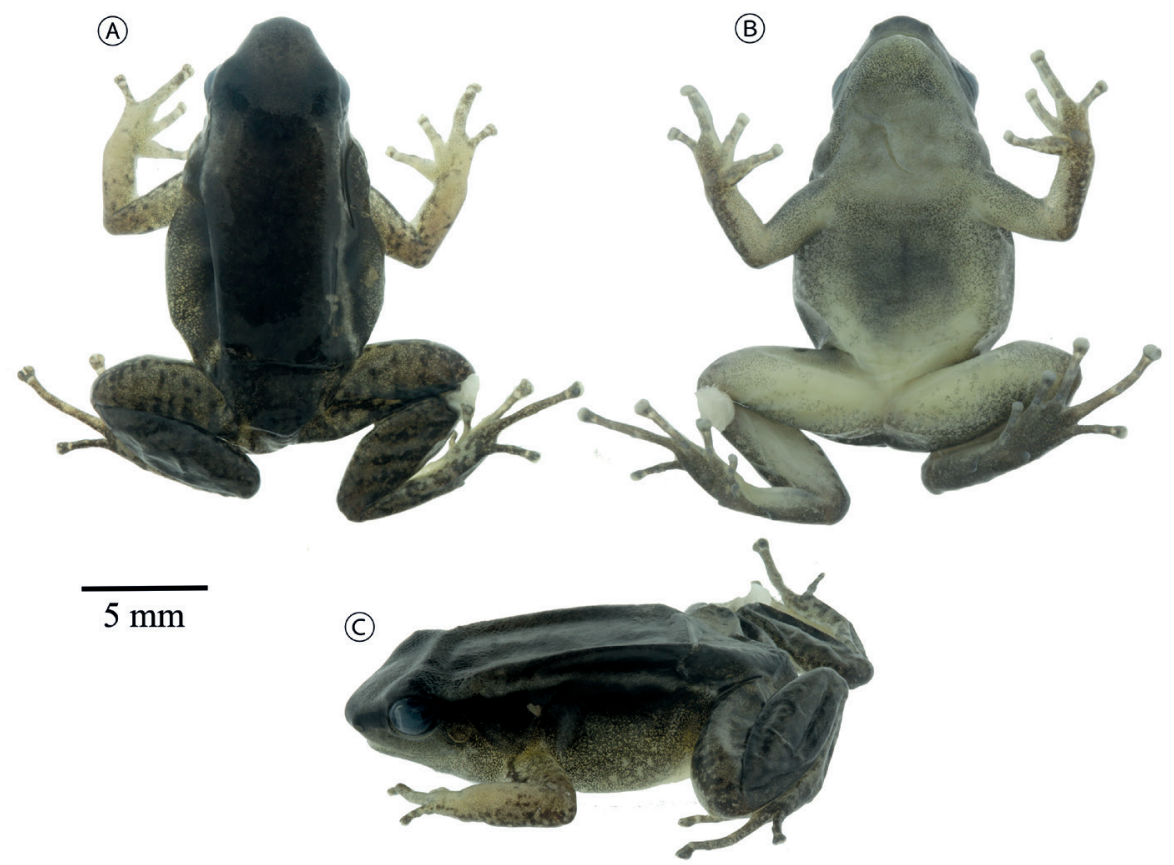

Figura 2. Hyloxalus sanctamariensis sp. nov. Holotipo IAvH-Am-14658, macho adulto preservado en etanol $70 \%, \mathrm{LRC}=18,0 \mathrm{~mm}$. A. Vista dorsal. B. Vista ventral. C. Vista lateral. Fotografías: Andrés Acosta.
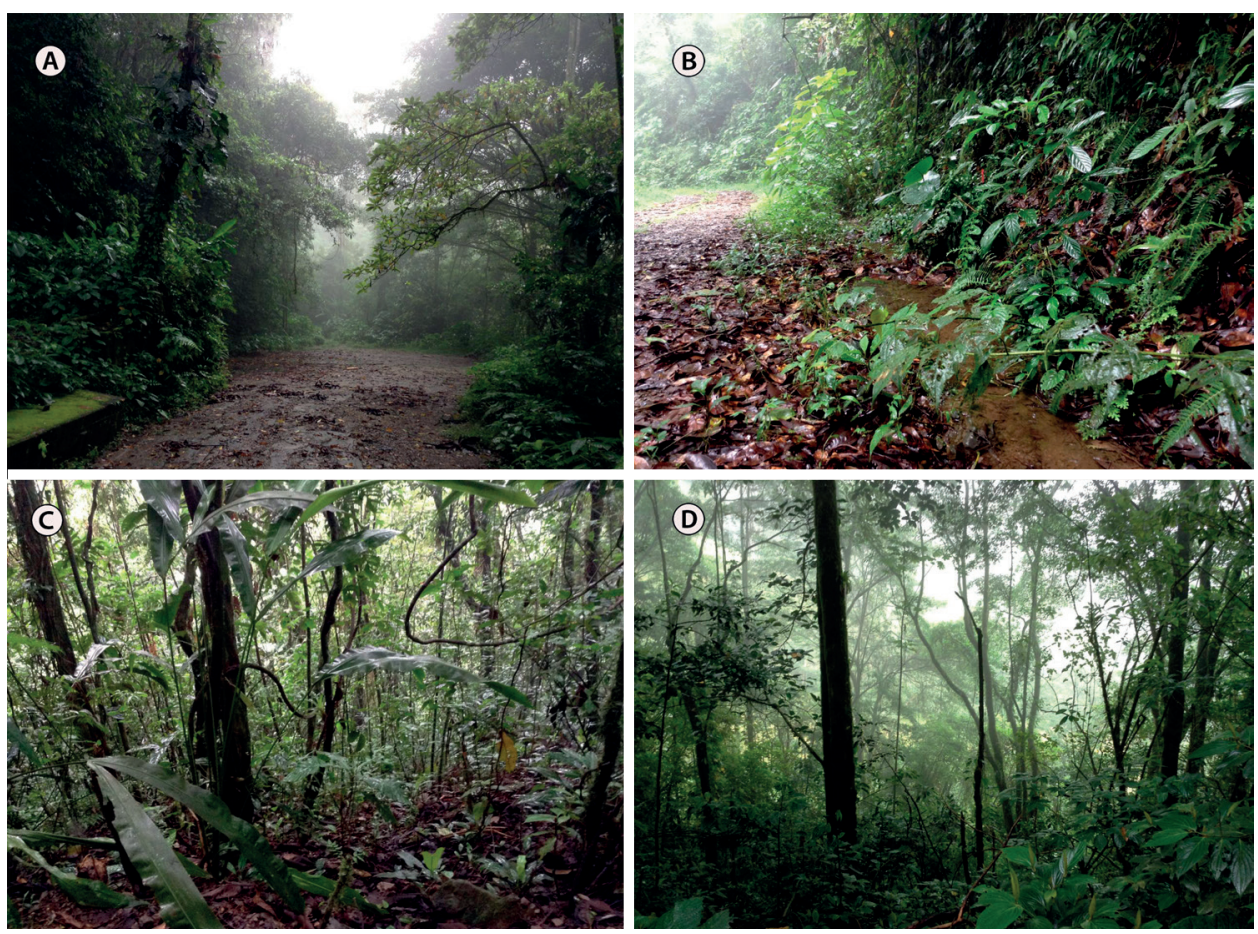

Figura 3. Panorámica de los hábitats y microhábitats de la localidad típica de Hyloxalus sanctamariensis. A. Panorámica de las áreas intervenidas al interior del bosque en la Reserva la Almenara. B. Microhábitats de las charcas de reproducción formadas por escorrentía del Bosque. C-D. Panorámica al interior del Bosque en la Reserva la Almenara. Fotos: Adrián Pinzón. 


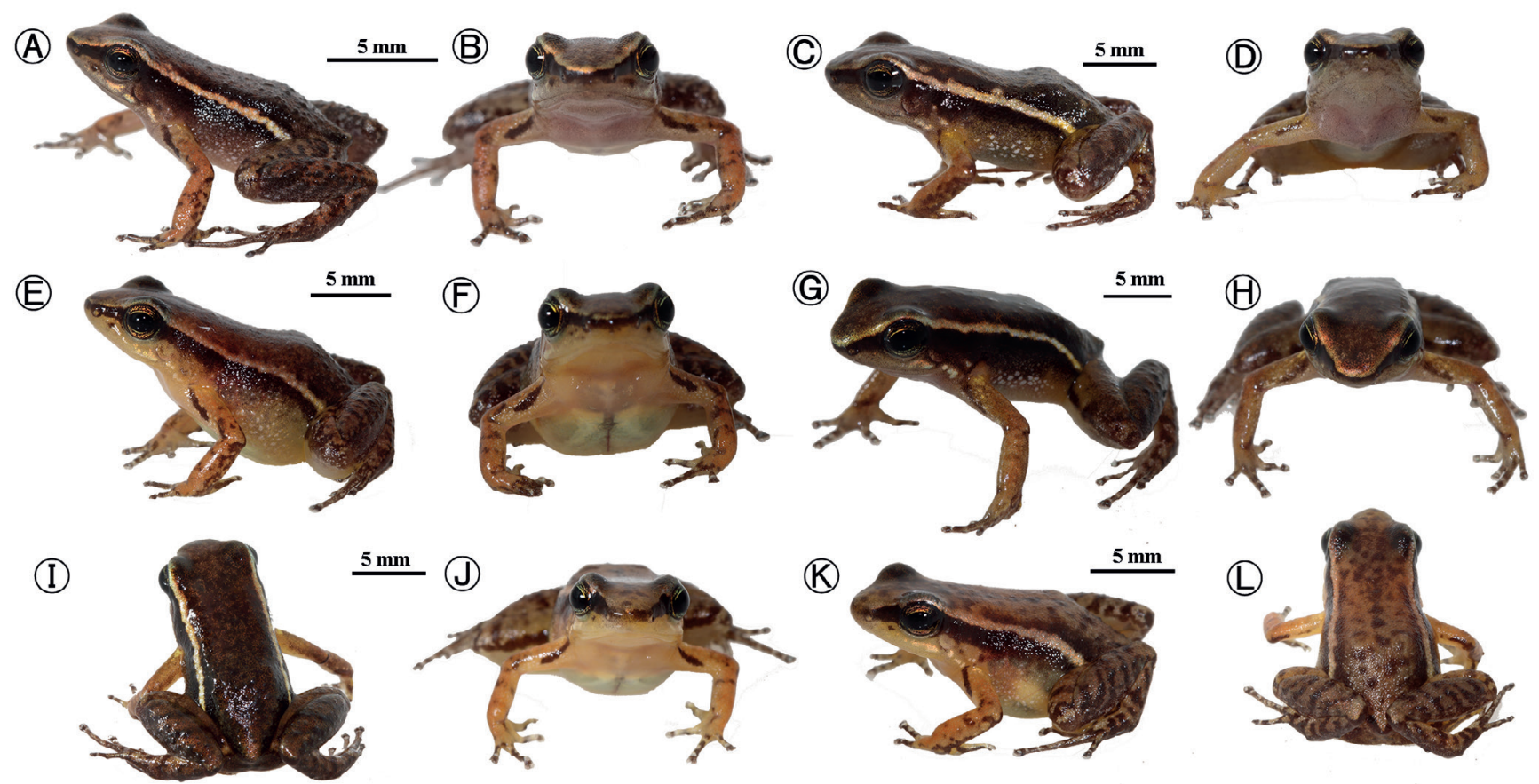

Figura 4. Serie típica in vivo (vista lateral y frontal) de Hyloxalus sanctamariensis sp. nov. A-B. Paratipo, macho adulto IAvH-Am-14675 (LRC = 16,9 mm). C-D. Paratipo, macho adulto IAvH-Am-14674 (LRC = 18,1 mm). E-F. Paratipo, hembra adulta IAvH-Am-14659 (LRC = 17,2 mm). G-H. Vista lateral, frontal y reversa en macho adulto IAvH-Am-14673(LRC =17,8 mm). I-J. Vista Lateral, frontal y reversa hembra adulta IAvH-Am-14672 (LRC = 17,1mm). K-L. Vista Lateral, frontal y reversa hembra adulta IAvHAm-14673 (LRC = 17,8 mm). Fotos: Andrés Acosta.

Definición. Una especie tentativamente asignada al género Hyloxalus y reconocible por la siguiente combinación de caracteres (1) LRC en machos adultos 16,9-18,1 $\mathrm{mm}(17,7 \pm 0,5, n=4)$; hembras adultas 17,1-20,1 mm $(18,3 \pm 1,4, n=4)$; (2) Disco del dedo manual III (dedo manual IV sensu Grant et al. 2017) no expandido, la anchura de la falange adyacente equivale al 59,7-90,5 \% (Figura 7); (3) dedo manual I (dedo manual II sensu Grant et al., 2017), ligeramente más largo o igual que el II (dedo manual III sensu Grant et al., 2017) (Figura 7); (4) rebordes dérmicos en el margen externo de los dedos manuales y pediales (siendo más evidentes); (5) discos de los dedos pediales moderadamente expandidos, la anchura de la falange adyacente al IV dedo pedial, equivale al 49,3-77,1 \% en el disco del dedo IV (Figura 7); (6) rebordes dérmicos en la margen externa de los dedos pediales evidentes (Figura 7); (7) pliegue tarsal externo ausente; tubérculo tarsal interno prominente y elongado a manera de pliegue; (8) palmeadura basal entre los dedos pediales II-IIIIV; (9) banda dorsolateral ausente; (10) banda lateral oblicua presente continua que se extiende desde la ingle hasta el extremo del rostro (Figura 6); (11) banda ventrolateral ausente; (12) garganta, pecho y vientre, presentan dimorfismo sexual evidente; en los machos adultos es café violáceo y en las hembras crema a amarillo pálido (Figura 7); (13) III dedo manual (dedo manual IV sensu Grant et al. 2017) no ensanchado en los machos (Figura 5); (14) testículos blancos; (15) tubérculos cloacales ausentes (16) proceso medial lingual ausente (17) la vocalización está definida por una frecuencia dominante entre 4213,3-5828,2 Hz y un duración de cada nota que varía entre 0,062-0,09 s (Figura 9, Figura 10).

Diagnosis. Ocho especies de Hyloxalus son reportadas en la cordillera Oriental, donde 


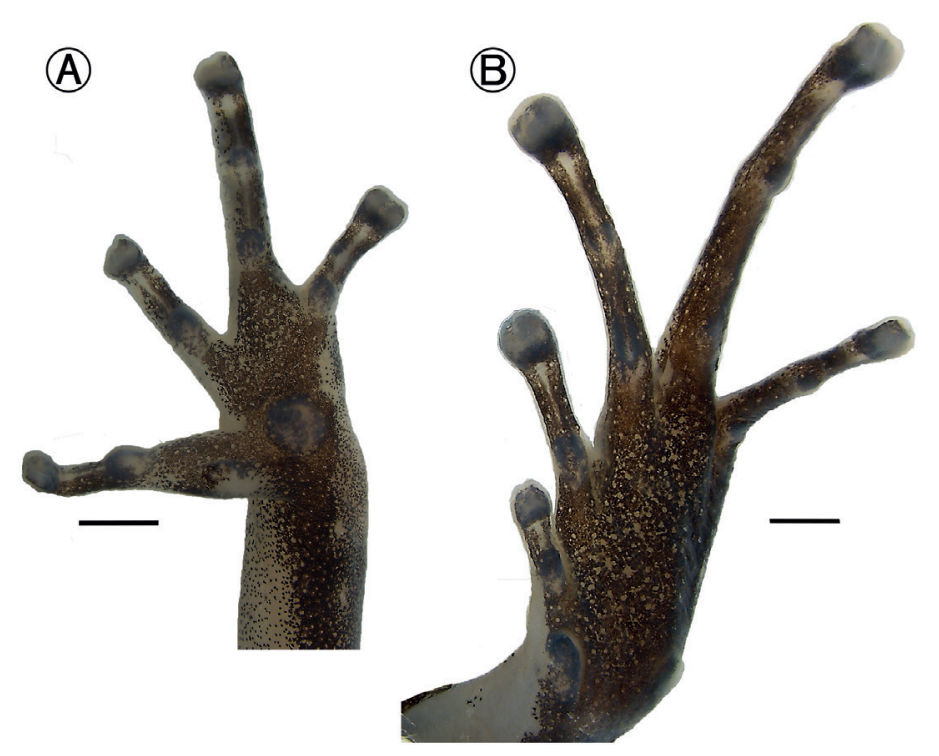

Figura 5. Hyloxalus sanctamariensis sp. nov. Paratipo IAvH-Am-14673 macho adulto. A. Vista ventral de la palmeadura manual. B. Vista ventral de la palmeadura pedial, Escala igual $=1 \mathrm{~mm}$. Fotos: Andrés Acosta.

tres tienen sus distribuciones asociadas a las vertientes andinas asociadas a la región cisandina de Colombia (Figura 1). En adición a esta riqueza regional, Hyloxalus sanctamariensis sp. nov. es una rana de tamaño medio que carece de banda ventrolateral (Figura $8 \mathrm{D}$ ). Este rasgo está presente en Hyloxalus cepedai junto con dos especies de Allobates (A. femoralis [Figura 8B] y A. juanii [Figura $8 \mathrm{C}])$.

Hyloxalus sanctamariensis sp. nov también difiere de $H$. cepedai por la ausencia de una banda dorsolateral (presente en H. cepedai, Figura 8A), la banda lateral oblicua presente (ausente H. cepedai), palmeadura basal entre los dedos pediales II-IIIIV (presente en III-IV en H. cepedai), el tercer dedo manual (IV dedo manual sensu Grant et al., 2017) no ensanchado en los machos adultos (ensanchado en $H$. cepedai), la duración de una nota individual varía entre $0,062-0,09$ s $(0,029-0,048$ s en $H$. cepedai) mientras que la duración entre notas varía entre 0,281-0,92 s (0,094-0,133s en H. cepedai). Hyloxalus sanctamariensis sp. nov. es muy similar a Hyloxalus picachos dado que comparten una banda lateral oblicua, la ausencia de banda ventrolateral y presentan una palmeadura basal entre los dedos pediales II-III-IV, pero difieren entre sí por la coloración in vivo del iris siendo cobre con retículos negros (amarillo-dorado con retículos gruesos en $H$. picachos) y la banda lateral oblicua se extiende hasta el rostro (alcanza hasta el tímpano o es ausente en $H$. picachos).

Al realizar comparaciones con las restantes especies de la cordillera Oriental, Hyloxalus sanctamariensis sp. nov. puede ser distinguida de Hyloxalus lehmanni y H. saltuarius por la ausencia de glándula en el brazo; difiere de H. edwardsi y $H$. ruizi por la ausencia de un escudo anal (presente en H. edwardsi y H. ruizi), la palmeadura basal entre los dedos pediales II-III-IV (membrana extensiva en H. edwardsi y H. ruizi) y la presencia de hendiduras vocales en los machos adultos (ausentes en $H$. edwardsi y $H$. ruizi). Hyloxalus sanctamariensis sp. nov. es fácilmente reconocible de $H$. vergeli por presentar la palmeadura basal entre los dedos pediales II-III-IV (membrana extensiva en $H$. vergeli). Finalmente, de Hyloxalus sanctamariensis sp. nov. difiere de $H$. subpunctatus por que los machos adultos presentan el saco vocal y el pecho 

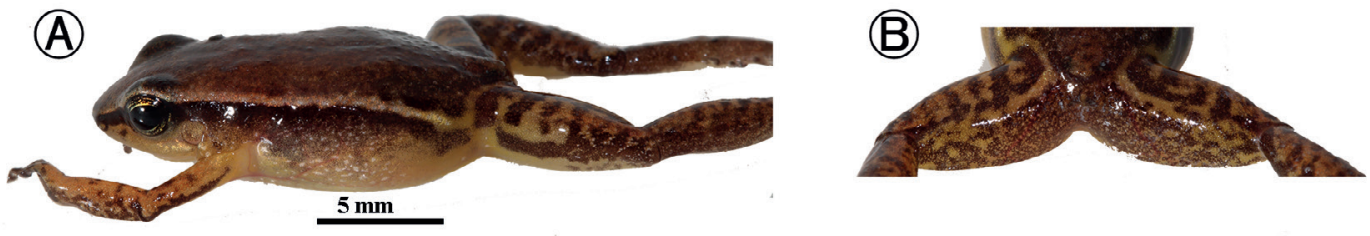

(C)
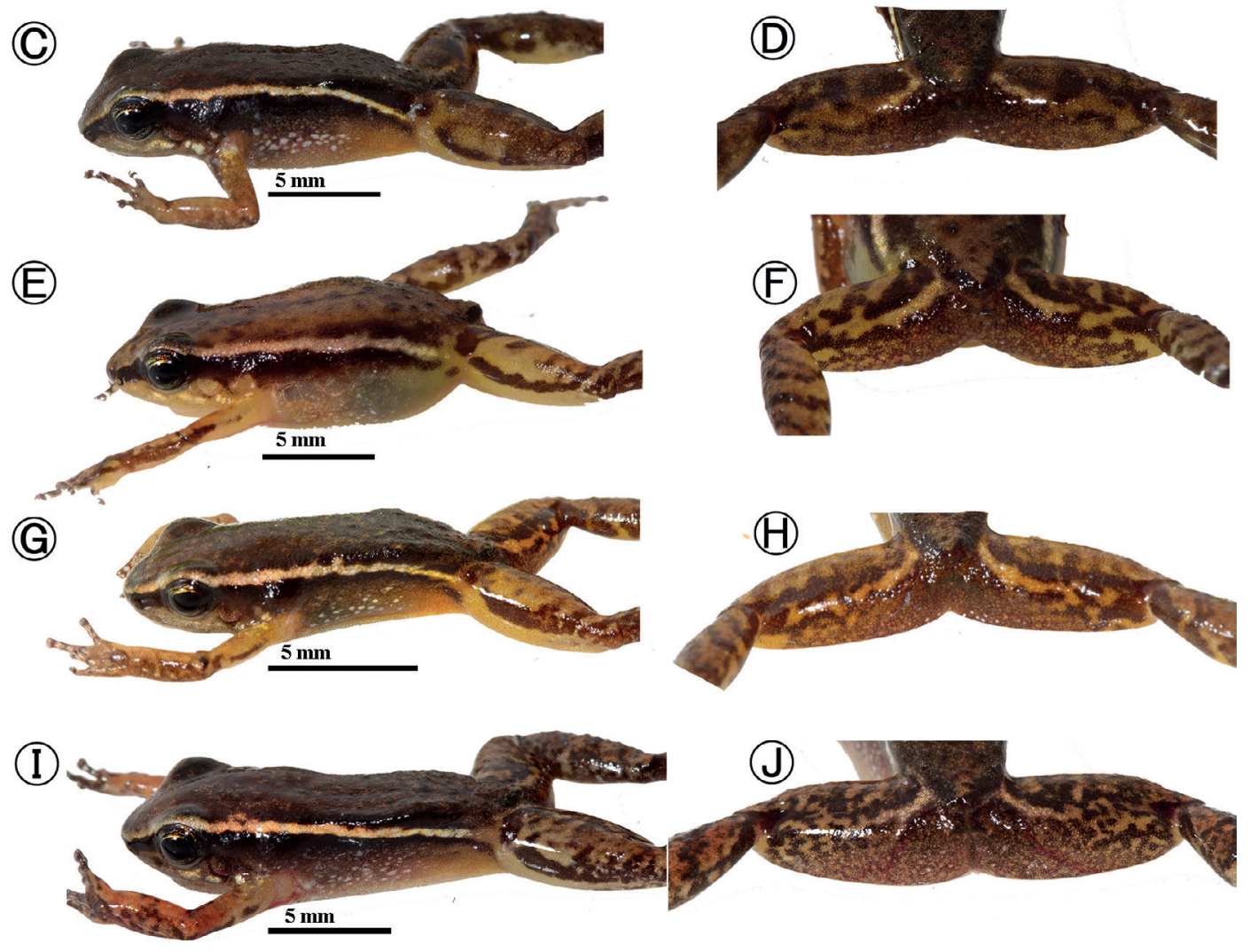

Figura 6. Variación de las superficies lateral y muslo posterior in vivo de Hyloxalus sanctamariensis sp. nov. A-B. Hembra adulta IAvH-Am-14659(LRC = 17,2 mm). C-D. Macho adulto IAvH-Am-14673 (LRC $=17,8 \mathrm{~mm}$ ). E-F. Hembra adulta, IAvHAm-14672 (LRC= 17,1 mm). G-H. Macho adulto IAvH-Am-14674(LRC = 18,1 mm). I-J. Macho adulto IAvH-Am-14675(LRC= 16,9 mm). Fotos: Andrés Acosta.

pigmentado (crema en los machos adultos de $H$. subpunctatus) menor tamaño corporal, los machos adultos 16,9-18,1 $\mathrm{mm}$, mientras que las hembras adultas 17,1-20,1 (machos adultos 15,5-23,1 mm, hembras adultas 15,5-27,5 mm en $H$. subpunctatus), y 124 llamados por minuto (60 llamados por minuto sensu Navas y Biever, 2001).

Descripción y variación de la serie típica (Figura 4, Figura 6). La variación morfométrica es presentada en la Tabla 1. Machos adultos entre
16,9-18,1 mm (n = 4) de longitud rostro cloacal (LRC) con la garganta y pecho oscuros, hembras adultas 17,1-20,1 $\mathrm{mm}(n=4)$ con las superficies ventrales inmaculadas (Figura 7). Piel de las superficies dorsales y laterales en la región cefálica, parpados y la porción anterior del tronco lisas (a nivel de los párpados medialmente un tubérculo aplanado en IAvH-Am-14675), mientras que la porción posterior es granular extendiéndose hasta los miembros posteriores; tubérculos cloacales ausentes. 


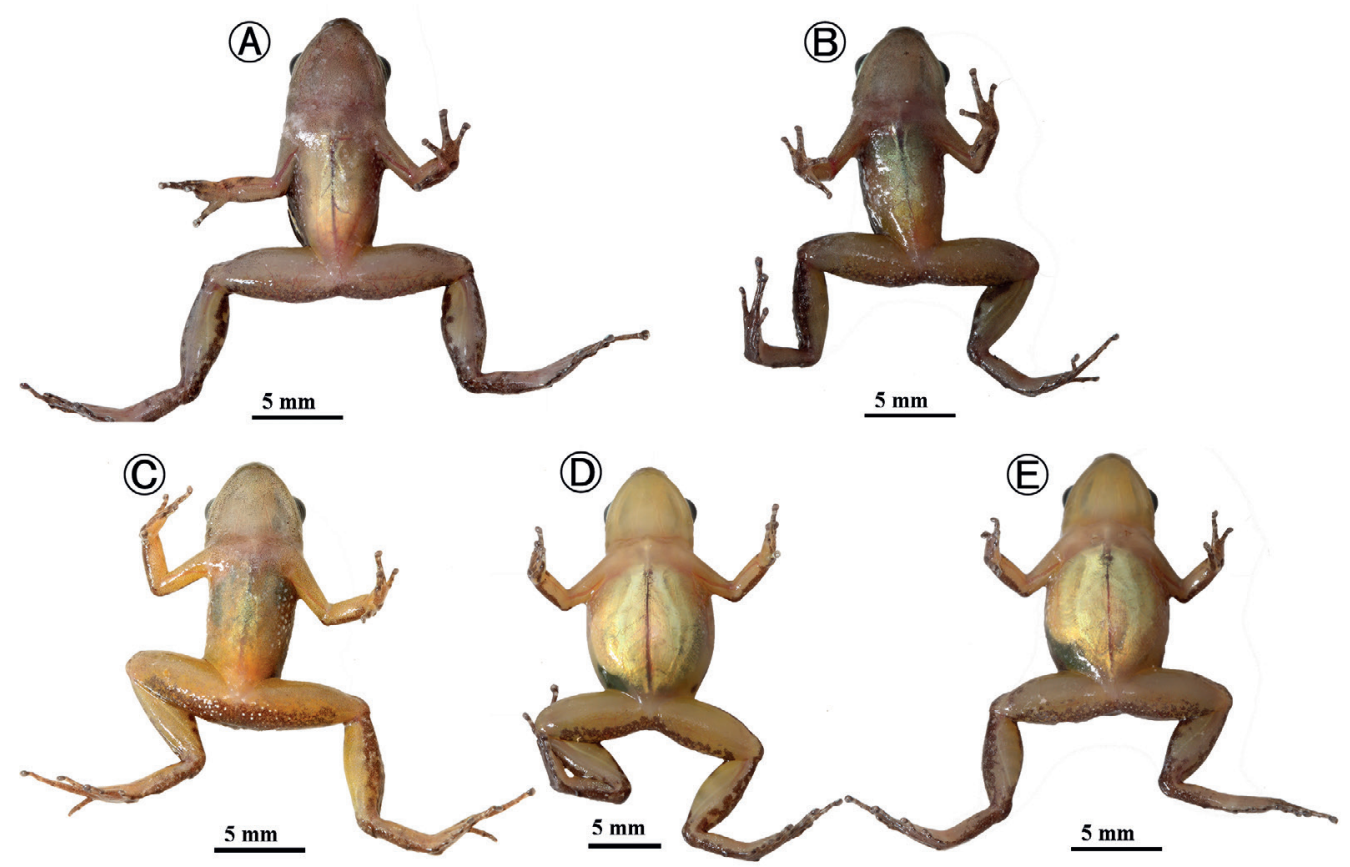

Figura 7. Coloración ventral que indica el dimorfismo sexual de la serie típica de Hyloxalus sanctamariensis sp. nov. A. Macho adulto IAvH-Am-14675 (LRC = 16,9 $\mathrm{mm})$. B. Macho adulto IAvH-Am-14673 (LRC = 17,8 mm). C. Hembra adulta IAvH-Am-14672 (LRC = 17,1 mm). D. Hembra adulta IAvH-Am-14655 (LRC = 18,6 mm). E. Hembra adulta IAvH-Am-14659 (LRC = 17,2 mm). Fotos: Andrés Acosta.

Anchura cefálica (a nivel de la base mandibular) equivale al 28,8-34,8 \% de la longitud rostro cloacal, y el 79,8-92,7 \% de la longitud cefálica. La distancia interorbital equivale al 35,5-50,1 \% de la anchura cefálica. Rostro corto, redondeado en vista dorsal entre las narinas, en vista lateral inclinado y redondeado. Canthus rostralis bien definido y redondeado. Región loreal casi aplanada con una débil concavidad que se inclina hacia la parte externa del labio superior. Diámetro del ojo equivale al 30,7-37,8 \% de la longitud cefálica. Distancia del ojo a la narina equivale al $60,8-75,1 \%$ de la longitud del rostro, y al 80,897,7 \% del diámetro del ojo. Narinas externas algo protuberantes, ovaladas y orientadas posterodorsalmente. Tres cuartas partes del anillo timpánico visibles en su porción antero-ventral, su diámetro equivale al 43,2-54,0 \% del diámetro del ojo. Dientes presentes en el arco maxilar.
Miembros anteriores esbeltos, longitud del antebrazo equivalente al 18,9-22,1 \% de la LRC y al $67,8-80,0 \%$ de su longitud manual. La longitud manual equivale al 25,3-28,7 \% de su LRC. Discos de los dedos manuales moderadamente expandidos, la anchura de la falange adyacente al dedo III manual (dedo manual IV sensu Grant et al., 2017) equivale al 59,7-90,5 \% en el disco del dedo III. Tercer dedo manual (dedo manual IV sensu Grant et al., 2017) no expandido en los machos adultos (levemente en el ejemplar tipo, IAvHAm-14658). Rebordes dérmicos ausentes en los dedos manuales. Dedo I manual (= dedo manual II sensu Grant et al., 2017) más largo (usualmente) o casi igual que el dedo II (=dedo manual III sensu Grant et al., 2017). El disco del dedo manual II (dedo manual III sensu Grant et al., 2017) entra en contacto con el último tubérculo subarticular del dedo III (dedo manual IV sensu Grant et al., 

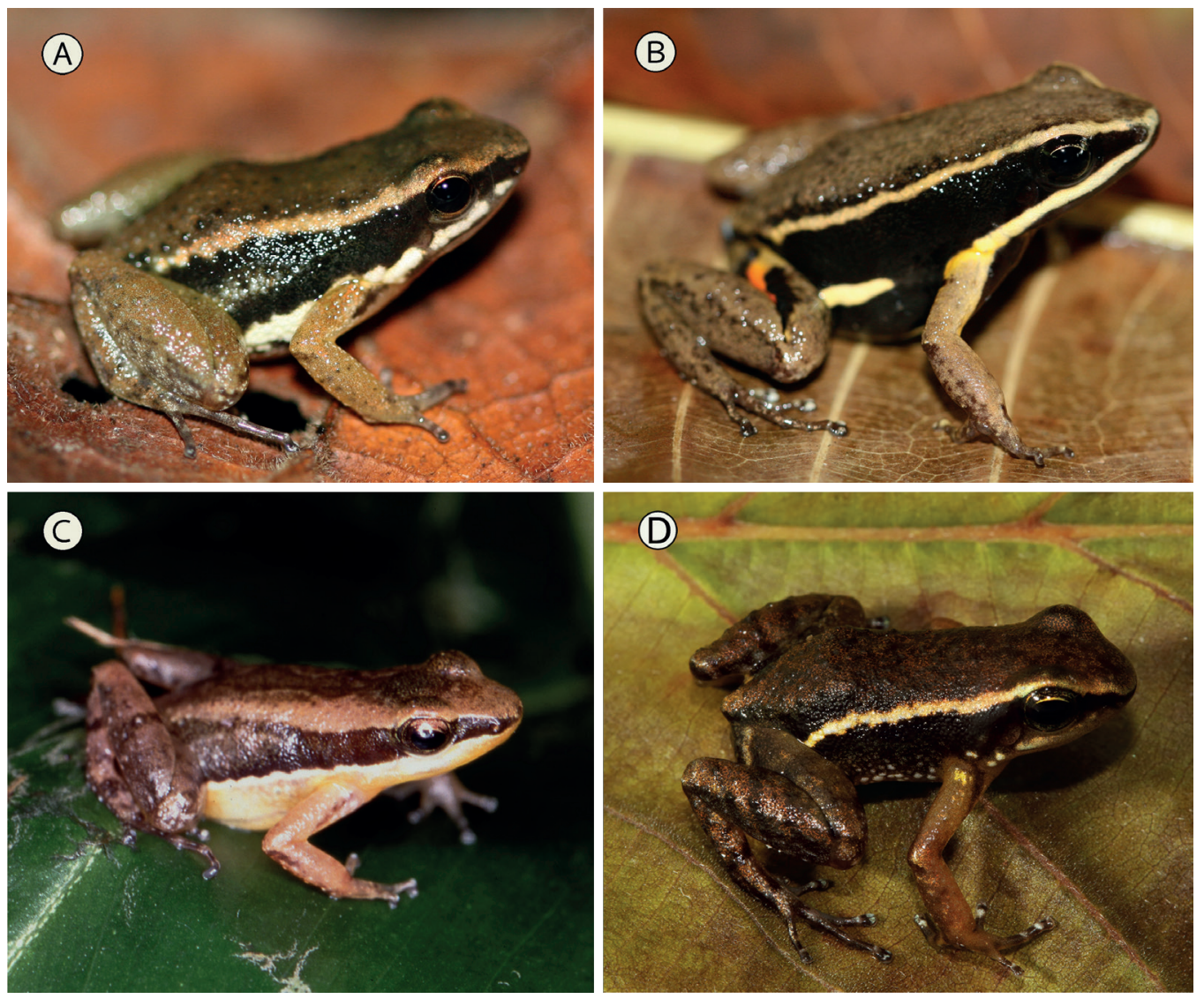

Figura 8. Vista lateral de algunas de las especies de Dendrobatoidea presentes en las estribaciones del piedemonte de la cordillera Oriental de Colombia (Anexo 2). A. Hyloxalus cepedai proveniente de Yopal, departamento de Casanare, macho adulto IAvH-Am 10713. B. Ejemplar liberado de Allobates femoralis del Parque Nacional Güeppi-Sekime, provincia de Maynas del departamento de Loreto, Perú. C. Allobates juanii, sitio Pozo Azul, municipio de Villavicencio, departamento del Meta, macho adulto MUJ 3364. D. Hyloxalus sanctamariensis sp. nov. sitio La Almenara, departamento de Boyacá, hembra adulta, IAvH-Am-14672. Fotos: Andrés Acosta.

2017); el disco del dedo manual IV (dedo manual V sensu Grant et al. 2017) no sobrepasa el último tubérculo subarticular del dedo III (dedo manual IV sensu Grant et al., 2017). Longitud relativa de los dedos manuales III $>$ IV $\geq$ II $>$ I $\quad(I V>V \geq I I I>I I$ sensu Grant et al., 2017). Tubérculos subarticulares 1-1-2-2. Tubérculos supernumerarios ausentes, tubérculos subarticulares redondeados; tubérculo tenar ovoide; tubérculo palmar redondeado y prominente; la relación entre el tubérculo palmar y tenar equivalente en diámetro; pliegues metacarpales ausentes.
Miembros posteriores relativamente robustos, longitud tibial equivale al 46,2-49,7 \% de la LRC y la longitud pedial equivalente al 45,7-47,9\% de la LRC. Membrana interdigital pedial basal entre los dedos II-III-IV y rebordes dérmicos en la margen externa de los dedos pediales evidentes. Longitud relativa de los dedos pediales IV $>$ III $>$ V $>$ II $>$ I. Disco del dedo III pedial se extiende más allá de penúltimo tubérculo subarticular del dedo IV. El disco del dedo $V$ entra en contacto con el penúltimo tubérculo subarticular del dedo IV pedial. Discos de los dedos pediales moderadamente 
expandidos, la anchura de la falange adyacente al IV dedo pedial, equivale al 49,3-77,1 \% en el disco del dedo IV. Tubérculos subarticulares pediales 1-1-2-3-2. Tubérculos supernumerarios plantares ausentes (Figura 5); tubérculo metatarsal interno elíptico; tubérculo metatarsal externo subcircular más pequeño que el tubérculo metatarsal interno, el diámetro del tubérculo metatarsal externo equivale al 53,7-93,5 \% del tubérculo metatarsal interno; tubérculo tarsal externo ausente; tubérculo tarsal interno prominente y elongado a manera de pliegue, siendo oblicuo al tarso, en algunos ejemplares se extiende en un pliegue delgado y corto orientado al tubérculo metatarsal (en el ejemplar IAvH-Am-14674 el pliegue entra en contacto con el tubérculo metatarsal interno).

Dimensiones del holotipo (en $\mathrm{mm}$ ). Longitud rostro cloacal 18,0; longitud manual 4,5; longitud tibial 8,3; longitud pedial 8,4; anchura cefálica 5,8; longitud cefálica 6,5; diámetro del ojo 2,1; distancia ojo-narina 2,0; distancia internarinas 2,3; longitud rostral 2,7; distancia interorbital 2,3; diámetro del tímpano 0,9 y longitud del antebrazo 3,6.

Color in vivo (Figura 4, 6 y 7). Basado en las notas de campo y la serie típica fotografiada in situ; Hyloxalus sanctamariesensis sp. nov, presenta en sus superficies dorsales un color café acanelado con pequeñas manchas irregulares y un café más oscuro que se extiende desde el extremo rostral hasta la región urostilar; color de fondo de las superficies dorsales del muslo, tibia y el tarso igual al dorso, con barras transversales de color café oscuro; las superficies de los miembros anteriores café claras con algunas manchas dispersas e irregulares de color café oscuro; región anterior del antebrazo con una banda longitudinal café oscuro. Flanco cefálico y troncal con una banda dorsolateral de color crema que se extiende desde el extremo del rostro hasta la ingle; esta banda dorsolateral en su margen ventral esta bordeada por una banda café oscura que se extiende desde el rostro, cubre la porción superior del tímpano, se ensancha a la altura de las extremidades anteriores y se adelgaza hacia la región inguinal; región labial amarillo pálido con algunas manchas irregulares de color crema en los machos adultos esta región se encuentra pigmentada de color café. Porción anterior del flanco troncal café que se degrada a crema hacia la región ventrolateral con pequeñas manchas irregulares de color blanco mientras que la región inguinal varía de amarillo pálido a café claro. Iris cobre con retículos negros. Muslo anterior varía de amarillo pálido a café claro con una banda longitudinal café. Muslo posterior con color de fondo amarillo pálido a café cubierto de pequeñas reticulaciones y una banda longitudinal irregular de color amarillo pálido. Superficies ventrales con un marcado dimorfismo sexual (Figura 7): en los machos el saco gular de color café violáceo, mientras en las hembras es crema y amarillo pálido; el vientre en los machos es café violáceo y hacia la porción media es crema mientras en las hembras el vientre es crema uniforme. Región palmar y plantar café violáceo.

Color en preservación (etanol 70 \%) (Figura 2). La coloración de las superficies dorsales se tornan café con manchas, pequeñas e irregulares café oscuras siendo en algunos ejemplares más densas; los muslos dorsales café claro con barras café oscuro; los miembros anteriores de color crema y algunos ejemplares presentan manchas dispersas de color café oscuro. En vista lateral las superficies del flanco cefálico la banda de la región loreal se torna café oscura y la región supralabial que varía de color crema en las hembras y con finas punteaduras café oscuro en los machos adultos; en la comisura labial unas manchas irregulares de color blanco, pero en algunos ejemplares de la serie estas manchas son visibles en la región infratimpánica e infraocular. La banda lateral oblicua de color crema bordeada en su región ventral por una banda café oscuro que disminuye en anchura hacia la región abdominal del flanco troncal. Región ventrolateral de color café claro con finas punteaduras café oscuro y en algunos ejemplares este patrón forma unas manchas irregulares crema. Superficies ventrales, exhiben un marcado dimorfismo sexual y en los machos la región del saco vocal, pecho y una porción del abdomen superior se tornan café; mientras que en las hembras adultas es crema. 
Vocalizaciones. El llamado de Hyloxalus sanctamariensis sp. nov. está compuesto por notas simples emitidas a una tasa constante (Figura 9); con una tasa de vocalización de 124 notas por minuto. La duración de cada nota (Figura 10) varía entre $0,062-0,09 \mathrm{~s}(0,07 \pm 0,006 ; n=70)$ y entre $324-388(355,7 \pm 19,8 ; n=44)$ oscilaciones por cada nota. La duración de los intervalos entre notas varía entre $0,281-0,92 \mathrm{~s}(0,112 \pm 0,40 ; n=70)$. La estructura espectral consiste en 5 armónicos con una frecuencia dominante entre $4213,3-5828,2 \mathrm{~Hz}$ $(5056,2 \pm 704,7 ; n=90)$.

Transporte de las larvas y descripción del renacuajo. Dentro de la serie típica obtenida 2 machos adultos (Figura 11) fueron registrados transportando larvas en su dorso en estadios 26 (sensu Gosner, 1960). Cada macho transportaba entre 10 (IAvH-Am-14675) y 6 (Holotipo, IAvHAm-14658) individuos. Los renacuajos (Anexo 2, Figura 12) son de cuerpo ovoide y deprimido (Figura 12), con elementos condrocraneales visibles (Figura 13); el rostro en vista dorsal y lateral redondeado. Las narinas son pequeñas, subcirculares dirigidas anterodorsalmente. Sus ojos son orientados dorsolateralmente. Espiráculo siniestro, cónico, con la porción distal del tubo es libre, orientada posterolateralmente y conspicua. El tubo cloacal, unido al lado derecho de la aleta ventral y su abertura orientada a la derecha. La musculatura caudal es robusta; los miomeros son más conspicuos y separados entre sí, en la porción distal de la cola. La aleta dorsal, levemente es más ancha que la aleta ventral. El sistema de línea lateral no es visible.

El disco oral débilmente emarginado, orientado anteroventralmente bordeado por papilas marginales elongadas y de forma piramidal (Figura 14); las papilas marginales están dispuestas entre dos hileras en la región labial anterior y tres hileras en la posterior; picos córneos superior e inferior, pigmentados y aserrados en su borde.

Formula dental 2/3 (ausentes en algunos de los renacuajos de la espalda), hilera de dientes

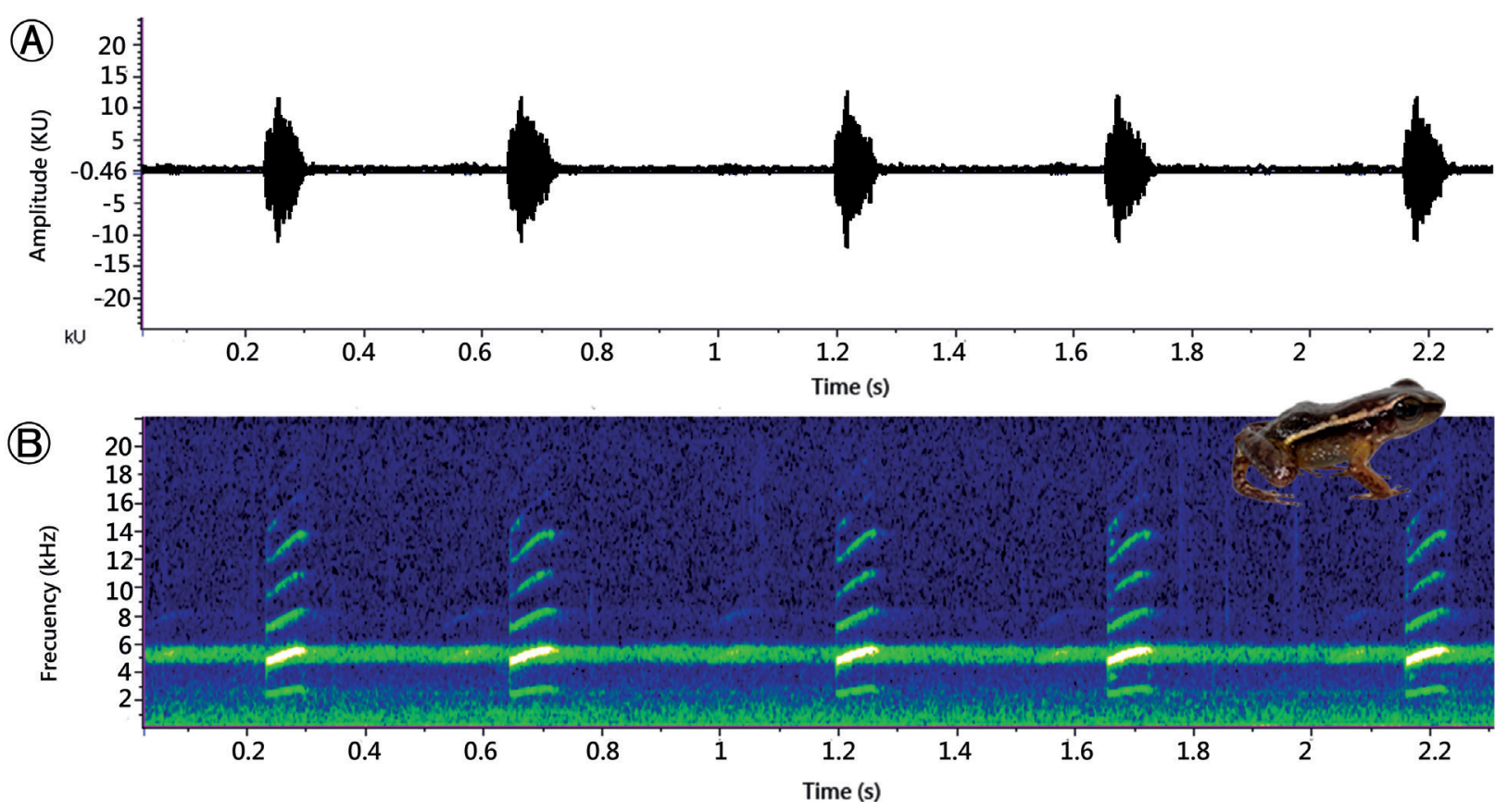

Figura 9. Llamado (con 5 notas) de un macho adulto de Hyloxalus sanctamariensis BSA-15986, grabado en la localidad típica en La Reserva La Almenara, Santa María, Boyacá. A. Oscilograma. B. Espectrograma muestra entre 5-6 armónicos por nota; http:/ / colecciones.humboldt.org.co/rec/ sonidos/BSA-15986/. 

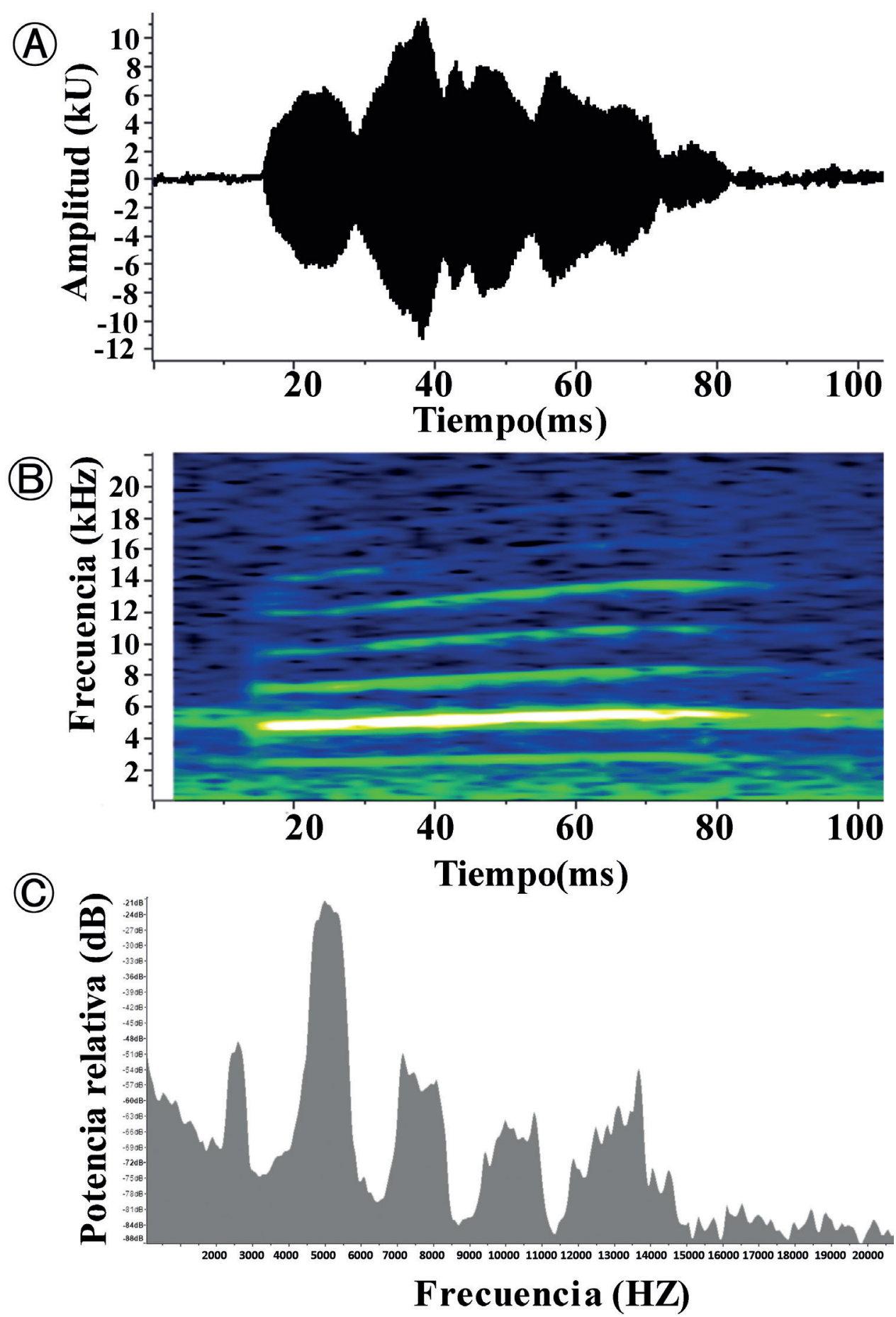

Figura 10. Nota individual de Hyloxalus sanctamariensis sp. nov. A. Oscilograma. B. Espectrograma con 6 armónico. C. Espectro de poder. BSA15986, grabado en la localidad típica en La Reserva La Almenara, Santa María, Boyacá; http:/ / colecciones.humboldt.org.co/rec/sonidos/BSA-15986/. 
(A)

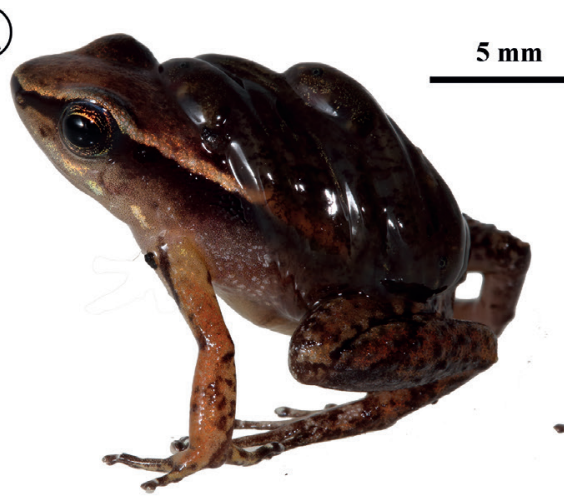

(B)

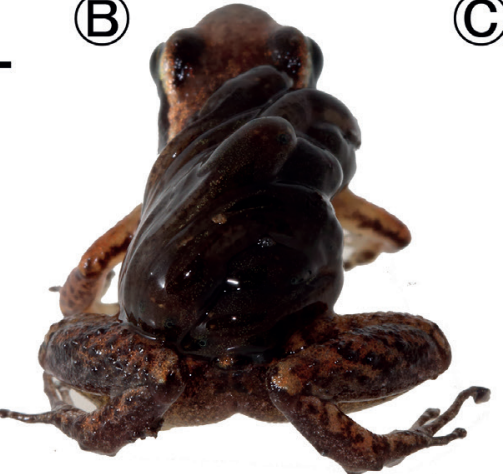

(C)

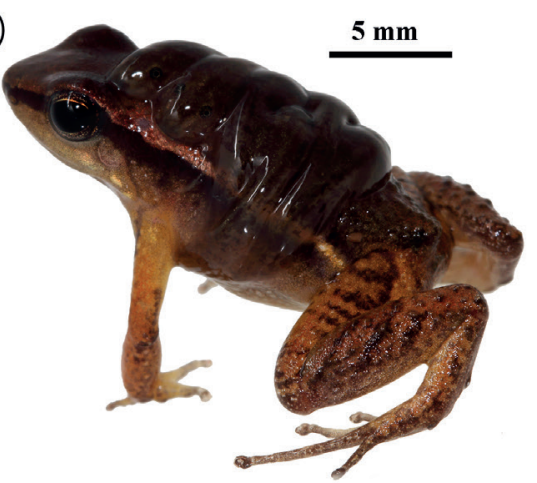

Figura 11. Vista lateral de dos machos nodriza de Hyloxalus sanctamariensis sp. nov. transportando sus renacuajos en el dorso en estadio 26 sensu Gosner, (1960). A-B. Vista lateral-reversa IAvH-Am-14675 $(\mathrm{LRC}=16,9 \mathrm{~mm})$. C. vista lateral IAvH-Am-14658 (LRC=18,0 mm). Fotos: Andrés Acosta.

(A)

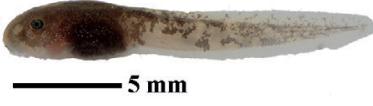

(D)

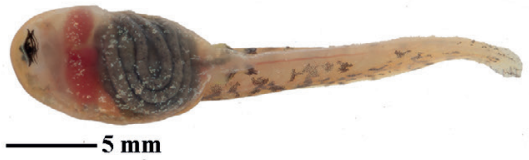

(F)
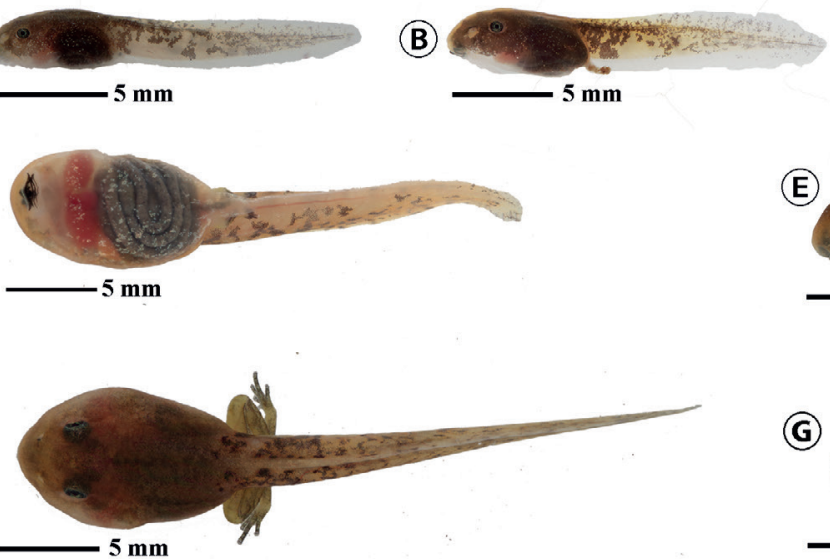

(C)
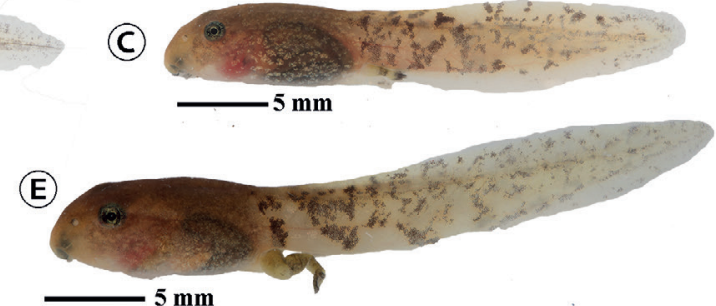

(G)

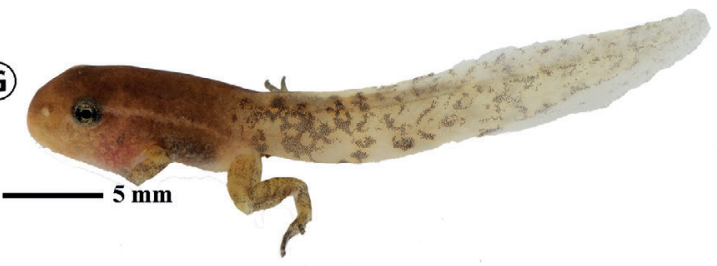

(I)

(H)

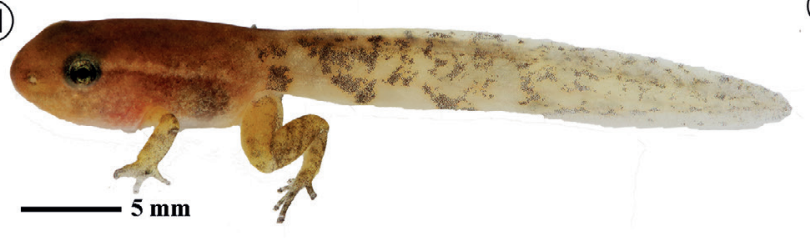

(J)
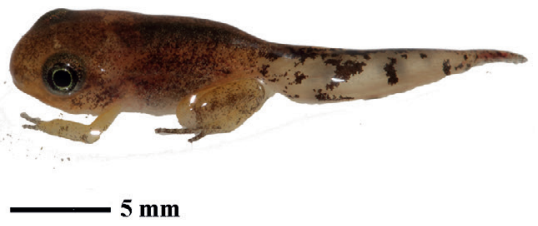

(K)

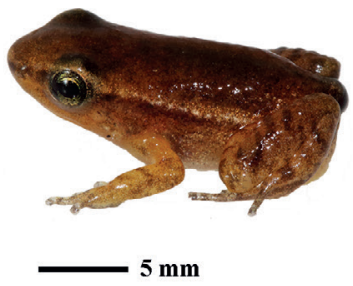

(L)

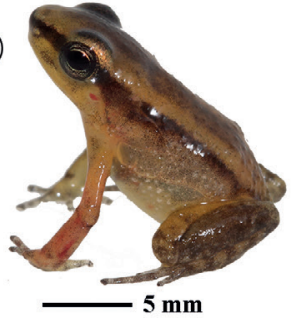

Figura 12. Cambio Ontogénico in vivo de Hyloxalus sanctamariensis sp. nov. Lote IAvH-Am-14680; A. Vista lateral, estadio 26 obtenido del dorso del macho. Vida libre: B. Vista lateral estadio 28. C. Vista lateral, Estadio 37. D. Vista ventral, Estadio 37. E. Vista lateral estadio 40. F. Vista dorsal estadio 40. G. Vista lateral estadio 41. H. Vista lateral estadio 42. I. Vista lateral estadio 43. J. Vista lateral estadio 45. K. Vista lateral estadio 46. L. Vista lateral postmetamórfico. Fotos: Andrés Acosta. 
A-1 es completa, la hilera A-2 es interrumpida medialmente semejando dos hileras separadas por el pico córneo; numerosas papilas submarginales; pico córneo inferior en forma de $\mathrm{V}$, y más angosto que el superior. La hilera de dientes P-1 es completa más angosta que las hileras P-2 y P-3; y P-3 de mayor longitud que P-2.

Color de los renacuajos in vivo (Figura 12). Las superficies dorsales del cuerpo de color café y las de la región caudal café más claro; el flanco cefálico café claro mientras que el flanco corporal café algo translucido con manchas irregulares más claras siendo el corazón e intestinos visibles; musculatura caudal crema con manchas irregulares café siendo más engrosadas en la base de la cola y difusas en la región más distal; aletas dorsal y ventral translucidas con el mismo patrón de la musculatura caudal; iris negro con punteaduras cobre. Superficies ventrales de la región corporal translucidas siendo visibles la región branquial y los intestinos; con algunas manchas irregulares de color blanco. Se evidencia que algunos de estos patrones de coloración cambian parcialmente durante el desarrollo ontogénico: en estadio 26 la superficie del cuerpo es café más oscura con algunas punteaduras crema: en estadio 38 el cuerpo es más claro y son notables las manchas irregulares café sobre la región abdominal y en estadio 40 el cuerpo se torna más homogéneo en coloración.

Color en preservación de los renacuajos (Formol $10 \%$ ). La porción anterior de la superficie dorsal en la región cefálica café claro, con elementos condrocraneales visibles. La región abdominal en vista dorsal café oscura. En vista lateral las superficies anteroventrales del rostro translucida y hacia la región infraorbital crema con finas punteaduras café oscuras mientras que la porción abdominal en la región dorsolateral y medial café oscura y la porción ventrolateral translucida siendo evidente la masa abdominal. La musculatura caudal crema, los miomeros visibles mientras que las aletas dorsal y ventral son translucidas con algunas manchas irregulares café, siendo en la porción anterior más concentradas y algunas de ellas forman retículos; mientras que en la porción más distal reducen su tamaño. Las superficies ventrales translucidas siendo evidente el disco oral donde el pico es negro al igual que los dentículos; los elementos condrocraneales son visibles de color crema y la masa intestinal café clara.

Distribución. Allobates sanctamariensis sp. nov. es conocida de dos localidades asociadas a los bosques subandinos pluviales circunscritas al interior del municipio de Santa María en el departamento de Boyacá entre 869-1289 m s.n.m. en las estribaciones orientales de la cordillera Oriental de Colombia (Figura 15).

Historia natural. Hyloxalus sanctamariensis sp. nov. es una especie diurna que habita en los bosques subandinos relictuales con cerca de 40 años de restauración (Figura 3). En estos ecosistemas el régimen de lluvias puntual es monomodal y son áreas con alta pluviosidad de 80,5-89,6 \% de humedad relativa media anual y una precipitación promedio de $322 \mathrm{~mm}$ anuales. Siendo los meses de menor precipitación diciembre-enero de 58,2 $\mathrm{mm}$ y los de mayor mayo-julio con $576 \mathrm{~mm}$, estos valores de precipitación coinciden con la estación reproductiva de la especie. Su actividad biológica es evidente después de lloviznas acompañadas de sol donde los machos adultos vocalizan entre la hojarasca protegiendo pequeños territorios. Durante el trabajo de campo se observaron varios ejemplares desplazándose y vocalizando activamente. Sus abundancias relativas son elevadas, ya que en 3 horas de trabajo se colectaron 8 adultos y se registraron más de 15 ejemplares adicionales junto con un número de renacuajos libres y posmetamórficos en diferentes estadíos de desarrollo en los canales de escorrentía. Los renacuajos son categorizados de tipo exotrófico, loticos (McDiarmid y Altig, 1999) y detritívoros. Hyloxalus sanctamariensis sp. nov. es simpátrica, pero no sintópica con Rheobates palmatus dado que en una de las localidades donde se reportan H. sanctamariensis sp. nov. está asociada a las márgenes y bosque protector de cauce alrededor de pequeñas quebradas de curso lento mientras que $R$. palmatus se registra al interior de pocetas en el cauce de las quebradas. 
(A)

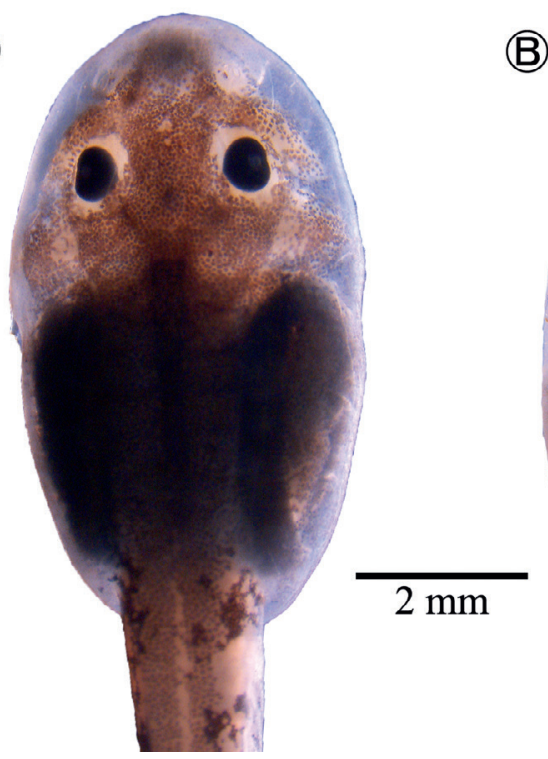

(B)

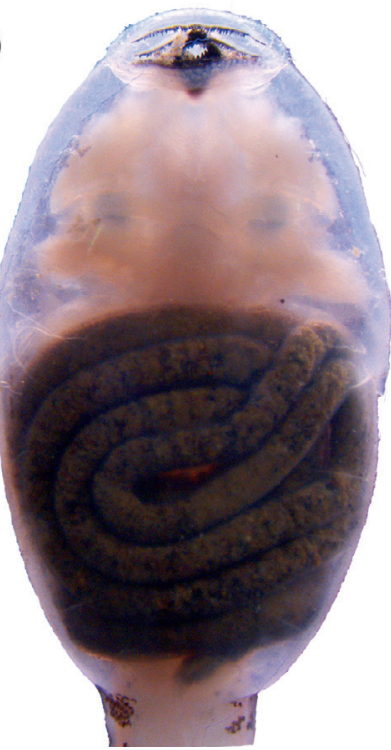

Figura 13. Renacuajo de Hyloxalus sanctamariensis sp. nov., exhibiendo los elementos condrocraneales, Lote IAvH-Am-14680. A. Vista dorsal. B. Vista ventral. Fotos: Andrés Acosta.
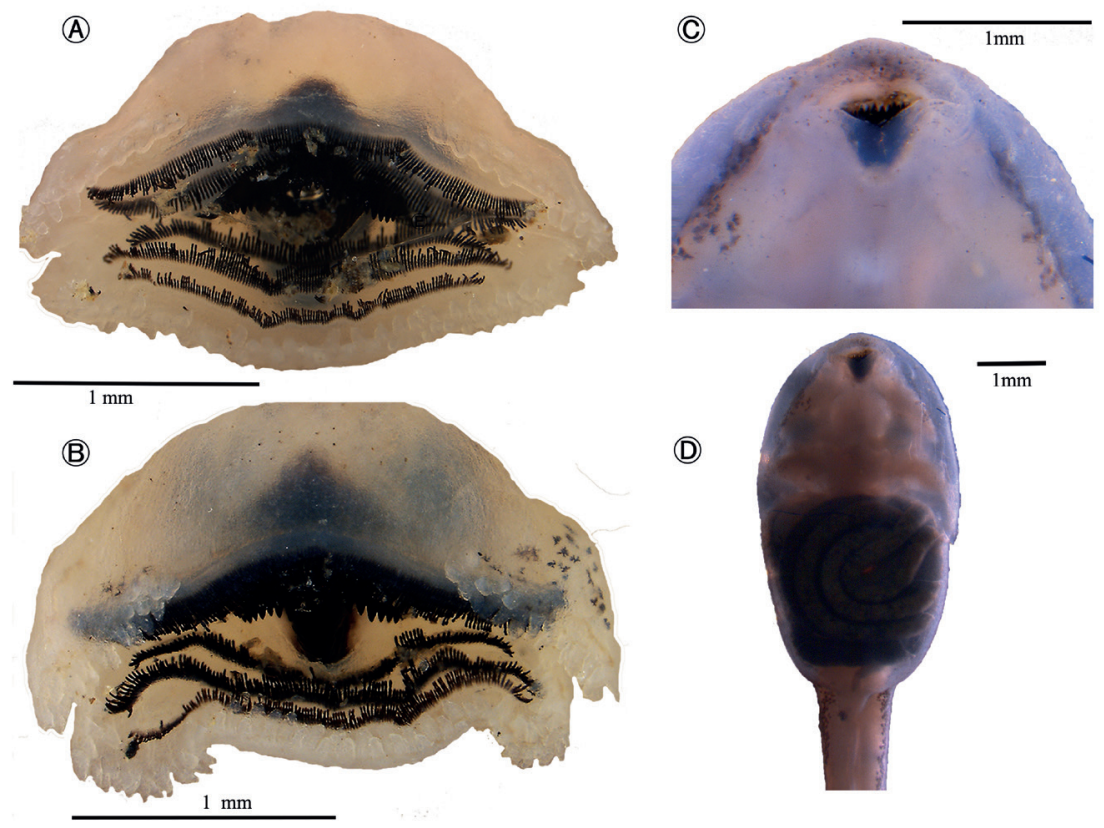

Figura 14. Vista ventral del disco oral de Hyloxalus sanctamariensis sp. nov. A. Estadio 29 (sensu Gosner, 1960) exhibiendo la formula dentaria 2/3, papilas marginales y parte del pico córneo, lote IAvHAm-14680; B) Estadio 41 (sensu Gosner 1960) exhibiendo las hileras P-1 a P-3, papilas marginales y parte del pico córneo anterior, lote IAvH-Am-14680. C-D. Renacuajo proveniente del dorso de parental, Estadio 26 (sensu Gosner, 1960) carente de formula dentaria y papilas marginales, siendo visible el pico córneo, lote IAvH-Am-14680. 


\section{Discusión}

Respecto a algunos aspectos puntuales de $H$. sanctamariensis sp. nov. y su similitud con otras especies de la cordillera Oriental, se puede evidenciar que uno de los aspectos comportamentales y a su vez considerada una sinapomorfia propuesta por Grant et al. (2006) es la condición del sexo del ejemplar nodriza; se identifica de esta manera que los machos de $H$. sanctamariensis sp. nov. transportan sus renacuajos (Figura 11) y este comportamiento considerado primitivo, es compartido con otras especies de la cordillera Oriental como H. subpunctatus de las partes altas en los Andes (Fandiño et al., 1998). Sin embargo, las implicaciones evolutivas de este comportamiento no han sido documentadas en la totalidad de las especies colombianas (Tabla 3), lo que requiere de mayor evidencia para sus análisis (Grant et al., 2006).

Otro caracter corresponde al patrón de la coloración caudal de las larvas (estados de carácter 87 sensu Grant et al., 2006), que es un rasgo no estudiado en casi todas las descripciones de las especies colombianas (Tabla 3) y por lo tanto requiere mayor evaluación al emplear combinaciones con otros caracteres larvales (Anganoy-Criollo, 2013; Sánchez, 2013). En Hyloxalus sanctamariensis sp. nov. este rasgo es estable durante el desarrollo ontogénico (Figura 12) con un patrón de manchas (melanóforos) irregulares (condición 1, sensu Grant et al., 2006) que a priori es descrito en Hyloxalus pulchellus (sensu Coloma, 1995), Hyloxalus bocagei (Páez-Vacas et al., 2010), Hyloxalus edwardsi ( sensu Lynch, 1982) e Hyloxalus subpunctatus (sensu Anganoy-Criollo, 2013, cuya variación incluye condiciones 1 y 2).
Así mismo, otro rasgo considerado pleisiomórfico entre los dendrobátidos es la presencia de una banda lateral oblicua completa (Myers et al., 1991; Grant et al., 2006; Anganoy-Criollo, 2012) que en Hyloxalus sanctamariensis sp. nov. es compartida con $\mathrm{H}$. picachos y Allobates ranoides de las estribaciones andinas en la cordillera Oriental, siendo un rasgo estable en todos los ejemplares adultos (Figura 6) y es conspicuo en las larvas (Figura 12) a partir de los estadios de desarrollo 41 (sensu Gosner, 1960).

Los recientes cambios nomenclaturales propuestos para Hyloxalus picachos y $H$. cepedai reflejan de forma puntual la problemática y limitaciones de las propuestas previas en la asignación genérica de algunas especies, basados en rasgos morfológicos y su congruencia con las hipótesis filogenéticas basados en datos moleculares; aún si empleamos sinapomorfias optimizadas inequívocamente como la presencia de banda ventrolateral pálida en el género Allobates que está presente en Hyloxalus cepedai (Morales, 2002; Grant et al., 2017) (Figura 8A). Esto conduce a la necesidad de mayor evidencia, ya que si evaluamos como marco de referencia la información biológica disponible de las 22 especies colombianas asignadas al género Hyloxalus, junto con las 12 especies de Allobates (Acosta-Galvis, 2017, http:/ / www.batrachia.com), la información sobre sus estados larvales, secuencias moleculares y vocalizaciones es limitada y heterogénea (Tabla 3). Bajo esta apreciación, uno de los retos en la generación robusta de hipótesis filogenéticas esta cimentada en adecuados métodos de inferencia, junto con la obtención y consolidación de esta evidencia con el objeto de medir los procesos de especiación y sus implicaciones evolutivas. 


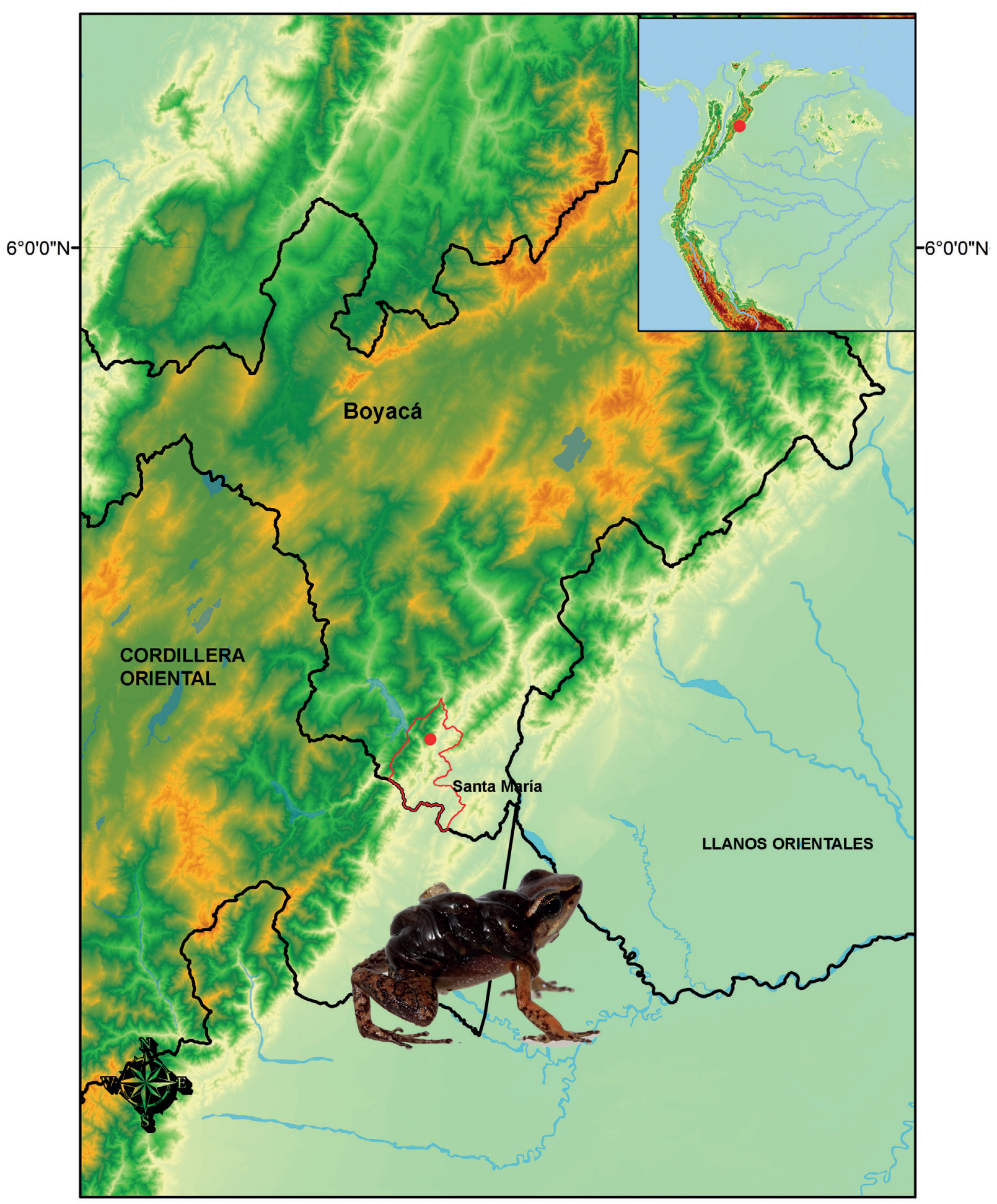

Figura 15. Distribución de Hyloxalus sanctamariensis sp. nov. en los bosques subandinos de las estribaciones orientales de la cordillera Oriental; localidad típica (punto rojo). 
Tabla 3. Síntesis del estado de conocimiento de las especies reportadas de los géneros Allobates e Hyloxalus en Colombia, basado en los referentes básicos de su historia natural.

\begin{tabular}{|c|c|c|c|}
\hline & Vocalizaciones & Renacuajos & $\begin{array}{l}\text { Genes secuenciados } \\
\text { (o aplicación en } \\
\text { filogenias) }\end{array}$ \\
\hline \multicolumn{4}{|l|}{ Familia Aromobatidae } \\
\hline Allobates femoralis (Boulenger, 1884) & Amézquita et al. 2009 & $\begin{array}{l}\text { Lescure 1976, Silverstone } \\
\text { 1976, Sánchez } 2013\end{array}$ & $\begin{array}{l}\text { Vences et al. 2000, } \\
\text { 2003, Santos et al. 2003, } \\
\text { Amézquita et al. 2009, } \\
\text { Pyron y Wiens 2011, } \\
\text { Grant et al. 2006, Muñoz } \\
\text { et al. 2015, Grant et al. } \\
\text { 2017. }\end{array}$ \\
\hline Allobates brunneus (Cope, 1887) & Lima et al. 2009 & Lima et al. 2009 & Grant et al. 2006, 2017. \\
\hline Allobates ignotus (Anangoy, 2012) & - & - & - \\
\hline Allobates juanii (Morales, 1994) & Grant y Rodríguez 2001 & - & $\begin{array}{l}\text { Pyron y Wiens 2011, } \\
\text { Grant et al. 2006, } 2017 .\end{array}$ \\
\hline Allobates marchesianus (Melin, 1941) & $\begin{array}{l}\text { Coloma 1995, Caldwell et } \\
\text { al. } 2002\end{array}$ & $\begin{array}{l}\text { Edwards 1974, Duellman } \\
\text { 1978, Coloma 1995, } \\
\text { Caldwell et al. 2002b, } \\
\text { Sánchez } 2013\end{array}$ & - \\
\hline Allobates myersi (Pyburn, 1981) & Pyburn, 1981 & - & - \\
\hline $\begin{array}{l}\text { Allobates niputidea Grant, Acosta y } \\
\text { Rada, } 2007\end{array}$ & - & Grant et al. 2007 & Grant et al. 2006, 2017. \\
\hline $\begin{array}{l}\text { Allobates paleovarzensis Lima, } \\
\text { Caldwell, Biavati y Montanarin, } \\
2010\end{array}$ & Lima et al. 2010 & Lima et al. 2010 & Grant et al. 2017 \\
\hline Allobates ranoides (Boulenger, 1918) & - & - & - \\
\hline Allobates talamancae (Cope, 1875) & Savage 2002 & $\begin{array}{l}\text { Savage 1968, Savage } \\
\text { 2002, Sánchez } 2013\end{array}$ & Grant et al. 2006, 2017. \\
\hline Allobates trilineatus (Boulenger, 1813) & $\begin{array}{l}\text { De la Riva et al. 1996, } \\
\text { Köhler y Lötters 1999, } \\
\text { Grant y Rodríguez 2001 }\end{array}$ & Sánchez 2013 & Grant et al. 2006, 2017. \\
\hline $\begin{array}{l}\text { Allobates wayuu (Acosta, Cuentas y } \\
\text { Coloma, 1999) }\end{array}$ & - & Acosta et al. 1999 & - \\
\hline \multicolumn{4}{|l|}{ Familia Dendrobatidae } \\
\hline Hyloxalus cepedai (Morales, 2000) & - & - & Grant et al. 2017 \\
\hline $\begin{array}{l}\text { Hyloxalus picachos (Ardila, Acosta y } \\
\text { Coloma, 1999) }\end{array}$ & - & - & Grant et al. 2017 \\
\hline $\begin{array}{l}\text { Hyloxalus fascianigrus (Grant y } \\
\text { Castro, 1998) }\end{array}$ & Grant y Castro 1998 & Grant y Castro 1998 & - \\
\hline $\begin{array}{l}\text { Hyloxalus abditaurantius (Silverstone, } \\
\text { 1975) }\end{array}$ & - & - & - \\
\hline
\end{tabular}


Cont. Tabla 3. Síntesis del estado de conocimiento de las especies reportadas de los géneros Allobates e Hyloxalus en Colombia, basado en los referentes básicos de su historia natural.

\section{Vocalizaciones}

\section{Renacuajos}

\section{Genes secuenciados (o aplicación en filogenias)}

\section{Familia Dendrobatidae}

Hyloxalus betancuri (Rivero y Serna, 1991)

Hyloxalus bocagei (Jiménez de la Espada, 1871)
Páez-Vacas et al., 2010, Sánchez 2013
Vences et al. 2000, 2003, Santos et al. 2003, PáezVacas et al. 2010, Pyron y Wiens 2011, Grant et al. 2006, 2017

\begin{tabular}{|c|c|c|c|}
\hline $\begin{array}{l}\text { Hyloxalus borjai (Rivero y } \\
\text { Serna,1995) }\end{array}$ & - & - & - \\
\hline $\begin{array}{l}\text { Hyloxalus breviquartus (Rivero y } \\
\text { Serna, 1986) }\end{array}$ & - & - & - \\
\hline $\begin{array}{l}\text { Hyloxalus chocoensis (Boulenger, } \\
\text { 1912) }\end{array}$ & - & - & - \\
\hline Hyloxalus edwardsi (Lynch, 1982) & - & Lynch 1982, Sánchez 2013 & - \\
\hline $\begin{array}{l}\text { Hyloxalus excisus (Rivero y Serna, } \\
2000 \text { "1995") }\end{array}$ & - & - & - \\
\hline $\begin{array}{l}\text { Hyloxalus faciopunctulatus (Rivero, } \\
\text { 1991) }\end{array}$ & - & - & - \\
\hline Hyloxalus infraguttatus (Boulenger, 1898) & - & Coloma, 1995 & $\begin{array}{l}\text { Santos et al. 2003, Grant et } \\
\text { al. } 2006\end{array}$ \\
\hline Hyloxalus lehmanni (Silverstone, 1971) & - & Sánchez 2013 & Grant et al. 2006 \\
\hline $\begin{array}{l}\text { Hyloxalus pinguis (Rivero y Granados, } \\
\text { 1989) }\end{array}$ & - & - & - \\
\hline $\begin{array}{l}\text { Hyloxalus pulchellus (Jiménez De la } \\
\text { Espada, 1875) }\end{array}$ & Coloma 1995 & Edwards 1974, Coloma 1995 & $\begin{array}{l}\text { Santos et al. 2003, Grant et } \\
\text { al. } 2006\end{array}$ \\
\hline Hyloxalus ramosi (Silverstone, 1971) & - & - & - \\
\hline Hyloxalus ruizi (Lynch, 1982) & - & - & - \\
\hline $\begin{array}{l}\text { Hyloxalus saltuarius (Grant y Ardila, } \\
\text { 2002) }\end{array}$ & - & - & - \\
\hline Hyloxalus sauli (Edwards, 1974) & Duellman 1978 & Edwards 1974 & Grant et al. 2006 \\
\hline Hyloxalus subpuntactus (Cope,1899) & $\begin{array}{l}\text { Navas, 1996, } 1996 \text { a, Fandiño } \\
\text { et al. 1997, Navas y Bevier } \\
\text { 2001, }\end{array}$ & $\begin{array}{c}\text { Stebbins } \\
\text { y Hendrickson 1959, } \\
\text { Fandiño et al. 1997, } \\
\text { Anganoy-Criollo 2013, } \\
\text { Sánchez } 2013\end{array}$ & $\begin{array}{l}\text { Vences et al. 2003, Páez- } \\
\text { Vacas et al. 2010, Pyron y } \\
\text { Wiens 2011, Grant et al. } \\
\text { 2006, Muñoz et al. 2015, } \\
\text { Grant et al. } 2017\end{array}$ \\
\hline Hyloxalus vergeli (Hellmich, 1940) & - & Sánchez 2013 & Grant et al. 2017 \\
\hline
\end{tabular}




\section{Agradecimientos}

Esta contribución se realizó en el marco de las actividades de investigación en las Colecciones Biológicas del Instituto de Investigación de Recursos Biológicos Alexander von Humboldt auspiciado por la Resolución 0069 de 2017 - MADS. El trabajo de campo fue posible gracias a la salida de campo del curso Colecciones Biológicas de la Universidad de los Andes y en especial a Andrés Cuervo y sus estudiantes Nicolás Muñoz y Mariana Pineda. Igualmente hacemos extensivo nuestro agradecimiento a Nohora Alvarado coordinadora de la Biblioteca del Instituto Humboldt y Daniela Fernández del banco de imágenes quienes amablemente facilitaron la digitalización de parte del material fotográfico. Sergio Córdoba y Kevin Borja permitieron el depósito de las vocalizaciones en la colección de sonidos ambientales del BSA. Finalmente, a John Lynch y a los evaluadores anónimos por sus invaluables comentarios $\mathrm{y}$ aportes en este manuscrito.

\section{Referencias}

Acosta-Galvis, A. R., Cuentas, D. y Coloma, L. (1999). Una nueva especie de Colostethus (Anura: Dendrobatidae) de la región del Caribe de Colombia. Revista de la Academia Colombiana de Ciencias Exactas, Físicas y Naturales, 23 (Suplemento especial): 225-230.

Altig, R. y McDiarmid, R. W. (1999). Body plan: development and morphology. En McDiarmid, R.W.y Altig R. (Eds.) Tadpole: the biology of anuran larvae. London: The University of Chicago Press. 458 pp.

Amézquita, A., Lima, A. P., Jehle, R., Castellanos, L., Ramos, O., Crawford, A. J., Gasser, H. y Hoedl, W. (2009). Calls, colours, shape, and genes: a multi-trait approach to the study of geographic variation in the Amazonian frog Allobates femoralis. Biological Journal of the Linnean Society, 98(4): 826-838.

Anganoy-Criollo, M. (2012). A new species of Allobates (Anura, Dendrobatidae) from the western flank of the Serranía de Perijá, Colombia. Zootaxa, 3308(1): 49-62.
Anganoy-Criollo, M. (2013). Tadpoles of the High-Andean Hyloxalus subpunctatus (Anura: Dendrobatidae) with description of larval variation and species distinction by larval morphology. Papéis Avulsos de Zoologia, 53 (15): 221-224.

Angarita-Sierra, T., Anganoy-Criollo, M., OspinaSarria, J. J., Pedroza-Banda, R. y Lynch, J. D. (2013). Guía de campo de los anfibios y reptiles del departamento de Casanare-Colombia. BogotáArauca: Universidad Nacional de Colombia, Sede Orinoquia, YOLUKA ONG, Fundación de Investigación en Biodiversidad y Conservación. 117 pp.

Ardila-Robayo, M. C., Acosta-Galvis, A. R. y Coloma, L. (1999). Una nueva especie de Colostethus Cope, 1867 (Amphibia: Anura: Dendrobatidae) de la cordillera Oriental colombiana. Revista de la Academia Colombiana de Ciencias Exactas, Físicas y Naturales, 23 (Suplemento especial): 239-244.

Ardila-Robayo, M. C. y Acosta-Galvis, A. R. (2000). Anfibios. Colombia diversidad biótica III la región de vida paramuna de Colombia. Bogotá D. C.: Universidad Nacional de Colombia. Pp. 617-628.

Bernal, M. H. y Lynch, J. D. (2008). Review and analysis of altitudinal distribution of the Andean anurans in Colombia. Zootaxa, 1826(1): 1-25.

Boulenger, G. A. (1912). Descriptions of new batrachians from the Andes of South America, preserved in the British Museum. Annals and Magazine of Natural History, Series 8, 10: 185-191.

Caldwell, J. P., Lima, A. P. y Keller, C. (2002). Redescription of Colostethus marchesianus (Melin, 1941) from its type locality. Copeia, 2002 (1): 157165.

Caldwell, J. P., Lima, A. P., Biavati, G. M. y Guyer, C. (2002 b). Descriptions of tadpoles of Colostethus marchesianus and Colostethus caeruleodactylus (Anura: Dendrobatidae) from their type localities. Copeia, 2002(1): 166-172. 
Charif, R., Waack, A. y Strickman, L. (2010). Raven Pro 1.4. Ithaca, NY: Cornell Lab of Ornithology. 379 pp.

Chen, M. y Combs, C. (1999). An alternative anesthesia for amphibians: ventral application of benzocaine. Herpetological Review, 30(1): 34-34.

Cisneros-Heredia, D. F. y Mcdiarmid, R. W. (2007). Revision of the characters of Centrolenidae (Amphibia: Anura: Athesphatanura), with comments on its taxonomy and the description of new taxa of glassfrogs. Zootaxa, 1572: 1-82.

Cochran, D. M. y Goin, C. J. (1970). Frogs of Colombia. Estados Unidos: Smithsonian Institution Press. 655 pp.

Coloma, L. A. 1(995). Ecuadorian frogs of the genus Colostethus (Anura: Dendrobatidae), Natural History Museum, University of Kansas, (87): 1-72.

Cocroft, R. B. y Ryan, M. J. (1995). Patterns of advertisement call evolution in toads and chorus frogs. Animal Behaviour, 49(2): 283-303.

De la Riva, I., Márquez, R., y Bosch, J. (1996). The advertisement calls of three South American poison frogs (Amphibia: Anura: Dendrobatidae), with comments on their taxonomy and distribution. Journal of Natural History, 30(9):14131420.

Dinerstein, E., Olson, D. M., Graham, D. J., Webster, A. L., Primm, S. A., Bookbinder, M. P., Ledec, G. y Young, K. R. (1995). A conservation assessment of the terrestrial ecoregions of Latin America and the Caribbean. Washington DC.: World Bank. 129 pp.

Duellman, W. E. (1978). The biology of an equatorial herpetofauna in Amazonian Ecuador Lawrence. University of Kansas, Museum of Natural History, Miscellaneous Publication, 65:1-352.

Duellman, W. E. y Pyles, R. A. (1983). Acoustic resource partitioning in anuran communities. Copeia, 1983(3): 639-649.

Duellman, W. E. y Lehr, E. (2009). Terrestrial Breeding Frogs (Strabomantidae) in Perú. Berlin Natur und Tier Verlag. 382 pp.
Edwards, S. R. (1974). Taxonomic notes on South American dendrobatid frogs of the genus Colostethus. Occasional Papers of the Museum of Natural History, University of Kansas, 30: 1-14.

Fandiño, M. C., Lüddecke, H. y Amézquita, A. (1997). "Vocalisation and larval transportation of male Colostethus subpunctatus (Anura: Dendrobatidae). Amphibia-Reptilia, 18(1): 39-48.

Gosner, K. L. (1960). A simplified table for staging anuran embryos and larvae with notes on identification. Herpetologica, 16(3): 183-190.

Grant, T. (2004). On the identities of Colostethus inguinalis (Cope, 1868) and C. panamensis (Dunn, 1933), with comments on C. latinasus (Cope, 1863) (Anura: Dendrobatidae). American Museum Novitates, (3444): 1-24.

Grant, T. y Castro, F. (1998). The cloud forest Colostethus (Anura, Dendrobatidae) of a region of the cordillera Occidental of Colombia. Journal of Herpetology, 32(3): 378-392.

Grant, T., Humphrey, E. C. y Myers, C. W. (1997). The median lingual process of frogs: a bizarre character of Old World ranoids discovered in South American dendrobatids. American Museum Novitates, (3212): 1-40.

Grant, T. y Rodríguez, L. O. (2001). Two new species of frogs of the genus Colostethus (Dendrobatidae) from Perú and a redescription of $C$. trilineatus (Boulenger, 1883)." American Museum Novitates, (3335): 1-24.

Grant, T. y Ardila-Robayo, M. C. (2002). A new species of Colostethus (Anura: Dendrobatidae) from the eastern slopes of the cordillera Oriental of Colombia. Herpetologica, 58(2): 252-260.

Grant, T., Frost, D. R., Caldwell, J. P., Gagliardo, R., Haddad, C. F., Kok, P. J. y Wheeler, W. C. (2006). Phylogenetic systematics of dart-poison frogs and their relatives (Amphibia: Athesphatanura: Dendrobatidae). Bulletin of the American Museum of natural History, 1-262.

Grant, T., Acosta-Galvis, A.R. y Rada, M. (2007). A name for the species of Allobates (Anura: 
Dendrobatoidea: Aromobatidae) from the Magdalena Valley of Colombia. Copeia, 2007(4): 844-854.

Grant, T, Rada, M., Anganoy-Criollo, M., Batista, A., Días, P. H., Jeckel, A. M, Machado, D. J. y Rueda-Almonacid, J. V. (2017). Phylogenetic Systematics of Dart-Poison Frogs and their Relatives Revisited (Anura: Dendrobatoidea). South American Journal of Herpetology, 12(Special Issue 1):S1-S90.

Kaplan, M. (1997). A new species of Colostethus from the Sierra Nevada de Santa Marta (Colombia) with comments on intergeneric relationships within the Dendrobatidae. Journal of Herpetology, 31(3): 369-375.

Koch, C., Venegas, P. J. y Rödder, D. (2011). Advertisement call of Hyloxalus elachyhistus (Edwards, 1971) (Anura, Dendrobatidae). Salamandra, 47(2):116-119.

Kok, P. J. (2010). A redescription of Anomaloglossus praderioi (La Marca, 1998) (Anura: Aromobatidae: Anomaloglossinae), with description of its tadpole and call. Papéis Avulsos de Zoologia, 50(4): 51-68.

Kok, P. J., Willaert, B. y Means, D. B. (2013). A new diagnosis and description of Anomaloglossus roraima (La Marca, 1998) (Anura: Aromobatidae: Anomaloglossinae), with description of its tadpole and call. South American Journal of Herpetology, 8(1): 29-45.

Köhler, J. y Lötters, S. (1999). Annotated list of amphibian records from the Departamento Pando, Bolivia, with description of some advertisement calls. Bonner Zoologische Beiträge, 48:259-273.

Köhler, J., Jansen, M., Rodríguez, A., Kok, P. J. R., Toledo, L. F., Emmrich, M., Glaw, F., Haddad, C. F. B., Rödel, M. O. y Vences, M. (2017). The use of bioacoustics in anuran taxonomy: theory, terminology, methods and recommendations for best practice. Zootaxa, 4251 (1): 001-124.

Lescure, J. (1976). Contribution à l'étude des amphibiens de Guyane française. VI. Liste préliminaire des anoures. Bulletin du Muséum National d'histoire Naturelle, 377:475-525.

Lima, A. P., Caldwell, J. P. y Strussmann, C. (2009). Redescription of Allobates brunneus (Cope) 1887 (Anura: Aromobatidae: Allobatinae), with a description of the tadpole, call, and reproductive behavior. Zootaxa, 1988 (1): 1-16.

Lima, A., Caldewell, J., Biavati, G. y Montanarin, A. (2010). A new species of Allobates (Anura: Aromobatidae) from paleovárzea forest in Amazonas, Brazil. Zootaxa, 2337:1-17.

Lynch, J. D. (1982). Two new species of poison-dart frogs (Colostethus) from Colombia. Herpetologica, 38:366-374.

Lynch, J. D. (2006). The amphibian fauna in the Villavicencio region of eastern Colombia. Caldasia, 28(1): 135-155.

McDiarmid, R. W. y Altig, R. (1999). Tadpoles: the biology of anuran larvae, University of Chicago Press. 444 pp.

Morales, V. R. (2002 “2000”). Sistemática y biogeografía del grupo trilineatus (Amphibia, Anura, Dendrobatidae, Colostethus), con descripción de once nuevas especies. Publicaciones de la Asociación de Amigos Doñana, 13: 1-59.

Muñoz-Ortiz A., Velásquez-Álvarez, A. A., Guarnizo, C. E y Crawford, A. J. (2015). Of peaks and valleys: testing the roles of orogeny and habitat heterogeneity in driving allopatry in midelevation frogs (Aromobatidae: Rheobates) of the northern Andes. Journal of Biogeography, 42: 193-205.

Myers, C. W. (1991). Distribution of the dendrobatid frog Colostethus chocoensis and description of a related species occurring macrosympatrically. American Museum Novitates, 3010: 1-15.

Myers, C. W., Paolillo, O. A. y J. W. Daly. (1991). Discovery of a defensively malodorous and nocturnal frog in the family Dendrobatidae: phylogenetic significance of a new genus and species from the Venezuelan Andes. American Museum Novitates, (3002): 1-33. 
Navas, C. A. (1996). Thermal dependency of field locomotor and vocal performance of highelevation anurans in the tropical Andes. Journal of Herpetology, 30(4): 478-487.

Navas, C. A. (1996 a). The effect of temperature on the vocal activity of tropical anurans: a comparison of high and low-elevation species. Journal of Herpetology, 30(4): 488-497.

Navas, C. A., y Bevier, C. R. (2001). Thermal dependency of calling performance in the eurythermic frog Colostethus subpunctatus. Herpetologica, 57(3): 384-395.

Olson, D. M. y Dinerstein, E. (2002). The Global 200: Priority ecoregions for global conservation. Annals of the Missouri Botanical Garden, 89: 199$224 \mathrm{p}$.

Páez-Vacas, M. I., Coloma, L. A. y Santos, J. C. (2010). Systematics of the Hyloxalus bocagei complex (Anura: Dendrobatidae), description of two new cryptic species, and recognition of $H$. maculosus. Zootaxa, 2711: 1-75.

Pedroza-Banda, R., Ospina-Sarria, J. J., AngaritaSierra, T., Anganoy-Criollo, M. y Lynch, J. D. (2014). Estado del conocimiento de la fauna de anfibios y reptiles del departamento de Casanare, Colombia. Revista de la Academia Colombiana de Ciencias Exactas, Físicas y Naturales, 38(146): 17-34.

Pyburn, W. F. (1981). A new poison-dart frog (Anura: Dendrobatidae) from the forest of southeastern Colombia. Proceedings of the Biological Society of Washington, 94: 67-75.

Pyron, R. A. y Wiens, J. J. (2011). A large-scale phylogeny of Amphibia including over 2800 species, and a revised classification of extant frogs, salamanders, and caecilians. Molecular Phylogenetics and Evolution, 61: 543-583.

Rivero, J. A. (1991). New Colostethus (Amphibia, Dendrobatidae) from South America. Breviora. Museum of Comparative Zoology, Cambridge, Massachusetts, 493:1-28.

Rivero, J. A., y Serna, M. A. (1986). Dos nuevas especies de Colostethus (Amphibia, Dendrobatidae). Caldasia, 15: 525-531.
Rivero, J. A. y Serna, M. A. (1991). Tres nuevas especies de Colostethus (Amphibia, Dendrobatidae) de Colombia. Trianea, 4: 481-495.

Rivero, J. A. y Granados-Díaz, H. (1990 “1989”). Nuevos Colostethus (Amphibia, Dendrobatidae) del departamento de Cauca, Colombia. Caribbean Journal of Science, 25: 148-152.

Rivero, J. A. y Serna, M. A. (1995). Nuevos Colostethus (Amphibia, Dendrobatidae) del departamento de Antioquia, Colombia, con la descripción del renacuajo de Colostethus fraterdanieli. Revista de Ecologia Latino Americana, 2(1-3): 45-58.

Sánchez, D. A. (2013). Larval morphology of Dart-Poison Frogs (Anura: Dendrobatoidea: Aromobatidae and Dendrobatidae). Zootaxa, 3637(5): 569-591.

San Mauro, D., Gower, D. J., Oommen, O. V., Wilkinson, M. y Zardoya, R. (2004). Phylogeny of caecilian amphibians (Gymnophiona) based on complete mitochondrial genomes and nuclear RAG1. Molecular Phylogenetics and Evolution, 33(2): 413-427.

Santos J.C., Coloma, L.A. y Cannatella, D. C. (2003). Multiple, recurring origins of aposematism and diet specialization in poison frogs. Proceedings of the National Academy of Sciences, USA 100: 2133521100 .

Santos J. C., Baquero, M., Barrio-Amoros, C., Coloma, L. A., Erdtmann, L. K., Lima, A. P. y Cannatella, D. C. (2014). Aposematism increases acoustic diversification and speciation in poison frogs. Proceedings of the Royal Society B: Biological Sciences, 281: 20141761.

Savage, J. M. (1968). The dendrobatid frogs of Central America. Copeia, 1968(4): 745-776.

Savage, J. M. (2002). The amphibians and reptiles of Costa Rica: a herpetofauna between two continents, between two seas. University of Chicago Press. $954 \mathrm{pp}$.

Silverstone, P. A. (1971). Status of certain frogs of the genus Colostethus with descriptions of new 
species. Contributions in Science, Natural History Museum. Los Angeles County, (215): 1-8.

Silverstone, P. A. (1975). Two new species of Colostethus (Amphibia: Anura: Dendrobatidae) from Colombia. Contributions in Science. Natural History Museum of Los Angeles County, (268): $1-10$.

Silverstone, P. A. (1976). A revision of the PoisonArrow Frogs of the Genus Phyllobates Bibron in sagra (Family Dendrobatidae). Natural History Museum of Los Angeles County, Science Bulletin, 27 (1-53).

Stebbins, R. C. y Hendrickson, J. R. (1959). Field studies of amphibians in Colombia, South America. University of California Publications in Zoology, 56(5): 497-540.

\section{Anexo 1.}

Especímenes examinados. Hyloxalus cepedai: COLOMBIA, departamento de Arauca, municipio de Tamé, vereda Sabana de La Vega, Finca Casirba, 6²2'52.1"N-7155'1.3"O, 750 m s.n.m., IAvH-Am-10156, IAvH-Am-10162; departamento de Casanare, municipio de Nunchía, vereda Vega Piedecuesta, finca las Canarias, 450 m s.n.m., IAvHAm-6713; municipio de Yopal, corregimiento El Charte, vereda Rincón del Soldado, bosque El Secreto parte alta, $5^{\circ} 23^{\prime} 48,8^{\prime \prime} \mathrm{N}-72^{\circ} 29^{\prime} 14,6^{\prime \prime} \mathrm{O}, 1018$ m s.n.m., IAvH-Am-10713.

Hyloxalus picachos: COLOMBIA, departamento de Caquetá, municipio de San Vicente de Cagúan, inspección de policía Guayabal, finca Andalucía, $2^{\circ} 44^{\prime} 41^{\prime \prime} \mathrm{N}-74^{\circ} 53^{\prime} 22^{\prime \prime} \mathrm{O}, 1550 \mathrm{~m}$ s.n.m., IAvHAm-6520-35.

Hyloxalus pulchellus: COLOMBIA, departamento del Cauca, municipio Silvia, 2400 m s.n.m., IAvHAm-0020, 2320 m s.n.m., IAvH-Am-3448-9 IAvHAm-3485-3495; departamento de Nariño, laguna de La Cocha, 2790 m s.n.m., IAvH-Am-3446-7.
Vences, M., Kosuch, J., Lötters, S., Widmer, A., Jungfer, K. H., Köhler, J., y Veith, M. (2000). Phylogeny and classification of poison frogs (Amphibia: Dendrobatidae), based on mitochondrial $16 S$ and $12 S$ ribosomal RNA gene sequences. Molecular Phylogenetics and Evolution, 15(1): 34-40.

Vences M., Kosuch, J., Haddad, C. F. B., La Marca, E., Lötters, S. y Veith, M. (2003). Convergent evolution of aposematic coloration in Neotropical poison frogs: a molecular phylogenetic perspective. Organisms Diversity and Evolution, 3: 215-226.

Zardoya, R. y Meyer, A. (1996). Phylogenetic performance of mitochondrial protein-coding genes in resolving relationships among vertebrates. Molecular Biology and Evolution, 13: 933-942.

Hyloxalus subpunctatus: COLOMBIA, departamento de Boyacá, Parque Nacional Natural, Sierra Nevada del Cocuy, Valle del Frailejón, flanco sur de la Sierra Nevada del Cocuy, 3800 m s.n.m., 6 ${ }^{\circ} 43^{\prime} \mathrm{N}-72^{\circ} 45^{\prime} \mathrm{O}$, MUJ 406, municipio de Garagoa, vereda Ciénaga-Valvanera, Reserva Natural Privada El Secreto, 2100 m s.n.m., $5^{\circ} 07^{\prime} \mathrm{N}-73^{\circ} 15^{\prime} \mathrm{O}$, MUJ 1582; departamento de Cundinamarca, municipio de Cáqueza Parque Nacional Natural Chingaza, MUJ 598-99, MUJ 600, MUJ 1091, MUJ 1097-8, cerca de la quebrada La Siberia en la desembocadura del río La Playa, 2600 m s.n.m., $4^{\circ} 35^{\prime} \mathrm{N}-73^{\circ} 36^{\prime} \mathrm{O}$, MUJ 447-8, cerca al sitio La Playa, 3140 m s.n.m., $4^{\circ} 34^{\prime} \mathrm{N}-73^{\circ} 46^{\prime} \mathrm{O}$ MUJ 545, 548-51, sitio La Playa, 3000 m s.n.m., MUJ 1120, Parque Nacional Natural Chingaza hacia el sitio La Playa, 3140 m. s.n.m., 4³4'N-7357'30'”, MUJ 1111-2, carretera al sitio La Paila, $3150 \mathrm{~m}$ s.n.m., $4^{\circ} 28^{\prime} \mathrm{N}-73^{\circ} 47^{\prime} \mathrm{O}$, MUJ445, 2 kilómetros antes del río Frío, 3400 m s.n.m., $4^{\circ} 30^{\prime} \mathrm{N}-73^{\circ} 45^{\prime} \mathrm{O}$, MUJ 574 laguna de Buitrago, 3360 m s.n.m., $4^{\circ} 45^{\prime} \mathrm{N}-73^{\circ} 50^{\prime} \mathrm{O}$, MUJ 1099-1101 MUJ 1103-04, MUJ 1107-08, cerca de la laguna de Buitrago, 3200 
m s.n.m.. , $4^{\circ} 45^{\prime} \mathrm{N}-73^{\circ} 50^{\prime} \mathrm{O}$, MUJ 1115-18, vereda California, cerca al sector de Piedras Gordas , 3210 m s.n.m.., $4^{\circ} 45^{\prime} \mathrm{N}-73^{\circ} 51^{\prime} \mathrm{O}$ MUJ 1094, 3250 m s.n.m., MUJ 1095-6, 3210 m s.n.m., MUJ 1102, MUJ 1109, 3200 m s.n.m., MUJ 1113, 3240 m s.n.m., MUJ 1122-23, quebrada Piedras Gordas, 3210 m s.n.m., $4^{\circ} 45^{\prime} \mathrm{N}-73^{\circ} 51^{\circ} \mathrm{O}$, MUJ 1106, , sitio Piedras Gordas, 3250 m. s.n.m., $4^{\circ} 44^{\prime} \mathrm{N}-73^{\circ} 51^{\prime} \mathrm{O}$, MUJ555, vereda California, cerca de la quebrada Piedras Gordas, $2850 \mathrm{~m}$ s.n.m., $4^{\circ} 44^{\prime} \mathrm{N}-73^{\circ} 52^{\prime} \mathrm{O}$, MUJ 567-68, carretera a la laguna El Medio, 3210 m s.n.m., $4^{\circ} 32^{\prime} \mathrm{N}-73^{\circ} 45^{\prime} \mathrm{O}$, MUJ 1114, MUJ 671 ,valle del Frailejón, $4^{\circ} 36^{\prime} \mathrm{N}-73^{\circ} 46 \mathrm{O}, 3150-3500$ m s.n.m., MUJ 446, MUJ 1119 MUJ 1124-5, 3000 m s.n.m., MUJ 1129, 3500 m s.n.m., $4^{\circ} 36^{\prime} \mathrm{N}-73^{\circ} 46^{\prime} \mathrm{O}$, MUJ 1126, kilómetro 5 carretera "La Paila" vía al municipio de Fómeque, $3300 \mathrm{~m}$ s.n.m., $4^{\circ} 32^{\prime} \mathrm{N}-73^{\circ} 46^{\prime} \mathrm{O}$, MUJ 1121, embalse de Chuza cerca al Casino 2967 m s.n.m., $4^{\circ} 38$ N-7344'O, MUJ 1127-28, sitio Chuza cerca al embalse de Chuza, 2850 m s.n.m., $4^{\circ} 39^{\prime}$ N-734 $43^{\prime} \mathrm{O}$, MUJ 1131, 3300 m s.n.m.., $4^{\circ} 38^{\prime} \mathrm{N}-73^{\circ} 44^{\prime} \mathrm{O}$, 9 kilómetros al norte del campamento Monteredondo, $3140 \mathrm{~m}$ s.n.m., $4^{\circ} 40^{\prime} \mathrm{N}-73^{\circ} 44^{\prime} \mathrm{O}$, MUJ 1130, carretera del Parque nacional Natural Chingaza al municipio de Fómeque, sitio El Arnical, 3300 m s.n.m., $4^{\circ} 30$ $\mathrm{N}-73^{\circ} 46^{\prime} \mathrm{O}$, MUJ 556, Parque Nacional Natural Chingaza hacia el municipio de Guasca, laguna de Siecha, 3600 m s.n.m., $4^{\circ} 47^{\prime} \mathrm{N}-7^{\circ} 51^{\prime} \mathrm{O}$, MUJ 6934, cerca de la laguna de Buitrago, 3600 m s.n.m., $4^{\circ} 46^{\prime}$ N-7350' O, MUJ 435-37.

Hyloxalus saltuarius: COLOMBIA, departamento del Huila, municipio de Acevedo, vertiente occidental de la Cabaña Las Brisas, $1 \mathrm{~km}$ de la bocatoma, Parque Nacional Natural Cueva de Los Guácharos, 1700-2000 m s.n.m., IAvH-Am-7644-5.

Hyloxalus vergeli: COLOMBIA, departamento del Huila, municipio de Neiva, vereda Tamarindo, alto La Tribuna, Reserva Natural Privada Hocol, Centro de investigación y Educación La Tribuna, 780 m s.n.m., $3^{\circ} 4^{\prime} \mathrm{N}-75^{\circ} 22,3^{\prime} \mathrm{O}$, MUJ 4297-4328, MUJ 4344-4345, MUJ 4370, MUJ 5017-5018; departamento de Cundinamarca, municipio de Silvania, IAvH-Am-521, IAvH-Am-523, IAvHAm-527.
Allobates brunneus: COLOMBIA, departamento de Putumayo, Parque Nacional Natural La Paya, Cabaña Viviano Cocha, $0^{\circ} 7^{\prime} \mathrm{S}-74^{\circ} 56^{\prime} \mathrm{O}$, 320 m s.n.m., IAvH-Am-7807, Cabaña La Paya, $0^{\circ} 2^{\prime} \mathrm{S}-75^{\circ} 12^{\prime} \mathrm{O}, 330 \mathrm{~m}$ s.n.m., IAvH-Am-7118 IAvH-Am-9141-3.

Allobates femoralis: COLOMBIA, departamento de Amazonas, municipio de Leticia, selva al occidente del Internado Nazareth IAvH-Am-2867-8; Parque Nacional Natural Amacayacu, cabaña Matamata, IAvH-Am-4012, Parque Nacional Natural Amacayacu, IAvH-Am-2191, IAvH-Am-2312-4, centro de visitantes Parque Nacional Natural Amacayacu, IAvH-Am-5386; corregimiento La Chorrera, río Igará-Paraná, $50 \mathrm{kms}$ arriba de la Chorrera, 300 m s.n.m. IAvH-Am-3693-5, Puerto Rastrojo, río Mirití Paraná, IAvH-Am-3948, IAvHAm-4515; departamento de Caquetá, Las Islas Río Caquetá, IAvH-Am-0461. Belén de Los Andaquies, 312 m s.n.m.; IAvH-Am-5023; departamento del Cauca, municipio de Santa Rosa, vereda El Carmen, Pozo Miraflor, Finca El Triunfo, orilla río Tambor, 380 m s.n.m. IAvH-Am-5734; vereda Nabueno, Mary II, IAvH-Am-5764; departamento de Vaupés, municipio Taraira, Estación Biológica Caparú, Lago Taraira, IAvH-Am-0981; departamento del Meta, río Duda, Estación Primatológica Puerto Chamuza, Parque Nacional Natural Tinigua, IAvH-Am-5322, IAvH-Am-5303, IAvH-Am-5312.

Allobates juanii: COLOMBIA, departamento de Boyacá, municipio Campo hermoso, río Lengupa, vía Campo Hermoso al río Lengupa, $840 \mathrm{~m}$ s.n.m., IAvH-Am-6597-9; municipio Garagoa, vía Garagoa-San Luis de Gaceno, 520 m s.n.m., IAvH-Am-6609-23; departamento de Casanare, municipio de Aguazul, vereda La Turua, Taladro 221, IAvH-Am-9699-701; departamento del Meta, cuenca alta del río Orotoy, IAvH-Am-11500.

Allobates paleovarzensis: COLOMBIA: departamento de Amazonas, municipio de Leticia, Reserva Forestal del Río Calderón, Estación Biológica El Zafire, 400'21"S- 69 $54^{\prime} 45^{\prime \prime} \mathrm{O}, 146 \mathrm{~m}$. s.n.m. IAvH-Am-12046, IAvH-Am-10382. 
http://zoobank.org/:urn:lsid:zoobank.org:act:C06E11C1-FDE2-43FA-8260-717CF7E193FE

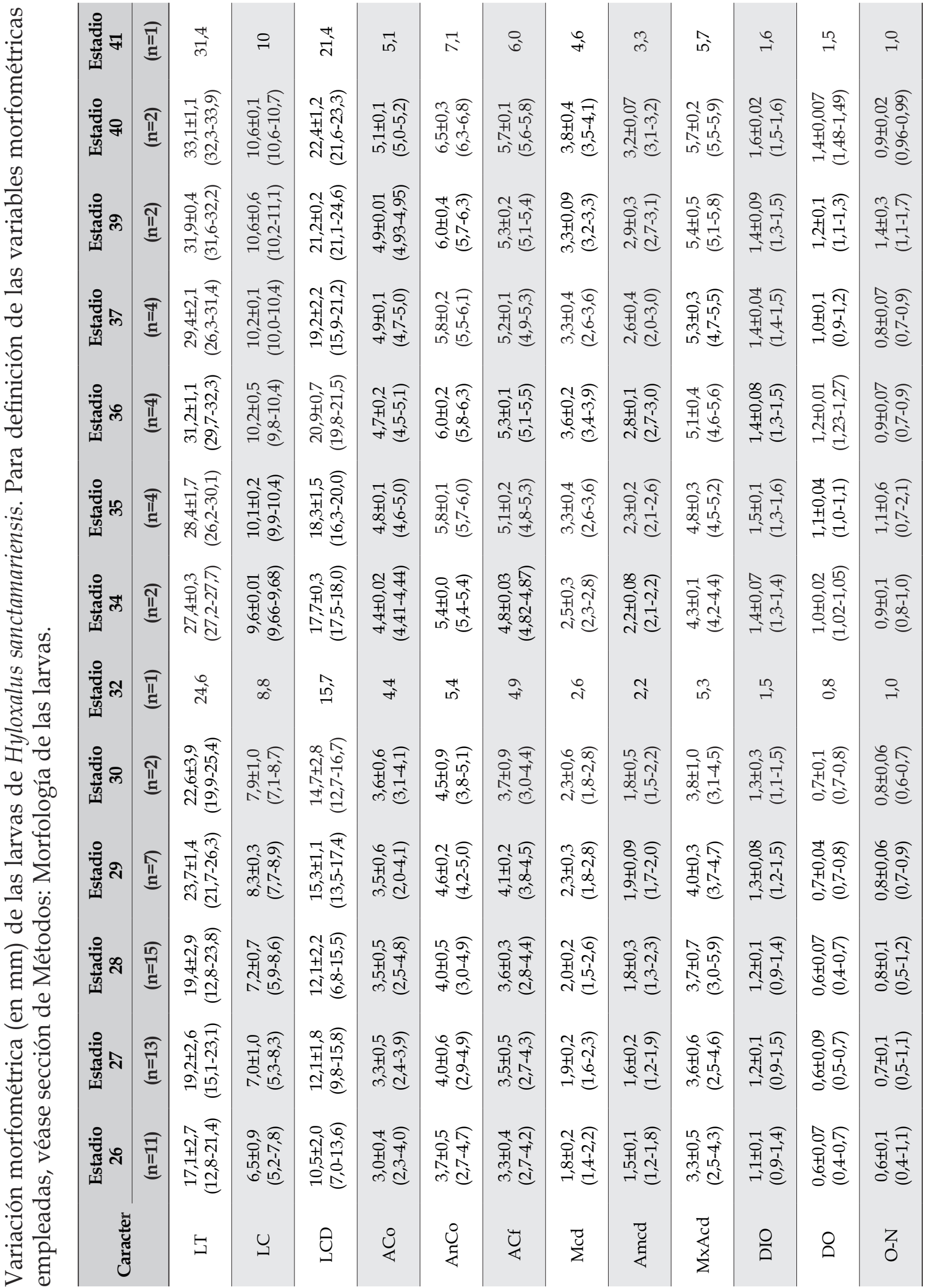




\begin{tabular}{|c|c|c|c|c|c|c|c|c|c|}
\hline.$\stackrel{\widetilde{U}}{\widetilde{J}}$ & 旁 F & 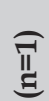 & $\stackrel{\sim}{\rightarrow}$ & $\stackrel{\infty}{\rightarrow}$ & $\stackrel{\vartheta}{\rightarrow}$ & ㄴ? & $\stackrel{12}{\sim}$ & $\stackrel{H}{\rightarrow}$ & $\widehat{\sigma}$ \\
\hline ڤ્ర & 急 & 䒕 & 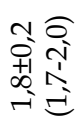 & 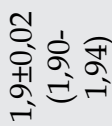 & 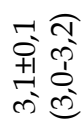 & 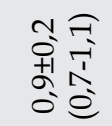 & 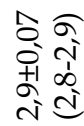 & 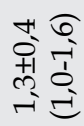 & 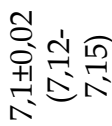 \\
\hline 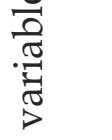 & 苞 & $\stackrel{\pi}{\pi}$ & 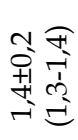 & 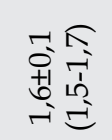 & 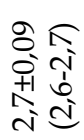 & 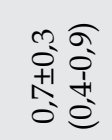 & 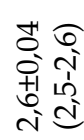 & 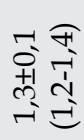 & 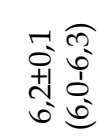 \\
\hline 号 & 总 & 离 & 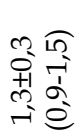 & 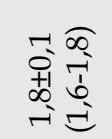 & 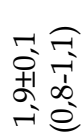 & 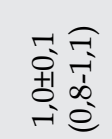 & 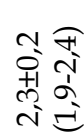 & 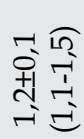 & 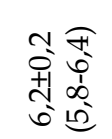 \\
\hline$\frac{U}{0}$ & 患 & 吾 & 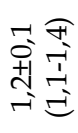 & 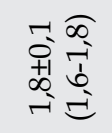 & 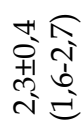 & 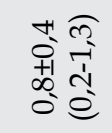 & 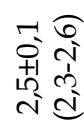 & 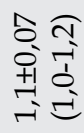 & 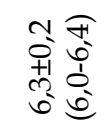 \\
\hline$\cdot \sqrt{\infty}$ & 疍 & $\stackrel{\overparen{\pi}}{\stackrel{\pi}{\|}}$ & 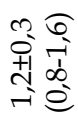 & 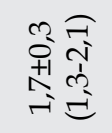 & 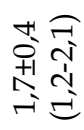 & 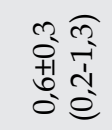 & 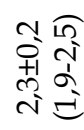 & $\begin{array}{l}\infty \\
0 \\
0 \\
+1 \\
+1 \\
+1\end{array}$ & 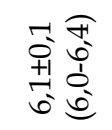 \\
\hline$\underset{\S}{\stackrel{\Xi}{ \pm}}$ & 疍 & 离 & 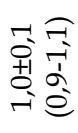 & 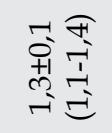 & 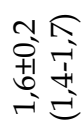 & 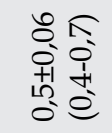 & 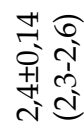 & 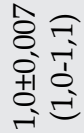 & 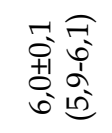 \\
\hline 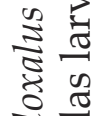 & 苞 & 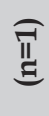 & $\stackrel{\circ}{\rightarrow}$ & $\underset{\leftarrow}{\stackrel{H}{*}}$ & $\stackrel{+}{N}$ & $\stackrel{8}{\circ}$ & $\stackrel{10}{N}$ & $\underset{-}{\circ}$ & ڤે \\
\hline 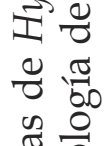 & 急 & $\underset{\mathbb{\pi}}{\stackrel{\pi}{\Xi}}$ & 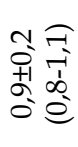 & 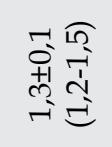 & 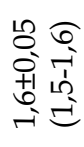 & 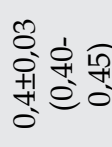 & 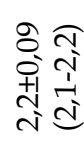 & $\begin{array}{ll}2 & 0 \\
0 & 0 \\
0 & 0 \\
+1 & 1 \\
0 & 0 \\
0 & 0\end{array}$ & 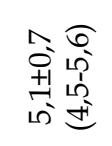 \\
\hline 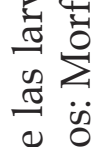 & 戔 & $\underset{\mathbb{N}}{\mathbb{N}}$ & 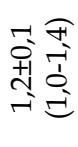 & 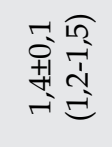 & 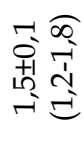 & 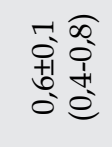 & 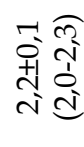 & $\begin{array}{ll}r & = \\
0 & = \\
0 & 0 \\
0 & 0 \\
-1 & 0\end{array}$ & 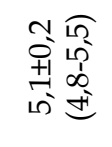 \\
\hline छ્ & : & $\begin{array}{l}\text { In } \\
\text { 페 }\end{array}$ & 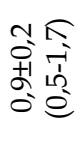 & 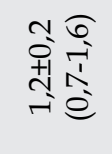 & 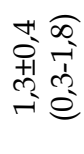 & 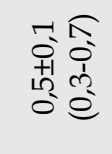 & $\begin{array}{ll}m & 0 \\
0 & 0 \\
+1 & 0 \\
0 & 0 \\
i= & =\end{array}$ & 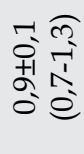 & 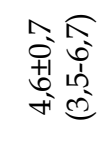 \\
\hline 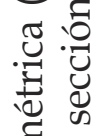 & 㺃 & 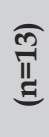 & 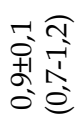 & 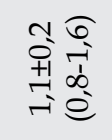 & 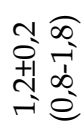 & 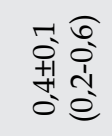 & 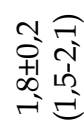 & 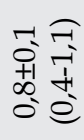 & 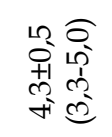 \\
\hline 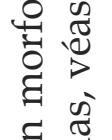 & 趆 & 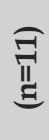 & 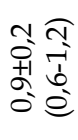 & 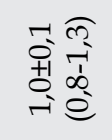 & 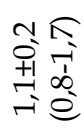 & 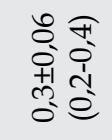 & 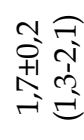 & $\begin{array}{ll}r & 0 \\
0 & - \\
+1 & -1 \\
0 & 10 \\
0 & 0\end{array}$ & 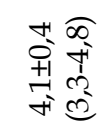 \\
\hline 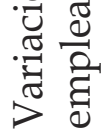 & & & 学 & $\overline{\vec{D}}$ & 1 & 㭉 & $\frac{8}{8}$ & $\stackrel{8}{\mathbb{T}}$ & 8 \\
\hline
\end{tabular}


Andrés R. Acosta-Galvis

Curador Colección de anfibios y reptiles, Instituto de Investigación de Recursos Biológicos Alexander von Humboldt Villa de Leyva, Boyacá, Colombia aacosta@humboldt.org.co

\section{Adrián Pinzón}

Investigador independiente Barrio Cundinamar, Santa María, Boyacá, Colombia ranran2085@gmail.com
Una nueva rana nodriza (Anura: Dendrobatidae) de los bosques de niebla asociados a la cuenca del Orinoco de Colombia

Citación del artículo: Acosta-Galvis, A. R. y Pinzón, A. (2018). Una nueva rana nodriza (Anura: Dendrobatidae) de los bosques de niebla asociados a la cuenca del Orinoco de Colombia. Biota Colombiana, 19 (Sup. 1): 160-190. DOI: 10.21068/c2018.v19s1a12. http://zoobank. org/:urn:lsid:zoobank.org:act:C06E11C1-FDE243FA-8260-717CF7E193F

Recibido: 8 de agosto de 2017

Aprobado: 30 de enero de 2018 


\section{Guía para autores \\ (http://revistas.humboldt.org.co/index.php/biota)}

\section{Envío del manuscrito}

El envío de un manuscrito implica la declaración explícita por parte del autor o los autores de que este no ha sido previamente publicado, ni aceptado para su publicación en otra revista u otro órgano de difusión científica. Todas las contribuciones son de la entera responsabilidad de sus autores y no del Instituto de Investigación de Recursos Biológicos Alexander von Humboldt, ni de la revista o sus editores.

Los trabajos pueden estar escritos en español, inglés o portugués, y no deben exceder las 40 páginas (párrafo espaciado a 1,5 líneas), incluyendo tablas, figuras y anexos. De particular interés para la revista son las descripciones de especies nuevas para la ciencia, nuevos registros geográficos, listados de especies temáticos o regionales, inventarios, bases de datos relacionados con biodiversidad, colecciones biológicas y reportes de muestreo.

Se reciben manuscritos que sean artículos científicos de investigación, así como notas de actualidad, reseñas, novedades bibliográficas y artículos de datos.

Los trabajos deben ser entregados a través del portal en línea (http://revistas.humboldt.org.co/index. php/biota) de la revista, siguiendo los pasos de registro como usuario. Todo el proceso editorial se desarrolla a través de esa plataforma.

\section{Evaluación del manuscrito}

Los manuscritos sometidos serán revisados por mínimo dos pares científicos calificados, cuya respuesta final de evaluación puede ser: a) publicado sin ningún cambio (se asume que no existe ningún cambio, omisión o adición al artículo, y que se recomienda su publicación en la forma actualmente presentada); b) aceptación condicional (se acepta y recomienda el artículo para su publicación solo si se realizan los cambios indicados por el evaluador, sean correcciones menores y no es necesaria una segunda re- visión o correcciones mayores y sí es necesaria una segunda revisión); y c) rechazo (cuando el evaluador considera que los contenidos o forma de presentación del artículo no se ajustan a los requerimientos y estándares de calidad de Biota Colombiana). Para proseguir con el proceso editorial para publicación, el manuscrito debe haber sido aceptado por el mínimo de dos pares científicos.

\section{Preparación del manuscrito}

Para la elaboración de los textos del manuscrito se debe usar un procesador de palabras (preferiblemente Word); los listados (a manera de tabla) deben ser elaborados en una hoja de cálculo (preferiblemente Excel). Para someter un manuscrito es necesario además anexar una carta de intención en la que se indique claramente:

1. Nombre completo del (los) autor (es), afiliaciones institucionales y direcciones para envío de correspondencia (es indispensable suministrar una dirección de correo electrónico para comunicación directa).

2. Título completo del manuscrito.

3. Nombres, tamaños y tipos de archivos suministrados.

4. Explicación concisa y clara, que no sobrepase tres líneas, explicando por qué el manuscrito en cuestión es ideal para que sea publicado en una revista como Biota Colombiana.

5. Lista mínimo de cuatro revisores sugeridos que puedan evaluar el manuscrito, con sus respectivas direcciones electrónicas.

**Para información sobre la preparación de un artículo de datos, continúe a la sección "Particularidades de los artículos de datos $\rightarrow$ Preparación de un artículo de datos" dentro de esta Guía de autores. 


\section{Lenguaje del manuscrito}

- Los manuscritos enviados a Biota Colombiana deben tener como requerimiento mínimo el uso adecuado del lenguaje en el que estén escritos, sea español, portugués o inglés, para asegurar la comunicación efectiva del artículo a los lectores.

- El estilo utilizado en el lenguaje del manuscrito enviado debe seguir las formalidades comúnmente aceptadas en escritos científicos y siempre buscar la claridad, concisión y cohesión en su expresión.

- Se sugiere utilizar guías de buena ortografía, redacción y estilo para el idioma en el que se escoja escribir.

\section{Especificaciones de formato}

- Para la presentación del manuscrito configure las páginas de la siguiente manera: hoja tamaño carta, márgenes de $2,5 \mathrm{~cm}$ en todos los lados, interlineado 1,5 y alineación hacia la izquierda (incluyendo título y bibliografía).

- Todas las páginas de texto deben numerarse en la parte inferior derecha de la hoja.

- Use letra Times New Roman o Arial, tamaño 12 puntos en todos los textos. Máximo 40 páginas, incluyendo tablas, figuras y anexos. Para tablas cambie el tamaño de la fuente a 10 puntos. Evite el uso de negritas o subrayados.

- Escriba los nombres científicos de géneros, especies y subespecies en cursiva (itálica). Proceda de la misma forma con los términos en latín (por ej. sensu, et al.). No subraye ninguna otra palabra o título. No utilice notas al pie de página.

- En cuanto a las abreviaturas y sistema métrico decimal, utilice las normas del Sistema Internacional de Unidades (SI) recordando que siempre se debe dejar un espacio libre entre el valor numérico y la unidad de medida (por ej. 16 $\mathrm{km}, 23{ }^{\circ} \mathrm{C}$ ). Para medidas relativas como $\mathrm{m} / \mathrm{seg}$., use m.seg-1.

- Escriba los números del uno al diez siempre con letras, excepto cuando preceden a una unidad de medida (por ej. $9 \mathrm{~cm}$ ) o si se utilizan como marcadores (por ej. parcela 2, muestra 7). Los números mayores a diez deben ser escritos con los símbolos numéricos arábigos. Si en el mismo párrafo se utilizan cifras menores a diez y cifras mayores a diez, se deben unificar para dejar las cifras solo con símbolos numéricos arábigos.

- No utilice punto para separar los millares, millones, etc (por ej. 54000). Utilice la coma para separar en la cifra la parte entera de la decimal (por ej. 3,1416) cuando el texto es en español. En el caso del inglés, los decimales se separan con puntos (por ej. 3.1416). Enumere las horas del día de 0:00 a 24:00.

- Exprese los años con todas las cifras sin demarcadores de miles (por ej. 1996-1998). En español los nombres de los meses y días (enero, julio, sábado, lunes) siempre se escriben con la primera letra minúscula, en inglés se escriben con la primera letra mayúscula (January, July, Saturday, Monday).

- Los puntos cardinales (norte, sur, este y oeste) en español siempre deben ser escritos en minúscula, a excepción de sus abreviaturas N, S, E, O (en inglés $W$ ), y cuando son referidos como puntos o hacen parte de un nombre propio (p.e. cordillera Oriental). La indicación correcta de coordenadas geográficas es como sigue: $02^{\circ} 37^{\prime} 53^{\prime \prime} \mathrm{N}-$ $56^{\circ} 28^{\prime} 53^{\prime \prime} \mathrm{O}$. La altitud geográfica se citará como se expresa a continuación: 1180 m s.n.m. y en inglés $1180 \mathrm{~m}$ a.s.l.

- Las abreviaturas se deben explicar la primera vez que son usadas.

- Al citar las referencias en el texto, siga las normas APA (Manual de Publicaciones de la American Psychological Association, Sexta Edición). Incluya los apellidos de los autores en caso de que sean uno o dos, y el apellido del primero seguido por et al. (en cursiva) cuando sean tres o más. En el caso de dos autores, los apellidos deben ser separados por la palabra "y" (por ej. Cochran y Goin, 1970). En inglés, los apellidos deben estar separados por " $\&$ ". Si menciona varias referencias, éstas deben ser ordenadas cronológicamente y separadas por punto y coma (por ej. Rojas, 1978; Bailey et al., 1983; Sephton, 2001, 2001). Inserte una coma después de los nombres de los autores y antes del año de la referencia (Acevedo, 2009). 
- Las referencias que son autoridad taxonómica de descripción no deben ser incluidas en la lista de referencias al final pero sí en el texto.

- Refiera las figuras (gráficas, diagramas, ilustraciones y fotografías) sin abreviación (por ej. Figura 3) al igual que las tablas (por ej. Tabla 1). Gráficos y figuras deben presentarse con tipo y tamaño de letra uniforme.

- Las figuras deben ser nítidas y de buena calidad, evitando complejidades innecesarias (por ej. tridimensionalidad en gráficos de barras, marcos o efectos tridimensionales); si es posible use solo colores sólidos en lugar de tramas. Las letras, números o símbolos de las figuras deben ser de un tamaño adecuado de manera que sean claramente legibles una vez reducidas.

- Cada figura debe estar insertada en el texto, y adicionalmente se debe enviar su archivo aparte en alta calidad en el paso de "Cargar los archivos complementarios". Para el caso de las fotografías y figuras digitales es necesario que estas sean guardadas como formato tiff, jpg o png con una resolución de 300 dpi.

- Las tablas y anexos deben ser simples en su estructura (marcos) y estar unificados. Haga las llamadas a pie de página de tabla con letras ubicadas como superíndice. Evite tablas grandes sobrecargadas de información y líneas divisorias o presentadas en forma compleja.

\section{Secciones del manuscrito}

** Para información sobre las secciones de un artículo de datos, continúe a la sección "Particularidades de los artículos de datos $\rightarrow$ Secciones de un artículo de datos" dentro de esta Guía de autores.

- Los manuscritos deben llevar el siguiente orden: título, resumen y palabras clave, abstract y keywords, introducción, materiales y métodos, resultados, discusión, conclusiones (optativo), agradecimientos (optativo) y referencias. Seguidamente, presente una página con la lista de tablas, figuras y anexos.

- Las secciones del manuscrito en el texto deben ir en negrilla, con solo la primera letra en mayúscula. Si necesita agregar subtítulos a las secciones, estos deben ir en la misma línea en la que comienza el texto del párrafo, separados por un punto del resto del texto, y en negrilla.

Título: conciso y explicativo, debe informar sobre el contenido del manuscrito.

Resumen: da un resumen de máximo 200 palabras sobre el manuscrito, en el que se debe incluir el objetivo, métodos, resultados y conclusiones principales del manuscrito. Si se presenta algo que sea novedoso o excepcional, se debe hacer mención aquí. El resumen se debe escribir en dos idiomas (español o portugués y abstract en inglés).

Palabras clave: máximo cinco palabras clave, complementarias al título del artículo, en español o portugués e inglés, separadas por un punto entre cada término. Deben presentarse en orden alfabético. Se sugiere el uso de tesauros temáticos para encontrar sinónimos y términos adecuados.

Introducción: presenta el tema y da el contexto necesario para el desarrollo del manuscrito. El propósito u objetivo principal del trabajo debe hacerse explícito en esta sección.

Materiales y métodos: hace una descripción detallada del procedimiento, incluyendo los materiales, lugar, fechas, métodos estadísticos, etc. que se utilizaron en el trabajo. Debe ser lo suficientemente completo para que otros investigadores puedan replicar el trabajo y si se usa una metodología novedosa debe explicarse y sustentarse.

Resultados: presenta los hallazgos del trabajo de manera organizada y con uso adecuado de figuras. Evitar la inclusión de tablas muy extensas en esta sección y más bien incluir como anexos si es el caso.

Discusión: se destacan los puntos más relevantes, polémicos o novedosos del trabajo y se explican los resultados principales en relación a la importancia o aportes del trabajo en su área.

Conclusiones: reflexiones finales sobre el trabajo con relación a su propósito y objetivos, frecuentemente direccionando hacia acciones e investigaciones futuras.

Agradecimientos: Párrafo sencillo y conciso entre el texto y la lista de referencias. Mencione fuentes 
de financiación o apoyo que recibió el proyecto. Evite títulos como Dr., Lic., TSU, etc.

Referencias: La revista sigue las normas de citación APA (Manual de Publicaciones de la American Psychological Association, Sexta Edición). La lista de las referencias contiene únicamente aquellas citadas en el texto. Ordénelas alfabéticamente por autores y cronológicamente para un mismo autor. Si hay varias referencias de un mismo autor(es) en el mismo año, añada las letras a, b, c, etc. al año. No abrevie los nombres de las revistas. Incluya todos los autores de la referencia. Presente las referencias al final del manuscrito.

\section{Ejemplos de citación}

\section{Artículo en revistas:}

Antonelli, A., Nylander, J. A., Persson, C. y Sanmartín, I. (2009). Tracing the impact of the Andean uplift on Neotropical plant evolution. Proceedings of the National Academy of Sciences, 106(24): 9749-9754.

\section{Libros:}

Gutiérrez, F. P. (2010). Los recursos hidrobiológicos $y$ pesqueros en Colombia. Bogotá: Instituto de Investigación de Recursos Biológicos Alexander von Humboldt. 118 pp.

\section{Tesis:}

Cipamocha, C. A. (2002). Caracterización de especies y evaluación trófica de la subienda de peces en el raudal Chorro de Córdoba, bajo río Caquetá, Amazonas, Colombia. (Trabajo de grado). Bogotá D. C.: Universidad Nacional de Colombia, Facultad de Ciencias, Departamento de Biología. 160 pp.

\section{Informes técnicos:}

Andrade, G. I. (2010). Gestión del conocimiento para la gestión de la biodiversidad: bases conceptuales y propuesta programática para la reingeniería del Instituto Humboldt. (Informe técnico). Bogotá D. C.: Instituto de Investigación de Recursos Biológicos Alexander von Humboldt. 80 pp.

\section{Capítulo en libro o en informe:}

Fernández F., Palacio, E. E. y MacKay, W. P. (1996). Introducción al estudio de las hormigas
(Hymenoptera: Formicidae) de Colombia. En Amat, G. D., Andrade, G. y Fernández, F. (Eds.). Insectos de Colombia. Estudios Escogidos. Pp: 349-412. Bogotá: Academia Colombiana de Ciencias Exactas, Físicas y Naturales y Centro Editorial Javeriano.

\section{Resumen en congreso, simposio, talleres:}

Señaris, J. C. (2001). Distribución geográfica y utilización del hábitat de las ranas de cristal (Anura; Centrolenidae) en Venezuela. Trabajo presentado en Programa y Libro de Resúmenes del IV Congreso Venezolano de Ecología, Mérida, Venezuela. p. 124.

\section{Ley o Decreto:}

Congreso de Colombia. (8 de febrero de 1994) Ley General de Educación. [Ley 115 de 1994]. DO: 41.214.

\section{Páginas web:}

No serán incluidas en la lista de referencias, sino que se señalan claramente en el texto al momento de mencionarlas.

\section{Particularidades de los artículos de datos}

Un Artículo de Datos o Data Paper es un tipo de publicación académica que surgió como un mecanismo para incentivar la publicación de datos sobre biodiversidad. Es un medio para generar reconocimiento académico y profesional adecuado a todas las personas que intervienen, de una manera u otra, en la gestión de información sobre biodiversidad, y además sirve para destacar la existencia y relevancia de los conjuntos de datos frente el resto de la comunidad científica.

Como su nombre lo sugiere, este tipo de artículos se basan en la descripción de un conjunto de datos primarios, y aunque no es una investigación científica sensu stricto, se espera que contengan información acerca de la historia del conjunto de datos (propósito del mismo, metodología sobre la toma de los datos, financiadores, coberturas taxonómicas y geográficas, etc.) y sobre su valor y utilidad (básica o aplicada) para la comunidad científica (Chavan y Penev, 2011) ${ }^{1}$. Lo novedoso y ventajoso de este mo-

\footnotetext{
${ }^{1}$ Chavan, V. y Penev, L. (2011). The data paper: The mechanism to incentivize data publishing in biodiversity science. BMC Bioinformatics 2011, 12(Sup. 15): S2
} 
delo de publicación es que el manuscrito siempre está vinculado al conjunto de datos, a través de un enlace a un repositorio web persistente y confiable, el IPT (Integrated Publishing Toolkit). Adicionalmente los metadatos que describen ese conjunto de datos y que están documentados en la misma herramienta, deben citar el artículo de datos.

Se recomienda someter un artículo de datos, cuando los datos a los que hace referencia son primarios, originales y están restringidos temporal y metodológicamente, se encuentran disponibles en agregadores de datos como el SiB Colombia y GBIF, y pueden ser estructurados con el estándar Darwin Core (DwC) como en el caso de:

- Observaciones de un proyecto particular

- Colecciones biológicas

- Listados de especies

- Datos genómicos

- Eventos de muestreo

- Inventarios

- Bases de datos

- Rasgos funcionales

Los conjuntos de datos que no cumplan estas características, no serán aceptados para publicación como artículo de datos. Tal es el caso de compilaciones de registros biológicos de fuentes secundarias (por ej., literatura).

\section{Preparación de un artículo de datos (publicación de datos y creación del manuscrito)}

Un artículo de datos busca describir todos los tipos de recursos de datos sobre biodiversidad. De esta manera, el artículo de datos siempre está enlazado al conjunto de datos que describe a través de una URL o DOI.

A continuación encontrará el procedimiento de cómo generar y someter un manuscrito para artículo de datos usando las herramientas y modelo de publicación del SiB Colombia. Cabe resaltar que la revista también recibe artículos de datos que tengan conjuntos de datos publicados en otras plataformas reconocidas, siempre y cuando cuenten con los requisitos de ser repositorios confiables y tengan un enlace IPT disponible. Igualmente, las secciones de los manuscritos enviados deben seguir las enunciadas en la Tabla 1.

Los artículos de datos, como los demás tipos de manuscritos enviados a la revista, serán sometidos a evaluación por pares y deben cumplir las mismas especificaciones de formato, normas de citación y uso del lenguaje, además de incluir una carta de intención, como se menciona en esta Guía de autores. Adicionalmente, durante la evaluación del manuscrito, los datos descritos deben estar disponibles en línea de manera abierta en un repositorio público y con una licencia robusta de atribución y uso.

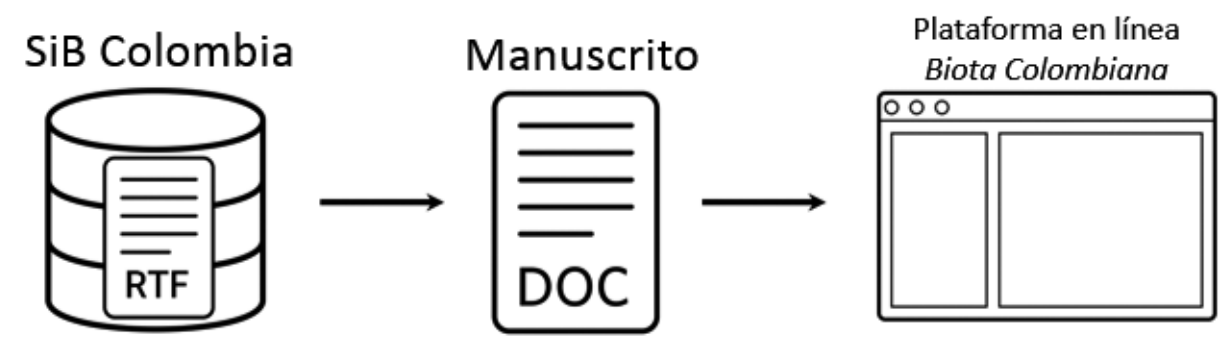

Figura 1. Proceso general de sometimiento de un artículo de datos desde el SiB Colombia a la revista Biota Colombiana. 
Paso 1.

Publicación de los datos a través del SiB Colombia

El SiB Colombia cuenta con un modelo de publicación de datos que hace uso del IPT como herramienta. Desde el IPT, es posible generar una primera versión del manuscrito a partir de los metadatos en formato de texto enriquecido (RTF), siempre $y$ cuando el conjunto de datos respectivo ya haya sido indexado por el SiB Colombia y cuente con los metadatos suficientes (el proceso de publicación de datos a través del SiB Colombia puede ser consultado en https://www.sibcolombia.net/).

A. Registro de organización. Para poder publicar a través del SiB Colombia, es necesario que la organización esté registrada como socio publicador. Se puede comprobar en este enlace si ya es así. En caso contrario, es muy sencillo hacer parte de la red de socios, solo se debe diligenciar el Formulario de Registro.

B. Estandarización de datos. Los datos se deben estructurar en una tabla plana haciendo uso del estándar Darwin Core (DwC). Para esto, se puede descargar la plantilla que se adapte a el tipo de datos o generar una plantilla a través del Generador de Plantillas Excel.

C. Calidad de sus datos. Se debe verificar y mejorar la calidad de los datos haciendo uso de herramientas para identificar, limpiar y corregir posibles errores geográficos, taxonómicos o de formato, entre otros.

D. Cargar datos en línea. El IPT es una herramienta que facilita compartir diferentes tipos de datos relacionados con la biodiversidad siempre y cuando estos se encuentren estructurados según el estándar DwC. Para cargar datos en el IPT, debe contar con una cuenta de usuario en uno de los IPT disponibles por el SiB Colombia. Si aún no se tiene una cuenta, puede contactar al Equipo Coordinador del SiB Colombia (EC-SiB) y solicitarla a través del correo electrónico sib@humboldt.org.co.

E. Mapear datos. Una vez se haya cargado el conjunto de datos, se debe verificar que estén siendo leídos en correspondencia con los elementos DwC. El manual de usuario del IPT está disponible para más información o se puede contactar al EC-SiB.
F. Creación de metadatos. La estructura de los metadatos se parece en gran medida a un artículo de investigación tradicional. Estos metadatos mantienen la estructura general de un artículo de datos y facilitan la generación del mismo. En la sección Metadatos del IPT, se debe documentar toda la información que permite dar un contexto a los datos. En total hay 12 secciones para ingresar información que describe el conjunto de datos. El manual de usuario del IPT está disponible para más información o se puede contactar al EC-SiB.

G. Publicar el recurso y notificar al EC-SiB. Una vez completados los pasos anteriores, el IPT activará la opción 'Publicar'. Se debe hacer clic en este botón y enviar un correo a sib@humboldt.org.co para notificar al EC-SiB de su publicación. El correo debe tener como asunto "Recurso publicado" y contener:

- Nombre

- Nombre de organización

- Nombre del recurso publicado

- URL de la vista general del recurso después de publicado

En este punto los datos serán indexados por el SiB Colombia y GBIF, y contarán con un identificador persistente DOI.

\section{Paso 2}

Generación del manuscrito para artículo de datos usando el IPT

El IPT en el cual ha sido publicado el conjunto de datos permite generar un manuscrito RTF que describe al conjunto de datos. El enlace al conjunto de datos aparecerá en el manuscrito bajo el título "Data published through GBIF". A continuación se describe el paso a paso para generar el manuscrito desde los metadatos del conjunto de datos publicado a través del SiB Colombia.

- En la página principal del recurso publicado a través del IPT, se debe hacer clic sobre el botón RTF para descargar una versión del manuscrito en texto enriquecido que se puede abrir en cualquier procesador de texto (por ej: Word) (Figura 2). 


\section{Escarabajos coprófagos de la cuenca alta y media del río Bita, Vichada} (Colombia)

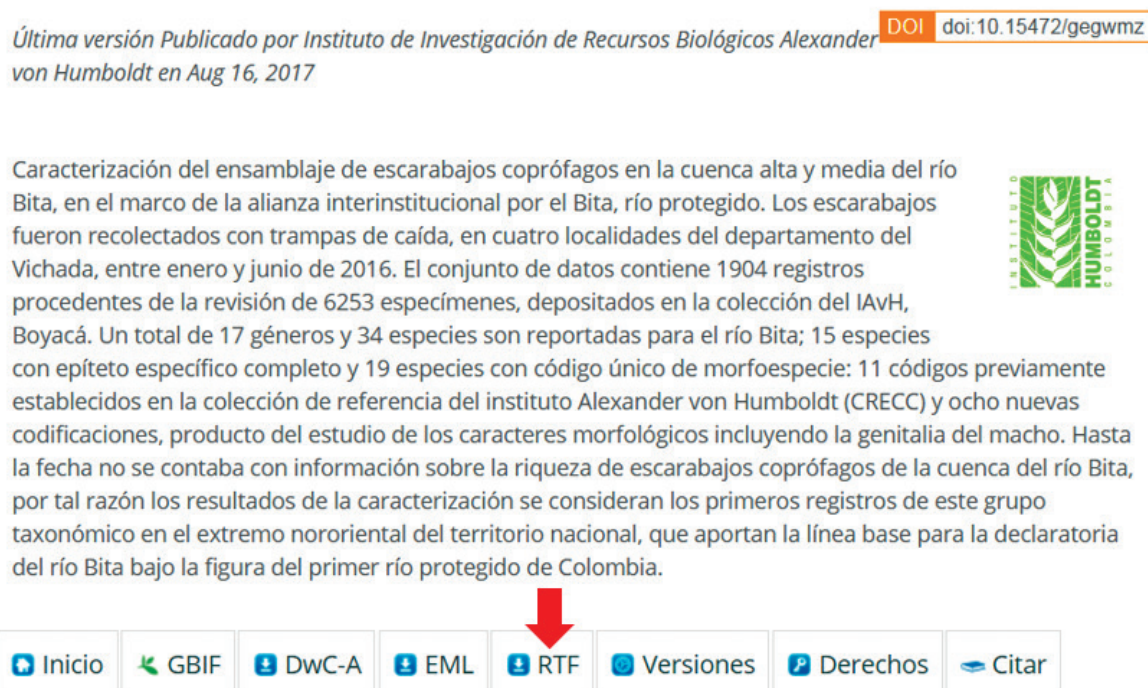

Figura 2. Los metadatos de una conjunto de datos, pueden ser descargados del IPT como archivo RTF, la primera versión del manuscrito para someter a la revista.

- El manuscrito descargado se encuentra en inglés. Los ajustes necesarios de acuerdo a los lineamientos de la revista Biota Colombiana deben ser realizados y la plantilla para artículos de datos se puede descargar aquí.

- Una vez ajustado el manuscrito con los textos adicionales, tablas y figuras, puede ser sometido a evaluación a través del portal en línea de la revista, siguiendo los pasos de registro como usuario. Todo el proceso editorial se desarrolla a través de esa plataforma.

\section{Paso 3}

\section{Ajustes y correcciones del manuscrito para artículos de datos}

Cuando el manuscrito ha sido sometido a evaluación, este se somete a revisión por pares evaluadores de acuerdo a los lineamientos establecidos por la revista para evaluadores de artículos de datos.

Después de evaluado, y en caso de ser aceptado, el manuscrito será devuelto al autor con los comentarios de los revisores y del editor de la revista con el objetivo de realizar las modificaciones antes de publicar. Como autor, deberá realizar todas las correcciones o adiciones recomendadas directamente en los metadatos del IPT y no en el manuscrito del artículo de datos. De esta forma se mejoran también los metadatos del conjunto de datos sometido.

Una vez se hayan mejorado los metadatos en el IPT, se debe actualizar la publicación del recurso para que los cambios se vean reflejados. En la página principal del recurso publicado a través del IPT, ubique el botón RTF y haga clic sobre el mismo para descargar una versión mejorada del manuscrito en texto enriquecido que puede abrir nuevamente en cualquier procesador de texto (por ej. Word).

Después de la re-inserción manual de los textos adicionales y asegurarse que esta versión cumple con los requerimientos de la revista, el manuscrito debe ser enviado nuevamente a la revista.

\section{Secciones de un artículo de datos}

A diferencia de los otros tipos de manuscritos que pueden ser sometidos a la revista Biota Colombiana, los artículos de datos incluyen las secciones estipuladas en la Tabla 1. 
Tabla 1. Estructura del artículo de datos y su correspondencia con los elementos del GMP incorporados en el IPT.

\section{Correspondencia con los elementos del IPT}

Nombre de la sección

\section{Título}

Autores

Afiliaciones

Autores de contacto
Derivado del elemento Título. Centrado sin punto al final.

Derivado de los elementos Creador del recurso, Proveedor de los metadatos y Partes asociadas. De estos elementos, se deriva la combinación nombre y apellido separados por comas. Las afiliaciones de los autores se indican con números $(1,2,3 \ldots)$ al final de cada apellido como superíndice. Centrado.

Derivado de los elementos Creador del recurso, Proveedor de los metadatos y Partes asociadas. De estos elementos, la combinación de organización, dirección, código postal, ciudad, país y correo electrónico, constituyen la afiliación. Si dos o más autores comparten la misma afiliación, se indica con el mismo número.

Derivado de los elementos Creador del recurso y Proveedor de los metadatos. De estos elementos, se deriva la combinación nombre, apellido y correo electrónico. Los correos electrónicos son escritos en paréntesis. Si hay más de un autor como contacto, estos van separados por comas. Si el Creador del recurso y Proveedor de los metadatos es el mismo autor, el Creador del recurso se refleja como el autor de contacto. Texto centrado.

Insertadas manualmente por el Editor Asistente de la revista para indicar las fechas de presentación original del manuscrito, revisión, aceptación y publicación como un artículos de datos en Biota Colombiana.

Fechas de recibido, revisado, aceptado y publicado

\section{Resumen}

Derivado del elemento descripción. El resumen debe incluirse tanto en español o portugués como inglés.

Derivadas del elemento palabras claves. Las palabras van separadas por comas. Las palabras deben estar escritas tanto en español o portugués como inglés.

Palabras Clave

Introducción No se deriva de ningún elemento del GMP y debe ser adicionada manualmente.

Cobertura taxonómica

Derivada de los elementos de la sección cobertura taxonómica: descripción, nombre científico, nombre común y categoría.

Cobertura geográfica

Derivada de los elementos de la sección cobertura geográfica: descripción, latitud mínima, latitud máxima, longitud mínima, longitud máxima.

Cobertura temporal

Derivada de los elementos de la sección cobertura temporal: fecha inicial y fecha final.

Derivada de los elementos de la sección datos del proyecto: título, persona del proyecto, fuentes de financiación, descripción del área de estudio y descripción del diseño.

Descripción del proyecto

Derivada de los elementos de la sección datos de la colección: nombre de la colección,

Descripción de la colección biológica

identificador de la colección, identificador de la colección parental, método de preservación de los especímenes y unidades curatoriales.

Derivado de los elementos de la sección métodos de muestreo: área de estudio, descripción del muestreo, control de calidad, descripción del paso metodológico.

\section{Materiales y métodos}

\section{Resultados}

$--$

Derivado de los elementos de la sección enlaces externos entre otros: nombre, conjunto de caracteres, URL del archivo, formato del archivo, versión del formato del archivo, fecha de publicación, idioma, derechos de propiedad intelectual. Puede adicionar manualmente una descripción adicional de los datos como texto, figuras y tablas.

Información adicional

Derivado del elemento información adicional.

Discusión

No se deriva de ningún elemento del GMP y debe ser adicionada manualmente, enfocada en el potencial de uso de los datos en investigación, educación o toma de decisiones.

Agradecimientos

Referencias

No se deriva de ningún elemento del GMP y debe ser adicionada manualmente.

Derivado del elemento referencia en bibliografía. 


\section{Guidelines for authors}

\section{(http:// revistas.humboldt.org.co/index.php/biota)}

\section{Submitting a manuscript}

Submitting a manuscript implies the explicit statement by the author(s) that the paper has not been published before, nor accepted for publication in another journal or other means of scientific diffusion. Contributions are entire responsibility of the author(s) and not the Research Institute of Biological Resources Alexander von Humboldt, or the journal and their editors.

Papers can be written in Spanish, English or Portuguese, and should not exceed the maximum length of 40 pages (with paragraph lines spaced at 1.5) including tables, figures and appendices. Of particular interest for this journal are descriptions of new species for science, new geographic records, thematic or regional species lists, inventories, databases related to biodiversity, biological collections and sampling reports.

Biota Colombiana receives scientific research articles, as well as notes, reviews, bibliographic novelties and data papers.

Manuscripts must be submitted through the online platform of the journal (http://revistas.humboldt. org.co/index.php/biota) as a registered user. The complete editorial process is managed in this platform.

\section{Evaluation}

Submitted manuscripts will be reviewed by at least two qualified scientific peers. Results of the peer revisions may include any of the following: a) accepted (in this case it is assumed that no change, omission or addition to the article is required and may be published as presented.); b) conditional acceptance (the article is accepted and recommended for publication only if indicated corrections are made; corrections may be minor and a second evaluation is not necessary or major and a second evaluation is necessary); and c) rejected (reviewer considers that the contents and/or form of the paper are not in accordance with requirements of publication standards of Biota Colombiana). For a manuscript to continue its editorial process, it must have been accepted by at least two reviewers.

\section{Preparation of Manuscript}

Any word-processor program may be used to write the text of the manuscript (Word is recommended). Lists or any other type of table must be presented in spreadsheets (Excel is recommended). To submit a manuscript, a cover letter that clearly indicates the following must be sent:

1. Full names, institutional filiations, and e-mail addresses of all authors. (Please note that email addresses are essential to direct communication)

2. Complete title of the article

3. Names, sizes and types of files provided.

4. Concise and clear sustentation of why the presented manuscript is in concordance with the type of articles published in the journal. Such explanation must not surpass a maximum of three lines.

5. List of the names and e-mail addresses of at least four peers who are qualified to review the manuscript.

\footnotetext{
**For information regarding the preparation of data papers, continue to "Details for Data Papers-> Preparation of Data Paper"
} 


\section{Use of Language}

- Manuscripts that are sent to Biota Colombiana have as a minimum requirement for consideration the appropriate use of language in writing, regardless if they are presented in Spanish, Portuguese or English.

- The style should follow the common formalities of scientific writing and be clear, concise and cohesive.

- The use of guides for correct spelling, grammar and style is recommended.

\section{Format}

- Texts must follow the format of standard letter size paper, with $2.5 \mathrm{~cm}$ margins on all sides, 1.5-spaced and left-aligned paragraphs (including title and bibliography).

- All pages must be numbered in the lower right corner.

- Font must be Times New Roman or Arial, size 12, in all parts of the text, except tables (size 10). Manuscript must not exceed a maximum length of 40 pages, including tables, figures and appendices. Avoid the use of bold or underlined font.

- Scientific names of genera, species and subspecies must be in italics, as well as Latin technical terms (i.e sensu, et al.). Avoid underlining any word or title. Do not use footnotes.

- For abbreviations and the metric system, use the standards of the International System of Units (SI). Leave a space between the numeric value and the measure unit (p.e. $16 \mathrm{~km}, 23{ }^{\circ} \mathrm{C}$ ). For relative measures such as $\mathrm{m} / \mathrm{sec}$, use $\mathrm{m} . \mathrm{sec}-1$.

- Write the numbers between one to ten in letters except when it precedes a measure unit (p.e. $9 \mathrm{~cm}$ ) or is used as a marker (p.e. lot 2, sample 7). Numbers greater than ten must be written in Arabic numerals. If in the paragraph both numbers lesser than ten and greater than ten appear, all should be written in Arabic numerals.

- Thousands, millions, etc. should not be separated by commas nor periods (p. e. 54000). Use periods to separate decimals (p. e. 3.1416). In Spanish, use commas to separate decimals (p. e. 3,1416). Hours should be represented in military time from 0:00 to $24: 00$.

- Years should be written without commas or periods (p. e. 1996-1998). In English months and days of the week are capitalized (January, July, Saturday, Monday), whereas in Spanish the first letter of months and days of the week are written with lower-case letters (enero, julio, sábado, lunes).

- Cardinal points (north, south, east and west) must be written in lower case letters, and only be capitalized if used in abbreviation N, S, E, W (O in Spanish) or as part of a proper name ( $p$. e. North Carolina). Correct use of coordinates is: $02^{\circ} 37^{\prime} 53^{\prime \prime} \mathrm{N}-56^{\circ} 28^{\prime} 53^{\prime \prime} \mathrm{O}$. Altitude should be expressed as $1180 \mathrm{~m}$ a.s.l. and $1180 \mathrm{~m}$ s.n.m. in Spanish.

- All abbreviations must be explained the first time they are used.

- When citing in-text references, follow APA citation norms (American Psychological Association Publications Manual, Sixth Edition). Include last names of authors if there are only one or two authors, or the first author followed by et al. (in italics) if there are three or more authors. In the case of two authors, last names must be separated by "\&" (p. e. Cochran \& Goin, 1970). In Spanish, last names of two authors must be separated by " $y$ ". If many references are cited, they must be ordered chronologically and separated by semicolons (p. e. Rojas, 1978; Bailey et al., 1983; Sephton, 2001, 2001). Notice that a comma must be inserted after the authors and before the year (Acevedo, 2009).

- Taxonomic references must not be included in the final list of Literature cited, but they must appear in the text of the manuscript.

- Refer to all figures (graphs, diagrams, illustrations, photos) and tables without abbreviation (p. e. Figure 3, Table 1). All figures and tables should have uniformity in font and letter size. 
- Figures must be clear and have a good quality. Unnecessary complexities (such as 3D effects, frames, etc.) should be avoided. If possible, only use solid colors instead of textures. Letters, numbers or symbols must be in legible sizes.

- All figures must be inserted in the text of the manuscript and sent in a separate file in high quality in the step of "Charge complementary files". For photos and digital figures, files must be in tiff, jpg or png format in a resolution not lower than $300 \mathrm{dpi}$.

- Tables and appendices must have a simple and uniform structure. Footnotes in tables must be as superscript letters. Avoid extensive tables with too much information and dividing lines.

\section{Parts of the Manuscript}

** For information about the parts of data papers, continue to "Details for Data Papers -> Parts of Data Paper".

- Submitted manuscripts must contain the following sections: title, abstract and keywords in English and Spanish, Introduction, Materials and methods, Results, Discussion, Conclusions (optional), Acknowledgements (optional) and Literature cited. At the end of the manuscript, include a list with the tables, figures and appendices.

- Sections subtitles must be written in bold, with only the first letter capitalized. If sections have subtitles, they must be written in bold in the first line of the paragraph, separated by a period from the beginning of the paragraph.

Title: concise and explanatory, must clearly communicate what will be found in the article.

Abstract: a summary of the article, with a maximum length of 200 words. It must include the objectives, methods, results and major conclusions of the study. If the article has a novel or extraordinary finding, it must be highlighted in this section. Abstracts must be written in two languages: Spanish or Portuguese, and English.
Keywords: up to five keywords. They must be complementary to the title (not repeated) and written in Spanish or Portuguese, and English. Words must be separated by periods and presented in alphabetical order. The use of thesaurus to find appropriate synonyms is recommended.

Introduction: presentation of the topic, with enough context to support the rest of the article. The main purpose or objective of the study must be made explicit in this section.

Materials and methods: a detailed description of the procedure, with materials, location, dates, statistics, etc. This description must be sufficiently detailed so that other researchers may replicate the study. If a novel procedure is used, it must be thoroughly explained.

Results: presents major findings in an organized and appropriate manner. Avoids the use of excessively long tables.

Discussion: most relevant, troublesome or novel points of the study are highlighted, and major results are explained in relation to the importance of the study and contributions to its field.

Conclusions: final reflections about the study, with a clear relation to its purpose and objectives, frequently pointing towards future actions and research.

Acknowledgements: Straightfoward and short paragraph between text of manuscript and Literature cited. Mention funding or support of the project. Avoid titles such as Dr., Lic., etc.

Literature cited: Follow APA citation norms (American Psychological Association Publications Manual, Sixth Edition). List of references must only include those that are cited within the text. Order the references in alphabetical order, and chronologically in the case of a sole author. If there are many references of a same author (s) in the same year, add letters a, b, c, etc. to the year. Do not abbreviate names of journals. Include all authors. This section must be at the end of the manuscript. 


\section{Citation examples}

\section{Article in journals:}

Antonelli, A., Nylander, J. A., Persson, C. \& Sanmartín, I. (2009). Tracing the impact of the Andean uplift on Neotropical plant evolution. Proceedings of the National Academy of Sciences, 106(24): 9749-9754.

\section{Books:}

Gutiérrez, F. P. (2010). Los recursos hidrobiológicos $y$ pesqueros en Colombia. Bogotá: Instituto de Investigación de Recursos Biológicos Alexander von Humboldt. 118 pp.

\section{Thesis:}

Cipamocha, C. A. (2002). Caracterización de especies y evaluación trófica de la subienda de peces en el raudal Chorro de Córdoba, bajo río Caquetá, Amazonas, Colombia. (Thesis). Bogotá D. C.: Universidad Nacional de Colombia, Facultad de Ciencias, Departamento de Biología.

\section{Technical reports:}

Andrade, G. I. (2010). Gestión del conocimiento para la gestión de la biodiversidad: bases conceptuales y propuesta programática para la reingeniería del Instituto Humboldt. (Technical report). Instituto de Investigación de Recursos Biológicos Alexander von Humboldt. Bogotá D. C., 80 pp.

\section{Book or report chapter:}

Fernández F., Palacio, E. E. \& MacKay, W. P. (1996). Introducción al estudio de las hormigas (Hymenoptera: Formicidae) de Colombia. In Amat, G. D., Andrade, G. \& Fernández, F. (Eds.). Insectos de Colombia. Estudios Escogidos. Pp: 349-412. Bogotá: Academia Colombiana de Ciencias Exactas, Físicas y Naturales \& Centro Editorial Javeriano.

\section{Congress, symposium or workshop summary:}

Señaris, J. C. (2001). Distribución geográfica y utilización del hábitat de las ranas de cristal (Anura; Centrolenidae) en Venezuela. Presented in Programa y Libro de Resúmenes del IV Congreso Venezolano de Ecología, Mérida, Venezuela. p. 124.

\section{Law or decree:}

Congreso de Colombia. (February 8th 1994) Ley General de Educación. [Ley 115 de 1994]. DO: 41.214.

\section{Web pages:}

Must be clearly included in the text of the manuscript, but not be included in Literature cited section.

\section{Details for Data Papers}

A Data Paper is a type of scientific publication that was designed to stimulate the publication of biodiversity data. Data Papers give academic and professional acknowledgement to those who intervene, in one way or another, in the management of information about biodiversity, as well as highlight the existence and importance of data sets to the rest of the scientific community.

As its name suggests, a Data Paper describes a primary data set. Although a Data Paper is not, strictly speaking, a scientific investigation, it must contain relevant information about the data set (objectives, methods for data collection, funding, taxonomic and geographic coverage, etc.), along with its value and utility (basic or applied) for the scientific community (Chavan \& Penev, 2011) ${ }^{1}$. The great advantage and novelty of this type of manuscript is that it is linked to the data set through a stable and trustworthy repository, the IPT (Integrated Publishing Toolkit). Also, the data set is supported by metadata also available through the IPT and linked to the Data Paper.

A Data Paper must be submitted only when the linked data are primary and original data that have a temporal and methodological restriction and are available in data aggregators such as $\underline{\mathrm{SiB} \text { Colombia }}$ and GBIF. Data must be able to follow the Darwin Core $(\mathrm{DwC})$ standard. Examples of such data sets include:

- Project observations

- Biological collections

- Species lists

\footnotetext{
${ }^{1}$ Chavan, V. y Penev, L. (2011). The data paper: The mechanism to incentivize data publishing in biodiversity science. BMC Bioinformatics 2011, 12(Sup. 15): S2
} 
- Genomic data

- Samples

- Inventories

- Databases

- Functional traits

Data sets that do not comply with the characteristics mentioned above will not be accepted for publication as a Data Paper. Such is the case of compilations of biological records that come from secondary sources (p. e. from published literature).

\section{Preparation of Data Paper (publication of data and creation of manuscript)}

Since the purpose of a Data Paper is to describe all available data resources regarding biodiversity, it must always be linked to the data set it describes through an URL or DOI.

Information about how to generate and submit a manuscript in order for it to be considered as a Data Paper by using the tools and publication model of SiB Colombia is found below. It must be noted, however, that Biota Colombiana also accepts Data Papers that link to data sets published in other known platforms as long as it is linked to a trustworthy repository and has an IPT link. The parts of a Data Paper manuscript are described in Table 1.
As other types of manuscripts that are submitted to the journal, Data Papers will be reviewed by peers and must comply with the same format specifications, citation norms and use of language. Similarly, Data Papers must also be presented with a cover letter, as mentioned in the present Guidelines for authors. Have in mind that as soon as the manuscript is submitted and under evaluation, described data must be available in a public online repository with an adequate license of use and attribution.

\section{Step 1}

\section{Data publication in SiB Colombia}

$\mathrm{SiB}$ Colombia uses a publication model pased on the IPT as its working tool. Using the IPT, the first version of the manuscript may be generated in rich text format (RTF), based on its associated metadata. This tool is available as long as the data set has been indexed by $\mathrm{SiB}$ Colombia and sufficient metadata are linked (more information on publication process of $\mathrm{SiB}$ Colombia may be consulted in https://www.sibcolombia.net/).

A. Registration of organisation. To publish through SiB Colombia, your organisation must be registered as a publishing partner. Consult this link to find already registered organisations. If your organisation is not registered, adding an organisation is easy through the Registration Format.

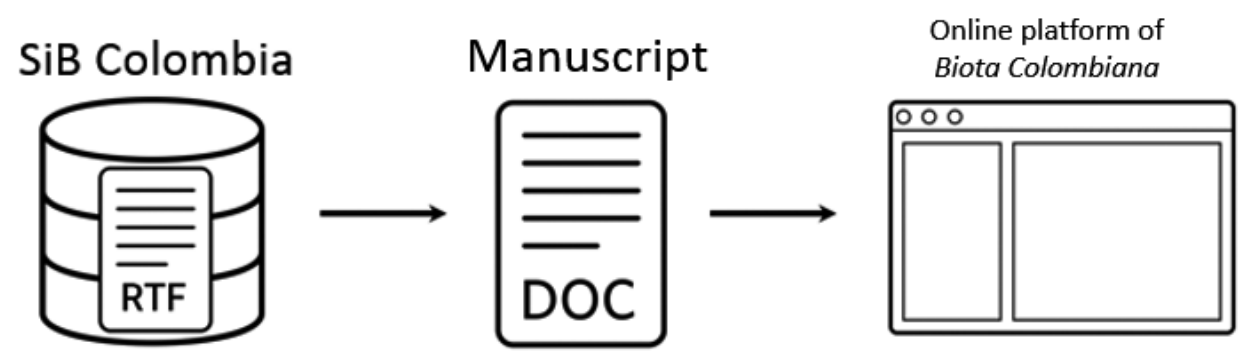

Figura 1. General process to submit a Data Paper from SiB Colombia to the journal Biota Colombiana. 
B. Data standardization. Data must be structured in a table using the Darwin Core $(\mathrm{DwC})$ standard. Download respective template that is appropriate for type of data or generate your template.

C. Data quality. Data quality must be verified and improved using available tools to identify and correct possible geographical, taxonomic or format errors, among others.

D. Online upload of data. IPT is a tool that shares different types of biodiversity data as long as data is structured using DwC standard. To upload data to the IPT, you must have an existing user account in the available IPT of SiB Colombia. If you do not have an account, you may contact the SiB Colombia Coordinating Team (EC-SiB) and request an account to the email address sib@humboldt.org.co.

E. Data mapping. Once the data set is uploaded, verify that it follows DwC elements. For more information, consult the IPT User Manual or contact EC-SiB.

F. Creation of metadata. Metadata structure is similar to that of a traditional research article. In this way, metadata has the same general structure of a Data Paper and thus facilitate the generation of the manuscript. In the metadata section of the IPT, all information that broadens the context of data must be included. There is a total of 12 sections to add information as metadata to describe the data set. For more information, consult the IPT User Manual or contact EC-SiB.

G. Publish resource and notify EC-SiB. Once all previous instructions are completed, IPT will be activate the "Publish" option. Click on the button and send an e-mail to sib@humboldt.org.co in order to notify EC-SiB about your publication. The e-mail must have as subject "Published resource" and include:

- Name

- Name of organisation

- Name of published resource
- URL of general view of resource after publication

Now data are indexed by SiB Colombia and GBIF, and have a digital object identifier, DOI.

Step 2

Creation of manuscript for submission as Data Paper through IPT

The IPT used for publishing the data set generates a RTF manuscript that describes the data set. The link to the data set in the manuscript appears under the title "Data published through GBIF". Here you will find step by step information about how to generate a manuscript based on the data set metadata published in SiB Colombia.

- On the resource homepage published in IPT, click on the RTF button to download the first version of the manuscript in rich text format, which may be opened in any text processor (p. e. Word) (Figure 2).

- Downloaded manuscript is in English. Necessary corrections to follow Biota Colombiana guidelines must be completed on the template. Data Papers template may be downloaded here.

- Once the manuscript is adjusted with additional text, tables and figures, it may be submitted to the journal Biota Colombiana through its online platform, following steps of registry as a user. The complete editorial process is developed through this platform.

\section{Step 3}

Adjustments and corrections of manuscript for data paper

When a manuscript is submitted as a Data Paper, it will go through the same peer review process as other articles of the journal, with specifications for Data Paper evaluation.

After evaluation, and if the manuscript is accepted, it will be returned to the author with the comments of reviewers and the journal's Editor so that respective modifications may be incorporated. 


\section{Escarabajos coprófagos de la cuenca alta y media del río Bita, Vichada (Colombia)}

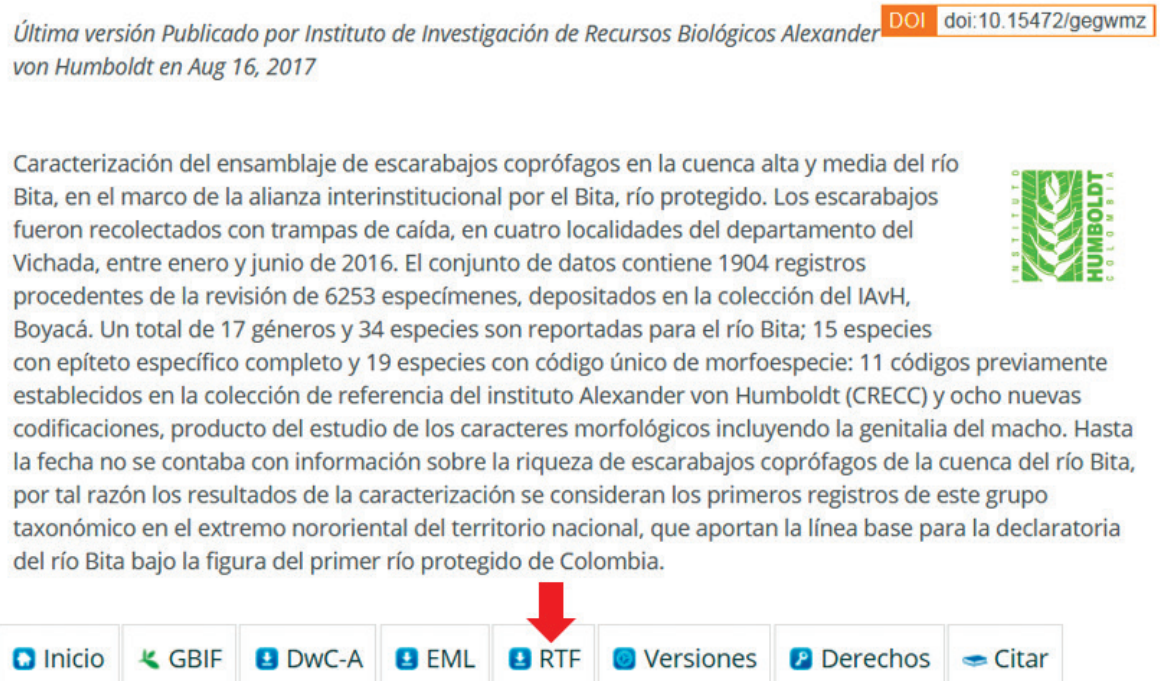

Figure 2. Metadata of a data set may be downloaded from the IPT as a RTF file, giving the first version of the manuscript that will be submitted to the journal.

As the author, you should do all corrections or modifications directly on the IPT metadata and not on the manuscript. In this way, the metadata of the linked data set are also improved by the peer review and editorial comments.

Once metadata in the IPT are improved, the resource publication must be updated so the changes are reflected. On the resource homepage of the published resource, click on the RTF button to download the improved version of the manuscript in rich text format that may be opened in any type of text processor (p. e. Word).
After the manual changes of additional text, figures and tables, and the corroboration that the manuscript follows all of the journal's requirements, it must be sent again through the online platform of Biota Colombiana.

\section{Parts of a Data Paper}

Data Papers differ from other articles that are published in the journal Biota Colombiana in the sections it should include and are mentioned in Table 1. 
Table 1. Structure of a Data Paper and correspondence with GMP elements of IPT.

Name of section

\section{Title}

Authors

Affiliations

\section{Correspondence with IPT elements}

Derived from the element Title. Centered and without period at the end.

Derived from the elements Resource creators, Metadata providers and Associated Parties. From the elements, the combination of name and last name, separated by a coma, is created. Author affiliations are indicated with numbers $(1,2,3 \ldots)$ at the end of each last name with a superscript. Centered.

Derived from the elements Resource creators, Metadata providers and Associated Parties. From these elements, the combination of organisation, address, postal code, city, country and email address constitute the complete affiliation. If one or more authors share the same affiliation, it is represented with the same number.

Derived from the elements Resource creators and Metadata providers. From the elements, the combination of name, last name, and email address is created. Email addresses are inside parentheses. If there is more than one author as contact, authors are separated by comas. If the Resource creator and Metadata provider is the same author, the Resource creator is assumed to be the contact. Text is centered.

\section{Dates of received, revised, accepted and published}

Manually incorporated by the editorial assistant of the journal to indicate respective dates of when the manuscript was received, revised, accepted and published as a Data Paper in Biota Colombiana.

\begin{tabular}{|c|c|}
\hline Abstract & $\begin{array}{l}\text { Derived from the element description. Abstract must be included in Spanish or } \\
\text { Portuguese, and English. }\end{array}$ \\
\hline Keywords & $\begin{array}{l}\text { Derived from the element keywords. Words are separated by comas. Keywords must be } \\
\text { written in Spanish or Portuguese, and English. }\end{array}$ \\
\hline Introduction & Not derived and must be added by the authors manually. \\
\hline Taxonomic coverage & $\begin{array}{l}\text { Derived from section of taxonomic coverage: description, scientific names, common names } \\
\text { and category. }\end{array}$ \\
\hline Geographic coverage & $\begin{array}{l}\text { Derived from section of geographic coverage: description, minimum latitude, maximum } \\
\text { latitude, minimum longitude, maximum longitude. }\end{array}$ \\
\hline Temporal coverage & Derived from section of temporal coverage: description, start date, end date. \\
\hline Project description & $\begin{array}{l}\text { Derived from section of project data: title, project personnel, funding, study area description, } \\
\text { design description. }\end{array}$ \\
\hline Collection data & $\begin{array}{l}\text { Derived from section of collection data: name of collection, collection identifier, parental } \\
\text { collection identifier, specimen preservation methods, curatorial units. }\end{array}$ \\
\hline Materials and methods & $\begin{array}{l}\text { Derived from section of sampling methods: study extent, study description, quality control, } \\
\text { step description. }\end{array}$ \\
\hline Results & -- \\
\hline Data description & $\begin{array}{l}\text { Derived from external links, among others: name, file URL, file format, version of file format, } \\
\text { publication date, language, copyright. An additional description of data such as text, figures } \\
\text { and tables may be added. }\end{array}$ \\
\hline Additional information & Derived from element of additional information. \\
\hline Discussion & Not derived and must be added by the authors manually. \\
\hline Acknowledgements & Not derived and must be added by the authors manually. \\
\hline Literature cited & Derived from element of citations. \\
\hline
\end{tabular}




\section{Biota Colombiana}

Volumen 19 (Sup. 1) - Colombia Bio y otras novedades científicas

Una publicación del / A publication of: Instituto de Investigación de Recursos Biológicos Alexander von Humboldt

En asocio con / In collaboration with:

Instituto de Ciencias Naturales de la Universidad Nacional de Colombia

Instituto de Investigaciones Marinas y Costeras - Invemar

Missouri Botanical Garden

\section{TABLA DE CONTENIDO/ TABLE OF CONTENTS}

Editorial

Una nueva especie de barniz de pasto Elaeagia (Rubiaceae), de la cordillera Oriental de Colombia. A new species of Elaeagia (Rubiaceae) from the cordillera Oriental of Colombia. Humberto Mendoza-Cifuentes y José Aguilar-Cano

Una nueva especie de Allomaieta (Melastomataceae - Cyphostyleae) del piedemonte amazónico de los Andes de Colombia. A new species of Allomaieta (Melastomataceae-Cyphostyleae) from the Amazonian foothills of the Colombian Andes. Humberto Mendoza-Cifuentes

Dos nuevas especies de Miconia (Melastomataceae) del piedemonte oriental de la cordillera Central de Antioquia, Colombia. Two new species of Miconia (Melastomataceae) from the eastern foothills of the Cordillera Central of Antioquia, Colombia. Humberto Mendoza-Cifuentes, Julián Aguirre-Santoro y Álvaro Idárraga

Dos nuevas especies de árboles molinillo (Magnolia: Magnoliaceae) de la serranía de los Yariguíes, departamento de Santander, Colombia. Two new species of "molinillo" tree (Magnolia: Magnoliaceae) from Serranía de los Yariguíes, Santander, Colombia. José Aguilar-Cano, Humberto Mendoza-Cifuentes y Melisa Ayala-Joya

Catálogo de la flora de los Parques Nacionales de Colombia: Parque Nacional Natural El Tuparro. Catalogue of the flora of the National Natural Parks of Colombia: El Tuparro National Natural Park. Humberto Mendoza-Cifuentes y Mireya P. Córdoba-Sánchez .

Primer registro del efemeróptero Oligoneuria (Oligoneurioides) amazonica (Demoulin, 1955) (Insecta: Ephemeroptera, Oligoneuriidae) para Colombia. First record of Mayfly Oligoneuria (Oligoneurioides) amazonica (Demoulin, 1955) (Insecta: Ephemeroptera, Oligoneuriidae) from Colombia. Cristian E. Granados-Martínez, Carlos A. Lasso y Juan M. Fuentes-Reinés .....

Variaciones morfológicas y algunas notas bioecológicas del cangrejo de agua dulce Neostrengeria charalensis Campos y Rodríguez, 1985 (Decapoda: Pseudothelphusidae), en ambientes exo y endocársticos de los Andes colombianos. Morphological variations and some bioecological notes of the freshwater crab Neostrengeria charalensis Campos \& Rodríguez, 1985 (Decapoda: Pseudothelphusidae), in exo and endocárstic environments of the Colombian Andes. Martha R. Campos, Ada Acevedo, Carlos A. Lasso y Jesús Fernández-Auderset

Ectoparásitos (Argulidae, Cymothoidae, Corallanidae) en rayas de agua dulce (Potamotrygonidae) de la Orinoquia colombiana. Ectoparasites (Argulidae, Cymothoidae, Corallanidae) in freshwater rays (Potamotrygonidae) of the Colombian Orinoquia. Carlos A. Lasso, Martha R. Campos, Mónica A. Morales-Betancourt y David Castro .....

Trichomycterus rosablanca (Siluriformes, Trichomycteridae) a new species of hipogean catfish from the Colombian Andes. Trichomycterus rosablanca (Siluriformes, Trichomycteridae) una especie nueva de bagre hipogeo de los Andes colombianos. Lina M. Mesa S., Carlos A. Lasso, Luz E. Ochoa y Carlos DoNascimiento

A new species of cave catfish, genus Trichomycterus (Siluriformes: Trichomycteridae), from the Magdalena River system, Cordillera Oriental, Colombia. Una nueva especie de bagre de caverna, género Trichomycterus (Siluriformes: Trichomycteridae), del sistema río Magdalena, cordillera Oriental, Colombia. César A. Castellanos-Morales

Una nueva rana de huesos verdes del género Scinax (Anura: Hylidae) asociada a los bosques subandinos de la cuenca del río Magdalena, Colombia. A new frog with green bones of the genus Scinax (Anura: Hylidae), associated with the sub-Andean forests of the Magdalena River basin, Colombia. Andrés R. Acosta-Galvis

Una nueva rana nodriza (Anura: Dendrobatidae) de los bosques de niebla asociados a la cuenca del Orinoco de Colombia. A new nurse frog (Anura: Dendrobatidae) from the cloud forests of the Orinoco basin of Colombia. Andrés R. Acosta-Galvis y Adrián Pinzón

\section{Notas}

Nuevos registros de plantas acuáticas para la región Guayana y notas sobre las islas flotantes en el río Guaviare, Guainía, Colombia. New records of aquatic plants from the Guayana region in Colombia, with notes on floating islands in the Guaviare River, Guainía. Anabel Rial

Primer registro del hemíptero Strudivelia cinctipes Champion, 1898 (Hemiptera: Veliidae) para ambientes cavernícolas de Colombia. First record of the hemiptera Strudivelia cinctipes Champion, 1898 (Hemiptera: Veliidae) for cave environments in Colombia. Hernán Aristizábal-García, Natalia Herreño-Castellanos y Carlos A. Lasso 